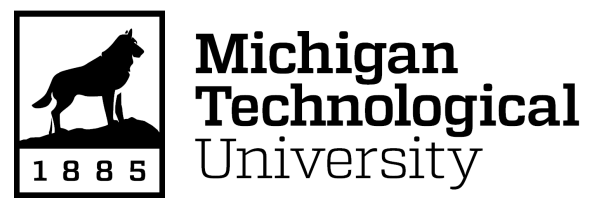

Michigan Technological University Digital Commons @ Michigan Tech

Dissertations, Master's Theses and Master's Reports

2016

\title{
ASSESSING THE IMPACTS OF CLIMATE CHANGE ON THE SURFACE TEMPERATURE OF INLAND LAKES IN MICHIGAN
}

Kaitlin Reinl

Michigan Technological University, klreinl@mtu.edu

Copyright 2016 Kaitlin Reinl

\section{Recommended Citation}

Reinl, Kaitlin, "ASSESSING THE IMPACTS OF CLIMATE CHANGE ON THE SURFACE TEMPERATURE OF INLAND LAKES IN MICHIGAN", Open Access Master's Thesis, Michigan Technological University, 2016.

https://doi.org/10.37099/mtu.dc.etdr/139

Follow this and additional works at: https://digitalcommons.mtu.edu/etdr

Part of the Environmental Engineering Commons, Environmental Health and Protection Commons, Environmental Indicators and Impact Assessment Commons, Natural Resources Management and Policy Commons, Terrestrial and Aquatic Ecology Commons, and the Water Resource Management Commons 


\title{
ASSESSING THE IMPACTS OF CLIMATE CHANGE ON THE SURFACE TEMPERATURE OF INLAND LAKES IN MICHIGAN
}

By

Kaitlin L. Reinl

\begin{abstract}
A THESIS
Submitted in partial fulfillment of the requirements for the degree of

MASTER OF SCIENCE

In Applied Ecology
\end{abstract}

MICHIGAN TECHNOLOGICAL UNIVERSITY

2016

(C) 2016 Kaitlin L. Reinl 
This thesis has been approved in partial fulfillment of the requirements for the Degree of MASTER OF SCIENCE in Applied Ecology.

School of Forest Resources and Environmental Science

Thesis Advisor: $\quad$ Dr. Joseph Wagenbrenner

Committee Member: $\quad$ Dr. Noel Urban

Committee Member: $\quad$ Michael Hyslop

School Dean: Dr. Terry Sharik 
To my goddaughters Emma June and Rosemary Louise. 


\section{Table of Contents}

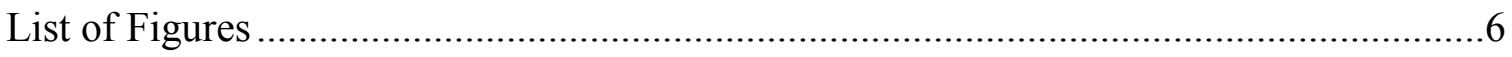

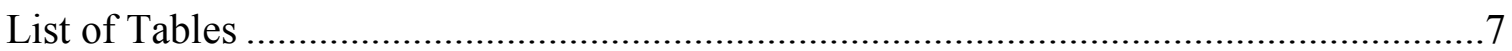

Preface

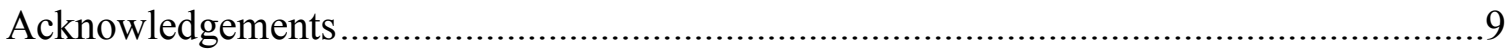

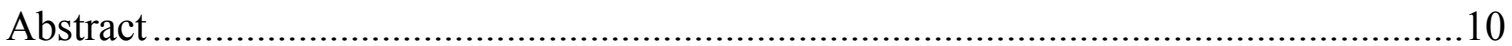

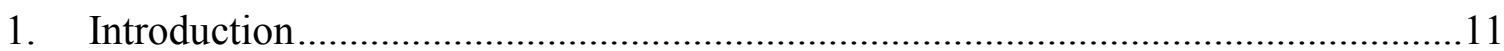

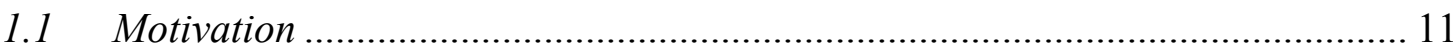

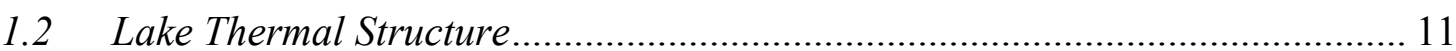

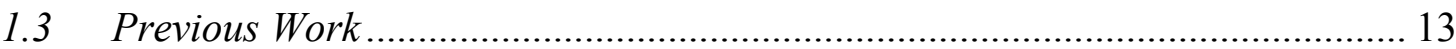

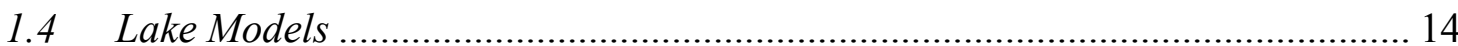

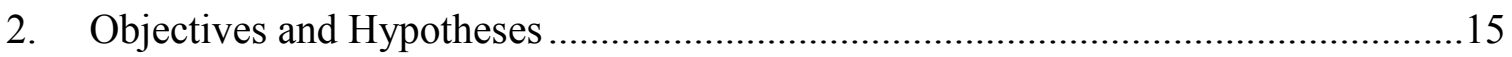

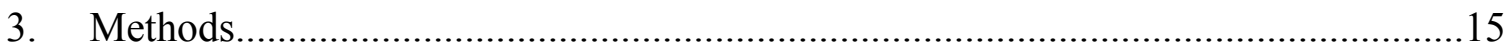

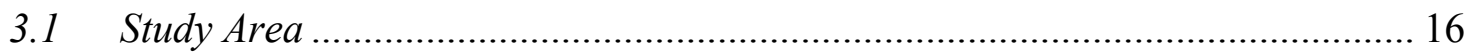

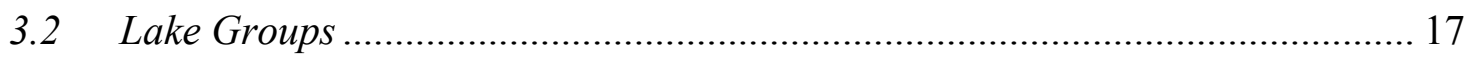

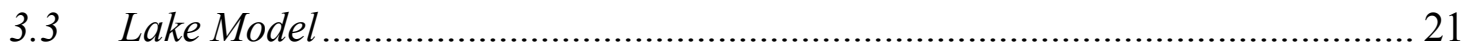

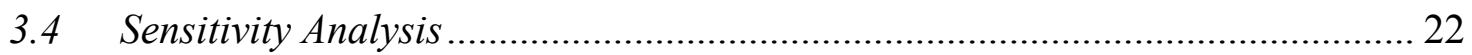

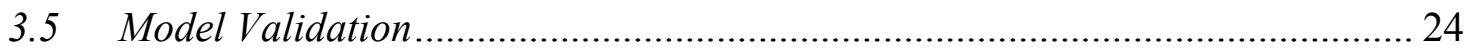

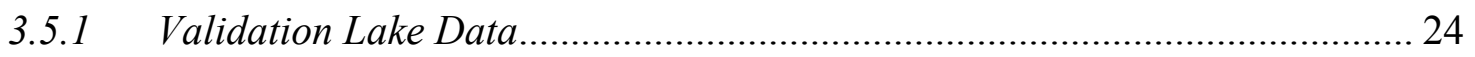

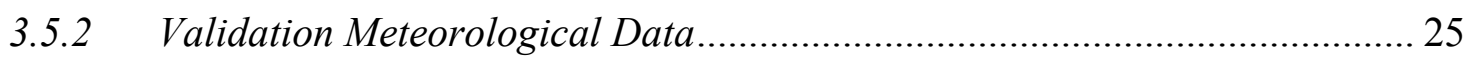

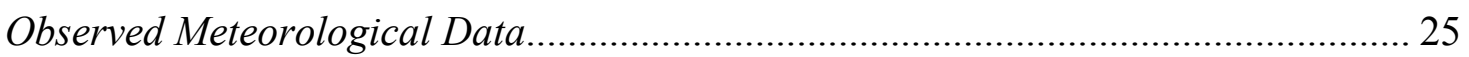

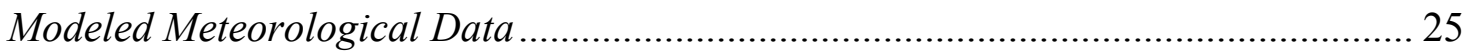

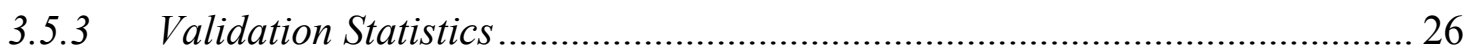

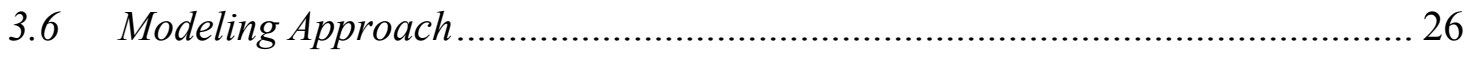

3.6.1 Prototype Lake Development and Characteristics ........................................ 26

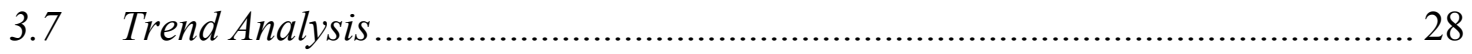

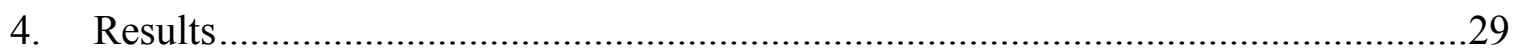

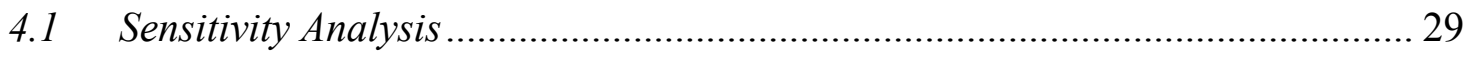

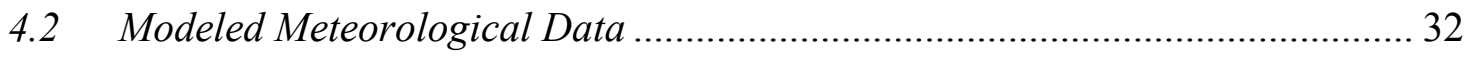

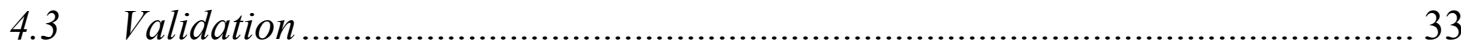

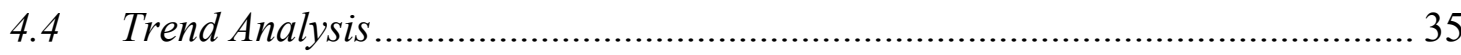

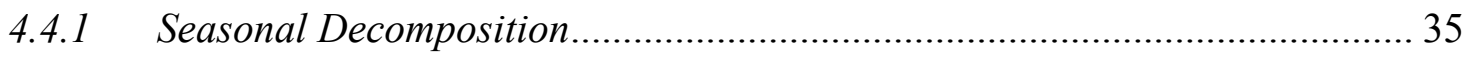

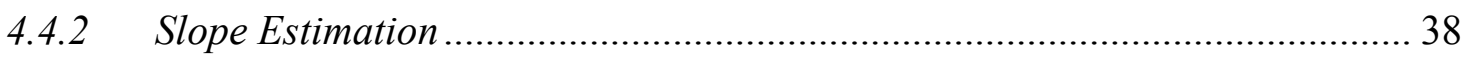

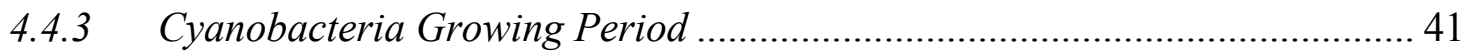




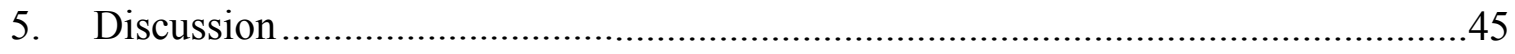

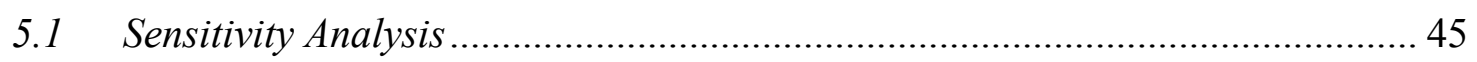

5.2 Modeled Meteorological Data ......................................................................... 46

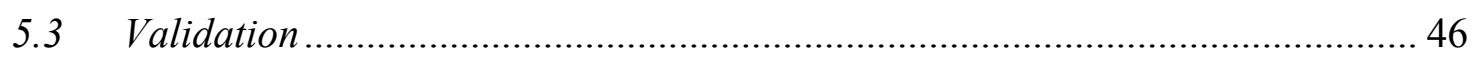

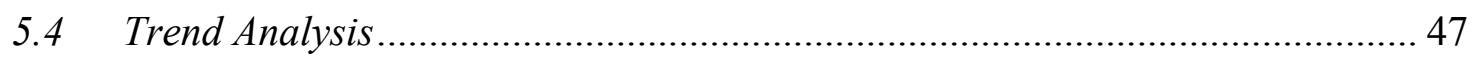

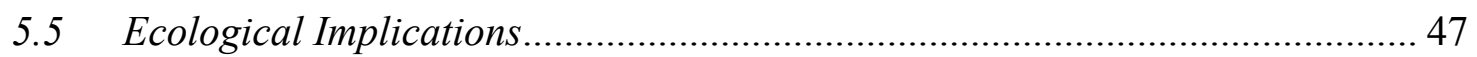

5.6 Limitations and Future Work .................................................................... 48

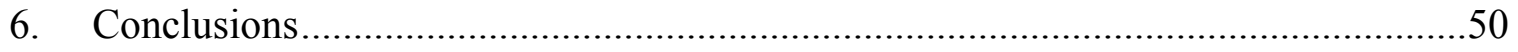

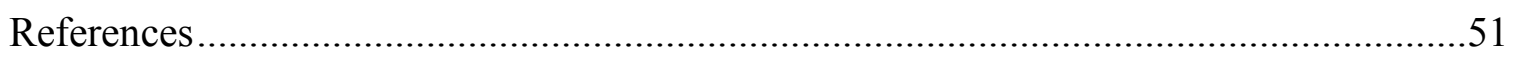

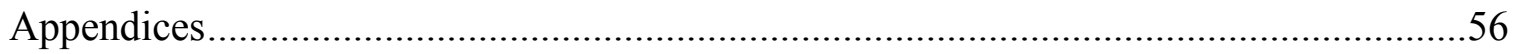

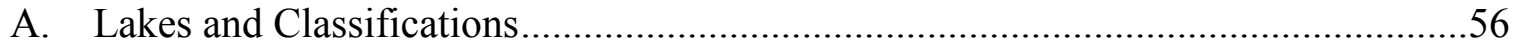

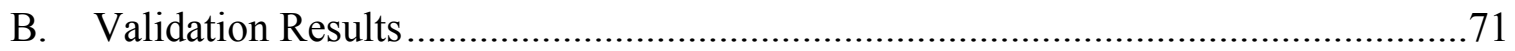

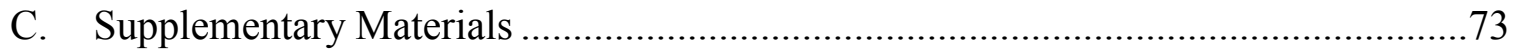

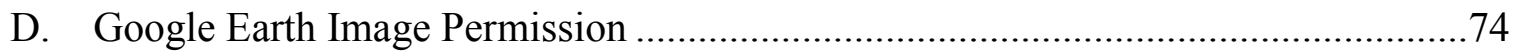




\section{List of Figures}

Figure 1.1. Major components of the lake heat budget (Adapted from 23) .................... 12

Figure 3.1. Map of lakes from the USGS National Hydrography Dataset (NHD) .......... 16

Figure 3.2. Schematic of hierarchy used to develop 27 lake groups based on ................. 17

Figure 3.3. Natural breaks in long-term mean temperature in Michigan used ................. 18

Figure 3.4. Spatial distribution of small, medium, and large lakes in the MSU dataset... 19

Figure 3.5. Spatial distribution of eutrophic, mesotrophic, and oligotrophic lakes ......... 19

Figure 3.6. Cumulative frequency distributions of lake surface area ........................... 21

Figure 3.7. Map of the location of the northern and southern validation sites ................ 24

Figure 4.1. Response of surface water temperature predictions to varied modeled ......... 30

Figure 4.2. Response of mean water temperature predictions to varied modeled ............ 31

Figure 4.3. Difference between modeled and observed (modeled - observed)................ 33

Figure 4.4 Seasonally decomposed trends in (a) solar radiation, (b) air temperature ...... 36

Figure 4.5. Seasonally decomposed trends from 2020 to 2099 for: (a) small ................. 37

Figure 4.6. Summary of changes in number of days with surface temperature above.... 43

Figure 4.7. Change in the number of days when surface water temperature is .............. 44

Figure 4.8. Change in the number of days when surface water temperature is above..... 45 


\section{List of Tables}

Table 3.1. Descriptive statistics for the 517 lakes in the MSU dataset........................... 16

Table 3.2. Summary of descriptive statistics for surface area in MSU and NHD ............ 17

Table 3.3. Summary of criteria used to develop lake classification scheme. .................. 18

Table 3.4 Naming convention, description, and number of lakes $(\mathrm{N})$ for the ................. 20

Table 3.5. Descriptive statistics of varied climate data for the sensitivity analysis......... 23

Table 3.6. Change of varied climate parameters means relative to the standard ............. 23

Table 3.7. Summary of lake property data for validation lakes...................................... 25

Table 3.8. Summary of prototype lake characteristics for each modeled lake ................. 27

Table 4.1. Climate model and observed means with root mean squared error................. 32

Table 4.2. Summary of validation results for mean $\left(\mathrm{T}_{\mathrm{m}}\right)$ and surface $\left(\mathrm{T}_{\mathrm{s}}\right)$ water ............ 34

Table 4.3 Estimates of slope, $95 \%$ confidence intervals for the slope, intercept, and...... 38

Table 4.4. Mean change in air temperature, air humidity, and cloudiness ..................... 39

Table 4.5 Estimates and 95\% confidence intervals for the slope, intercept, and............. 39

Table 4.6 Estimates of slope, 95\% confidence intervals for the slope, intercept, and..... 40

Table 4.7. Summary of mean change in surface water temperature for all modeled ....... 41

Table A.1. Summary of lake property data for the 545 lakes in the study. .................... 56

Table B.1. Summary of regression-based equivalence test for each validation ............... 71 


\section{Preface}

This thesis is original and unpublished work based on intellectual concepts conceived by Dr. Noel Urban. The results of this thesis will be submitted to peer-reviewed journals for publication. All work, data analyses, and manuscript composition were conducted by Kaitlin Reinl. Dr. Joseph Wagenbrenner, Dr. Noel Urban, and Michael Hyslop provided oversight and assistance in data analysis, experimental design, and manuscript composition. 


\section{Acknowledgements}

I would like to thank my advisor Joe Wagenbrenner for his guidance and support while I worked toward obtaining my Master's Degree. I will always be grateful for his aid in helping me to become a better student and researcher. I would also like to express my gratitude to Dr. Noel Urban for being the first to introduce me to the world of research that I have come to love so much. I also thank Mike Hyslop for his countless hours teaching me how to use GIS, answering my hundreds of questions, and guidance in conducting research.

The laughs, friendship, and support provided by my best friends, Gretchen Thomas and Kristen McNamara, helped me to get through tough times and made the good times even better. I will always cherish you both.

To my family, thank you for all of your support, encouragement, and believing in me even when I wasn't sure of myself.

Finally, I would like to thank my husband Alex Reinl for simply everything. Without your love and support, I never would have made it this far. 


\begin{abstract}
The aim of this study was to validate and apply a lake model for predicting the susceptibility of small inland lakes in Michigan to changes in thermal regime and increased cyanobacteria growth as a result of future climate conditions. The Freshwater Lake Model was selected, tested for sensitivity to various inputs, and validated through comparison to observed conditions. The sensitivity analysis showed that the lake model was most sensitive to solar radiation, air temperature, and air humidity. Comparison of predicted climate data with observed conditions revealed highly variable climate model error. The lake model validation was conducted using 10 lakes in Wisconsin with observed and modeled meteorological data from 1998 through 1999. The model was valid for predicting surface water temperature, but not for mean temperature, and modeling proceeded with only surface water temperature. The lake model validation resulted in over-prediction when using modeled climate data inputs, which is likely due to inaccuracy in the climate model.

The study area included 517 inland lakes in Michigan. These lakes were divided into 27 groups based on climate, size, and trophic state. Thirteen lake groups were modeled on a daily time step from 2020 to 2099 using prototype lakes and regionally downscaled, modeled climate data. The climate parameters forcing the lake model predictions were analyzed for long-term trends and differences across climates, lake size, and trophic state. The trends in surface water temperature for the entire period and each season from 2020 to 2099 were significant for all modeled lake groups, and lake model surface temperature predictions closely followed modeled air temperature. For all lake groups, the largest increases in surface temperature were observed in spring while the smallest increases occurred in winter. No statistical differences in long-term trends of surface temperature were found between any of the groups regardless of location, size, or trophic state. We analyzed the relationship between changes in periods of minimum and optimum algal growth conditions and climate, lake size, and trophic state. The largest increase in the period with surface temperature above minimum growth temperatures was predicted for small, oligotrophic lakes in the southern Lower Peninsula. This result can mainly be attributed to inherently warmer temperature earlier in the year in more southern latitude positions and the quicker response of small lakes to warming temperatures in comparison to larger lakes. The largest increase in the period with surface temperature above optimal growth temperatures was predicted for large, oligotrophic lakes in the Upper Peninsula. The predicted increase in the number of days the surface temperatures exceeded the optimum growing temperature in the colder Upper Peninsula was greater because of the relatively low number of days at the onset of the modeling period in comparison to lakes in more southern latitudes, and large lakes are able to uptake more heat for longer periods of time. The results of this study illustrated the future trends in surface water temperature and the potential implications for cyanobacteria growth, and can be used to develop plans to prevent and mitigate the spread of cyanobacteria as a result of climate change.
\end{abstract}




\section{Introduction}

\subsection{Motivation}

Small lakes are important in our daily lives. They provide a wealth of ecosystem services such as improving water quality, transporting nutrients, supporting biodiversity, and providing drinking water. In doing so, they support recreation, economic growth, and public health (1). Small inland lakes comprise more than twice the land surface area of large lakes and are much less represented in scientific literature than large lakes $(2,3)$.

Changes in lake temperature due to climate change may greatly alter lake ecosystem composition and function $(4,5,6)$. Lake warming results in decreasing plankton body size and a shift in species towards smaller organisms $(7,8)$. Phytoplankton growth is highly dependent on temperature, and future changes in temperature may affect the competition of phytoplankton communities and result in a loss of diversity in freshwater lakes $(9,10,11,12)$. A study including 143 lakes ranging from northern Europe to South America showed that there is an increase in the percentage of phytoplankton biomass that is cyanobacteria as climate becomes warmer (13). Cyanobacteria can grow at a minimum of $15^{\circ} \mathrm{C}(14,15)$. Optimum conditions for algal growth occur at $25^{\circ} \mathrm{C}$ or greater, and as temperature increases the growth rates of blue-green algae exceed those of green algae $(14,15)$. Warmer lake water temperatures may result in a longer duration of optimum conditions for cyanobacteria, resulting in higher potential for outbreaks of harmful algal blooms, even where physical factors have not supported algal blooms in the past $(12,16)$. Common varieties of bloom-forming blue-green algae that pose a threat include the genera Anabaena, Aphanizomenon, Microcystis, and Oscillatoria $(17,14)$. Each of these blue green algae produces liver toxins, and all except Microcystis produce neurotoxins (17). While these algae have capabilities of producing toxins, there are a variety of factors that regulate the amount and potency of the toxic byproducts produced, such as chlorophyll levels, lake mixing, and the ratio of toxin to non-toxin producing bacteria in a given bloom (17).

\subsection{Lake Thermal Structure}

The thermal structure of lakes is controlled by lake properties and external atmospheric forcing $(18,19)$. The majority of heat inflows and outflows in a lake occur at the water surface $(18,19)$. Heat exchanged with sediments can play an important role in very shallow lakes, but is negligible for most water bodies $(18,19)$. The main components of the lake surface heat exchange are net radiation, latent heat flux, sensible heat flux, sediment heat exchange, and heat storage in the lake (Figure 1.1) $(18,19)$.

Net radiation includes incoming solar radiation, incoming longwave radiation from the atmosphere, and longwave radiation emitted by the lake surface $(18,19)$. Incoming solar radiation absorbed by the lake and the amount of incoming radiation is affected by seasonality, latitude position, angle of the sun, scattering of sunlight in the atmosphere by dust and clouds, and the albedo of the lake surface $(18,19)$. The albedo of a lake is affected by ice and snow cover as well as water clarity $(20,21)$. Snow and ice cover increase the amount of reflected radiation and increasing water clarity decreases reflectance, generally speaking $(20,21)$. The effect of water clarity is complicated by the effect of spectral properties of phytoplankton communities because the reflectance is 
affected by which types of phytoplankton are present in the lake (21). For example, blue algae tend to absorb more light than green algae (21).

Latent heat is exchanged through evaporation and condensation, and sensible heat is exchanged through conduction and convection $(18,19)$. Latent heat is affected by the air temperature, surface water temperature, vapor pressure gradients, wind speed, and the presence of ice and snow (19). Sensible heat is affected by air and lake temperature as well as wind speed and the presence of ice and snow $(18,19)$. The relative importance of non-radiation terms in the heat budget for a given lake depends on seasonal variation and lake properties such as geographic location, lake size, and morphology (18). Lake heat storage and distribution in the water column is also affected by these factors (18) and determines the amount of heat available for exchange to the atmosphere. Heat uptake by lakes has also been found to be increase with surface area, mean depth, and basin slope $(18,22)$.

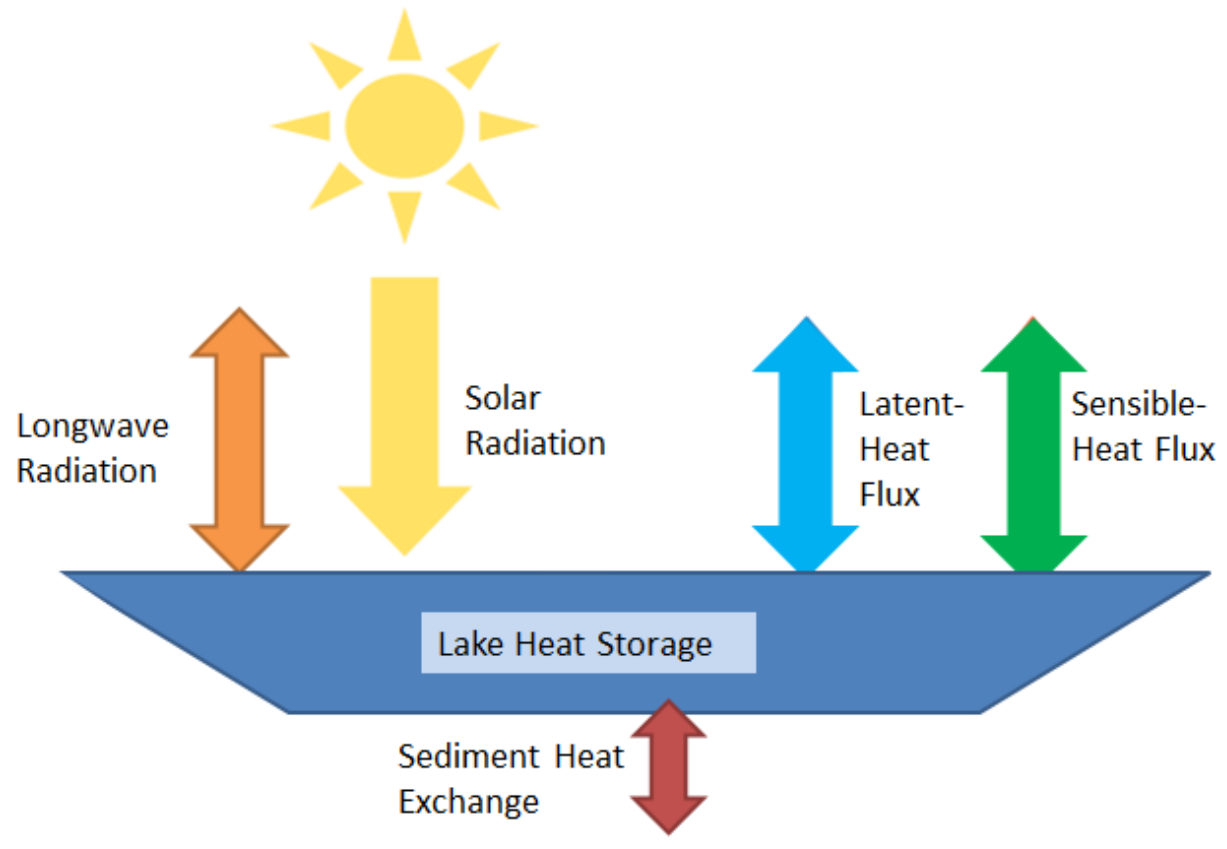

Figure 1.1. Major components of the lake heat budget (Adapted from 23).

The exchange of heat at the lake surface affects temperatures in the lake which affects the density of water (18). Water is most dense at approximately $4^{\circ} \mathrm{C}$ and becomes less dense as water is warmed or cooled $(18,20)$. This property plays a key role in lake stratification and mixing (18). In dimictic lakes, or lakes that mix twice per year, the lake becomes completely mixed during spring and fall, and the temperature of the water column is uniform at approximately $4^{\circ} \mathrm{C}(19,20)$. During the summer and winter the lake is stratified into the upper layer, the epilimnion, and the bottom layer, the hypolimnion $(19,20)$. These layers are divided by an area of rapid water temperature change with depth, called the thermocline $(19,20)$. The difference between surface and bottom temperature is larger in summer than in winter. From spring into summer, the surface of 
the lake begins to warm from increased solar radiation and air temperatures. The lake begins to stratify, and over the course of the summer the well mixed epilimnion depth increases and the denser, cooler water sinks to the bottom of the lake (19). From summer to fall, the air temperature cools and solar radiation inputs begin to decrease resulting in a net heat loss from the lake (19). Large wind storms aid in breaking down of stratification in late summer (20), and the water column cools to $4^{\circ} \mathrm{C}$ and again becomes well-mixed during the fall $(19,20)$. Finally, from fall to winter the lake surface cools and the lake becomes stratified again and the cooler layer sits on top of the warmer, denser layer (19, 20). The strength of stratification in winter depends on how cold surface temperature become (19). If the surface cools to $0^{\circ} \mathrm{C}$, ice may form (18) and strengthen stratification in the lake (19).

\subsection{Previous Work}

In a study evaluating contemporary evidence of the effects of climate change on lakes, temperature data were collected from 1990 to 2012 for 142 lakes in Wisconsin (24). An average warming trend of $0.042^{\circ} \mathrm{C}$ per year was observed across all lakes. Temperature increases in larger lakes $\left(>0.5 \mathrm{~km}^{2}\right)$ were found to be uniform in the water column while smaller lakes $\left(<0.5 \mathrm{~km}^{2}\right)$ were more affected at shallow depths. Larger lakes exhibited a higher median rate of increase in temperature than small lakes for all depths.

In a lake modeling study, the effect of future climate change on four Wisconsin lakes was evaluated using the Dynamic Reservoir Simulation Model (DYERSM) $(25,26)$. DYRESM was run on a daily time step for the years 1986, 1987, and 1989 for three northern lakes and 1921, 1971, and 1972 for one southern lake using current and doubled $\mathrm{CO}_{2}$ climate scenarios. The model predicted an average increase in surface water temperature of approximately $3^{\circ} \mathrm{C}$ and average increases in mean temperature ranging from $1^{\circ} \mathrm{C}$ to $7^{\circ} \mathrm{C}$. An increase in ice-free period was observed in northern lakes as well as increased stability in stratification in summer months.

The results of a lake modeling study in Minnesota from 1955 to 1979 using the lake model MINLAKE (27) under doubled $\mathrm{CO}_{2}$ climate conditions predicted an average increase of $3{ }^{\circ} \mathrm{C}$ in lake epilimnion temperature with the greatest increase taking place in the fall and spring and the least in summer and winter (28). Maximum surface water temperature was predicted to be higher in southern lakes than northern lakes. Mean water temperature was found to be affected more in oligotrophic lakes than eutrophic lakes due to higher light penetration.

Fang and Stefan (29) simulated the effect of climate change on the water temperature of 27 lakes type in the United States. The Minnesota Lake Model (MINLAKE96) (30) was run on a daily time step from 1961 to 1979 under observed and doubled $\mathrm{CO}_{2}$ climate conditions. The model predicted an average increase of $3.3^{\circ} \mathrm{C}$ and $2.6^{\circ} \mathrm{C}$ in surface and bottom temperatures, respectively (29). The study also showed longer periods of stratification with increased differences in surface and bottom temperatures of up to $3.2^{\circ} \mathrm{C}$.

Another modeling study was conducted for the period of 1961 to 2100 under the IPCC B2 emissions scenario (31) using the Freshwater Lake Model (FLake) $(32,33,34)$. The B2 emissions scenario corresponds to a moderate increase in greenhouse gas emissions (31). The results showed that lake water temperatures closely followed local 
air temperature trends in one polymictic and dimictic lake in Germany (35). A mean water temperature increase of $0.3^{\circ} \mathrm{C}$ per decade was observed for both lakes. However, the trends varied with season with the largest increasing trend observed in winter. The mixing regime of both lakes was predicted to shift to monomictic by the end of the $21^{\text {st }}$ century.

A comprehensive review of previous studies examined data from the Great Lakes Basin and Precambrian Shield regions (36). The review reported that the simulated lake surface water temperature increase ranges from $1^{\circ} \mathrm{C}$ to $7^{\circ} \mathrm{C}$. Studies in the review also predicted that differences between surface and bottom temperatures will increase, creating a steeper thermocline and longer, more stable periods of stratification. A decrease in ice cover was predicted with warmer climates, particularly in southern regions. Simulations of future hypolimnetic temperatures in deep lakes projected changes between a decrease of $6^{\circ} \mathrm{C}$ and an increase of $8^{\circ} \mathrm{C}$.

\subsection{Lake Models}

Lake models are invaluable tools in assessing the potential impacts of climate change on lakes. Here we will focus on one-dimensional models that represent the vertical temperature structure in a lake. Two main types of one-dimensional lake models are finite-difference $(37,38,39,40)$ and bulk $(37,41)$ models. Finite-difference models capture lake processes with more complexity, but are computationally intensive and require more data inputs (37). Finite-difference models do not assume that the lake is well-mixed $(37,38,39,40)$. The lake is gridded and the heat budget is solved for each grid and then averaged in the horizontal plane for each depth to determine the vertical profile of the lake $(37,39,40)$. This method can be applied for any physical lake parameter of interest. Examples of finite difference models include MINLAKE96 and DYRESM. Bulk models simplify calculations by assuming the lake has two layers in which the upper layer is well mixed $(37,41)$. Bulk models increase computational efficiency at the cost of losing complexity in lake processes and resolution in the predicted thermal profile (37). Bulk lake models are often used for parameterization in numerical weather prediction, where surface temperature is a main concern, and thus, most validation efforts have been aimed at determining the accuracy of surface temperature predictions (37).

One-dimensional lake models including MINLAKE96 (30), Hostetler model (42), LAKE model (43), and FLake were screened for accuracy, accessibility, type and resolution of input data, and outputs. These models were part of the Lake Model Intercomparison Project (LakeMIP) aimed, in part, to compare the performance and range of applicability of one-dimensional lake models in predicting surface water temperatures (37). All of the lake models satisfactorily reproduced observed surface water temperatures for Sparkling Lake in Wisconsin. The minimum correlation of model predictions with observed temperatures was 0.988, with the exception of MINLAKE96 for which correlation was not reported (37). In another phase of the LakeMIP, the models were applied to a shallow, turbid lake in Germany for the open water season in 2003 (38). The models produced root mean squared errors ranging from $0.80{ }^{\circ} \mathrm{C}$ to $1.96^{\circ} \mathrm{C}(38)$.

We chose the lake model FLake for our study. The accuracy of FLake has been documented in a number of studies that show the model adequately predicts lake surface temperature in a variety of lake types at different locations. FLake was used to determine the impact of climate change on the thermal structure of two lakes in Berlin, Germany 
$(35,44)$. One of the lakes is dimictic and the other is polymictic, and in both cases FLake was able to adequately reproduce the temperature and mixing regimes. In another study, FLake performed well when coupled with a regional climate model and used to predict surface temperatures and lake mixing for a small, shallow lake (45). FLake was run on a daily time step for the year 2005 for Sparkling Lake and Trout Bog, located in Vilas County, WI. These are dimictic lakes with moderate urban development and mostly forested watersheds. The model produced a Pearson correlation with observed data of 0.98 and a root mean squared error of $3.2^{\circ} \mathrm{C}(45)$. The performance of FLake was also tested for two African Great Lakes. The model was able to capture observed water temperatures and mixing within reason (46). The study also found that FLake was sensitive to accuracy of climate data and choice of lake depth and water transparency inputs (46).

FLake was chosen for this study due to its accuracy, accessibility, and ease of application, including availability of input data. FLake is publically available in a windows executable format, where minimal coding skills are required. FLake can produce accurate results with minimal data inputs and no model calibration.

\section{Objectives and Hypotheses}

The aim of this study was to validate and apply a lake model to identify which lakes are most susceptible to changes in thermal regime as a result of climate change. First, a lake model was selected and validated through comparison of lake model predictions to observed conditions. The validated lake model was then used to predict future water temperature conditions. The model predictions were used to assess potential risk for lakes to cyanobacteria growth.

The specific objectives of the study were to: 1) determine the ability of the lake model to reproduce observed conditions; 2) determine whether the magnitude of change in surface water temperature varied across climates, trophic states, and/or lake size; and 3) apply these results to determine the risk of increased cyanobacteria growth in lakes.

We hypothesized that the greatest magnitude of change in water temperature would be observed in northern, oligotrophic lakes. We also hypothesized that small, eutrophic lakes located in warmer climates would show the lowest magnitude of change in water temperature; however, these lakes would also be most susceptible to negative ecological effects.

\section{Methods}

The study area included 517 inland lakes in Michigan, which were divided into 27 groups based on climate, size, and trophic state. A lake model was selected, tested for sensitivity, and validated for predicting lake water temperatures using observed and downscaled climate data. A set of thirteen lake groups were selected and one prototype lake was developed for each group. The prototype lakes were modeled on a daily time step from 2020 to 2099 using regionally downscaled modeled climate data. The climate parameters forcing the model predictions and the lake model predictions were analyzed 
for long-term trends and differences in trends across climates, lake sizes, and trophic states. The relationships between climate, lake size, and trophic state and changes in the period when surface water temperatures were predicted to be above minimum and optimum growth conditions for cyanobacteria were also analyzed for trends for the years 2020 and 2099.

\subsection{Study Area}

The study area included inland lakes in Michigan, excluding the Great Lakes. We obtained surface area, mean depth, maximum depth, and Secchi depth for 517 lakes from a publicly available database (47), hereafter referred to as the "MSU dataset" (Table 3.1). Lake data were also collected from the USGS National Hydrography Dataset (NHD) (48) for comparison to the number, spatial coverage, and lake size distribution of the MSU dataset (Figure 3.1and Table 3.2).

Table 3.1. Descriptive statistics for the 517 lakes in the MSU dataset.

\begin{tabular}{lcccc}
\hline & Minimum & Maximum & Mean & Standard Deviation \\
\hline Surface Area $\left(\mathrm{km}^{2}\right)$ & 0.04 & 81.3 & 2.8 & 8.5 \\
Mean Depth $(\mathrm{m})$ & 0.8 & 42.5 & 4.3 & 3.6 \\
Maximum Depth $(\mathrm{m})$ & 2.1 & 86.9 & 14.1 & 8.5 \\
Secchi Depth $(\mathrm{m})$ & 0.5 & 8.7 & 3.1 & 1.3 \\
\hline
\end{tabular}

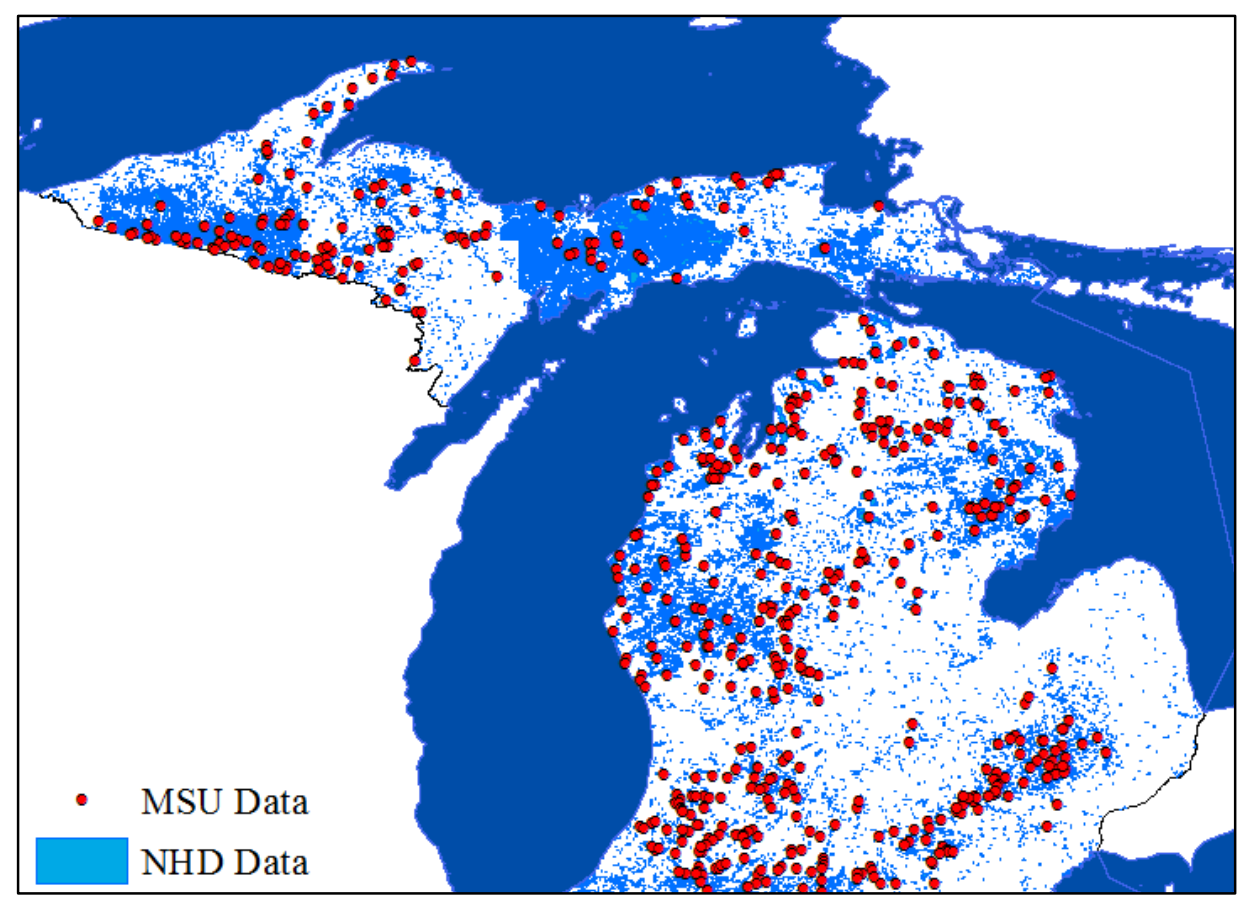

Figure 3.1. Map of lakes from the USGS National Hydrography Dataset (NHD) and data from a Michigan State University study (MSU dataset). 
Table 3.2. Summary of descriptive statistics for surface area in MSU and NHD datasets.

\begin{tabular}{lcc}
\hline Surface Area Statistic & MSU & NHD \\
\hline Number of lakes & 517 & 89995 \\
Minimum, $\mathrm{km}^{2}$ & 0.04 & 0.0003 \\
Maximum, $\mathrm{km}^{2}$ & 81.3 & 86.8 \\
Mean, $\mathrm{km}^{2}$ & 2.8 & 0.09 \\
Standard Deviation, $\mathrm{km}^{2}$ & 8.5 & 1.1 \\
\hline
\end{tabular}

\subsection{Lake Groups}

Lake groups were formed using a hierarchical scheme across climates, surface area, and trophic state, resulting in 27 lake groups for modeling purposes (Figure 3.2). The air temperature data used to determine the climate groups was statistically downscaled for the U.S. (49) and had a spatial resolution of $4.5 \mathrm{~km}$. The long-term mean air temperature was averaged over the period of 1870 to $1999(50,51)$. Climate groups were formed in GIS using natural breaks in air temperature (Figure 3.3), separating the 517 lakes into three climate groups: Upper Peninsula, Northern Lower Peninsula, and Southern Lower Peninsula (Figure 3.3 and Table 3.3). The lakes were also classified by surface area into three groups (small, medium, and large) based on quantiles in GIS (Table 3.3). Secchi depth was used to classify trophic state as either eutrophic, mesotrophic, or oligotrophic (52) for each lake (Table 3.3). The naming convention for the 27 groups is shown in Table 3.4 and the 517 lakes and their corresponding groups are shown in Appendix A.

Spatial distributions of lake size and trophic state are shown in Figure 3.4 and Figure 3.5 , respectively. The lake size groups are evenly distributed throughout the three climate regions. Lakes that are eutrophic and mesotrophic are also evenly distributed throughout the climate regions; however, there are more oligotrophic lakes in the more northern climate regions.

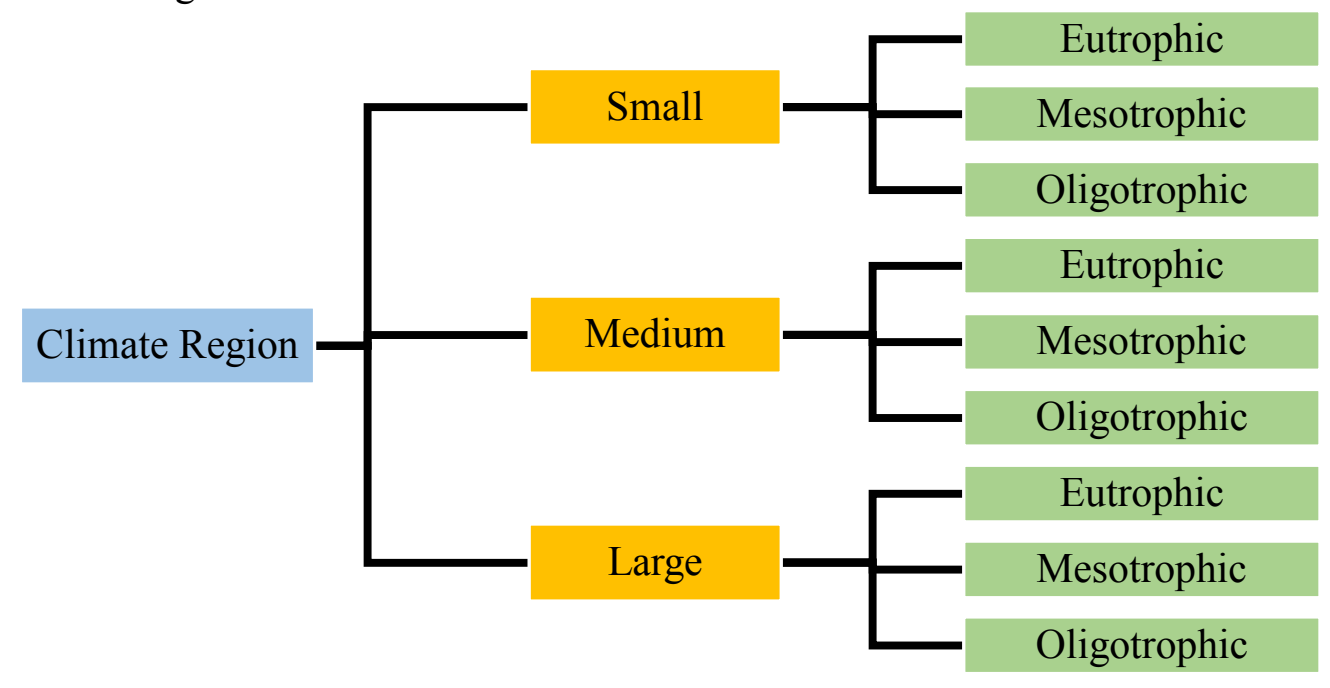

Figure 3.2. Schematic of hierarchy used to develop 9 lake groups based on size and trophic state for one of the three climate regions. One hierarchy exists for each of the three climate regions. 


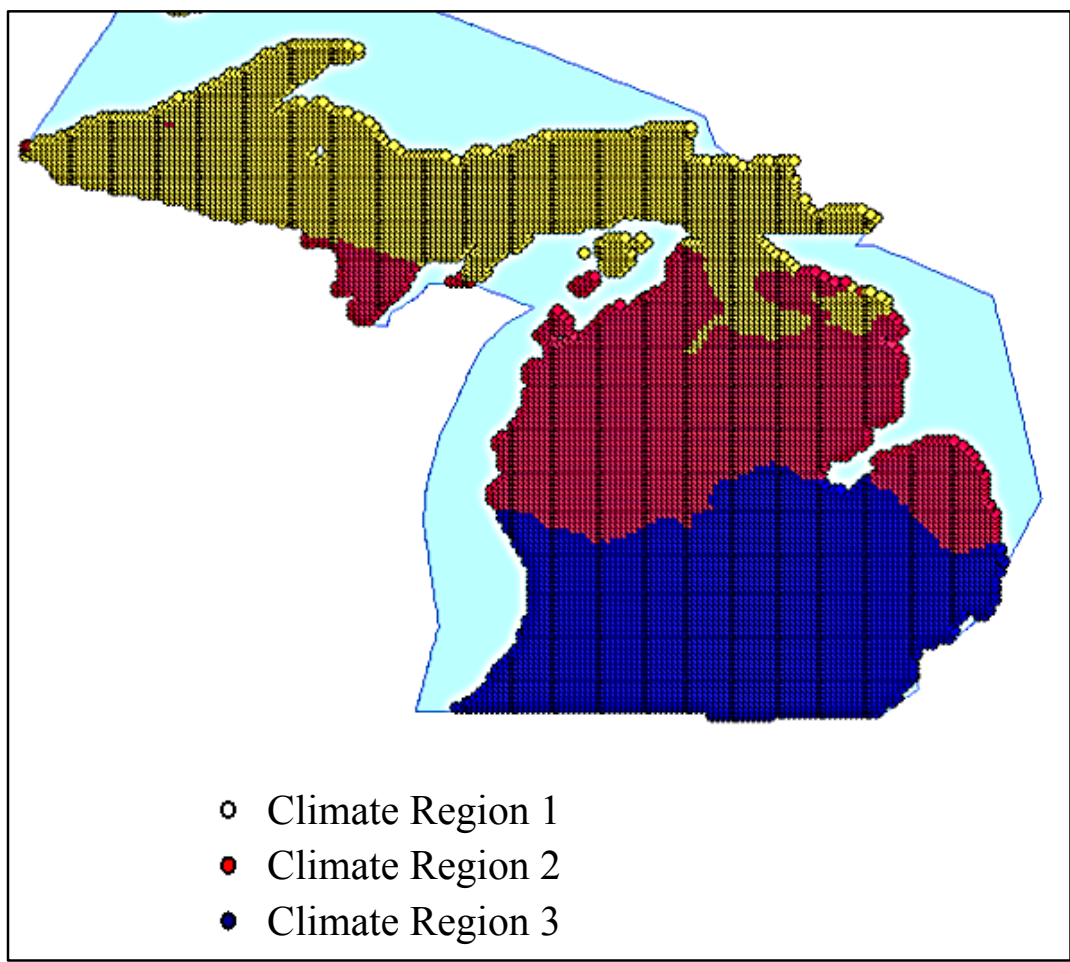

Figure 3.3. Natural breaks in long-term mean temperature in Michigan used to develop climate groups where Climate Region 1, 2, and 3 are the Upper Peninsula, northern Lower Peninsula, and southern Lower Peninsula, respectively.

Table 3.3. Summary of criteria used to develop lake classification scheme.

\begin{tabular}{|c|c|}
\hline Factor & Criteria \\
\hline Climate Class & Temperature $(\mathrm{K})$ \\
\hline Upper Peninsula & $<278.43$ \\
\hline Northern Lower Peninsula & $278.43-281.01$ \\
\hline Southern Lower Peninsula & $>281.01$ \\
\hline Size Class & Surface Area $\left(\mathrm{km}^{2}\right)$ \\
\hline Small & $<0.05$ \\
\hline Medium & $0.05-1.25$ \\
\hline Large & $1.25+$ \\
\hline Trophic State & Secchi Depth (m) \\
\hline Eutrophic & $0-2$ \\
\hline Mesotrophic & $2-4$ \\
\hline Oligotrophic & $4+$ \\
\hline
\end{tabular}




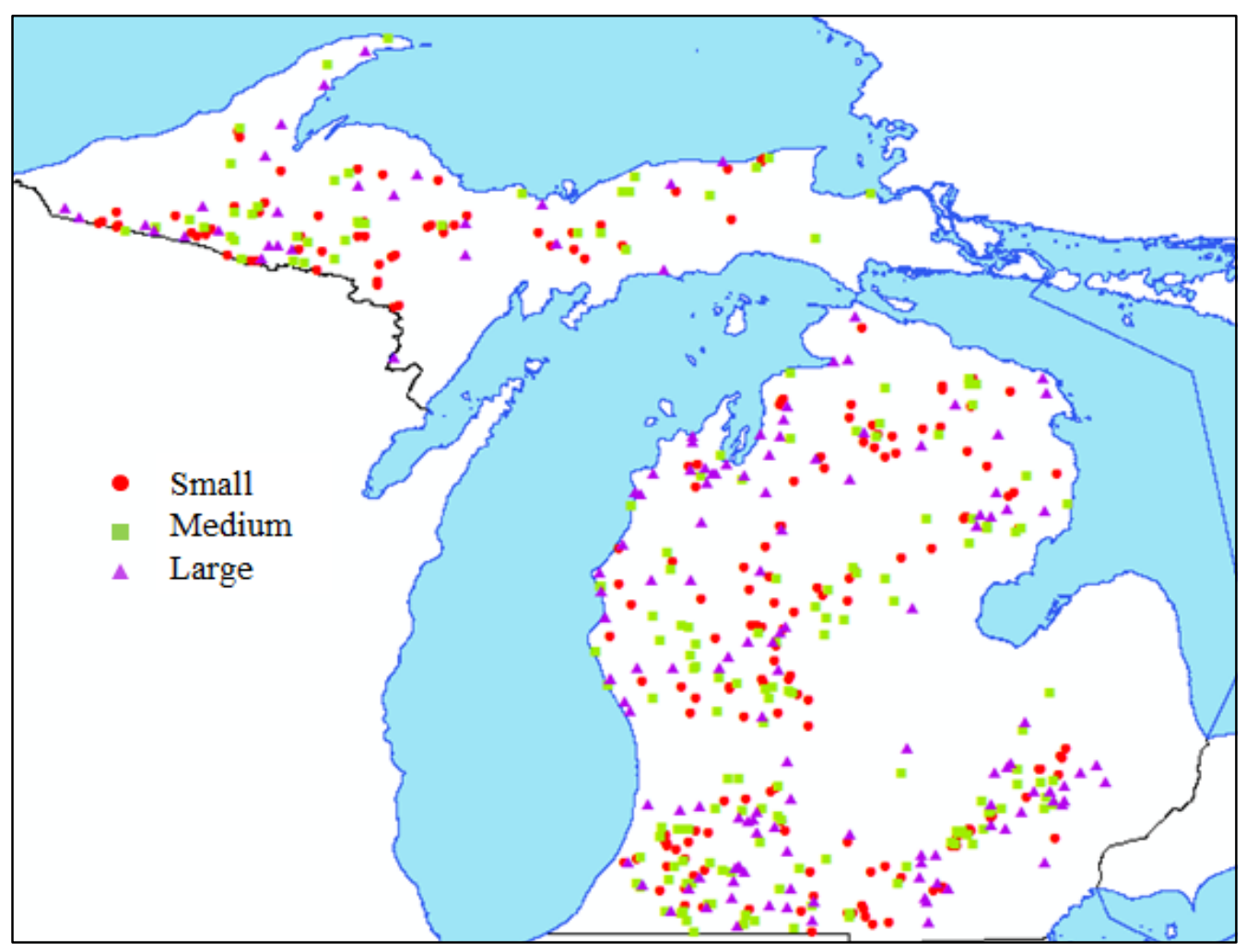

Figure 3.4. Spatial distribution of small, medium, and large lakes in the MSU dataset.

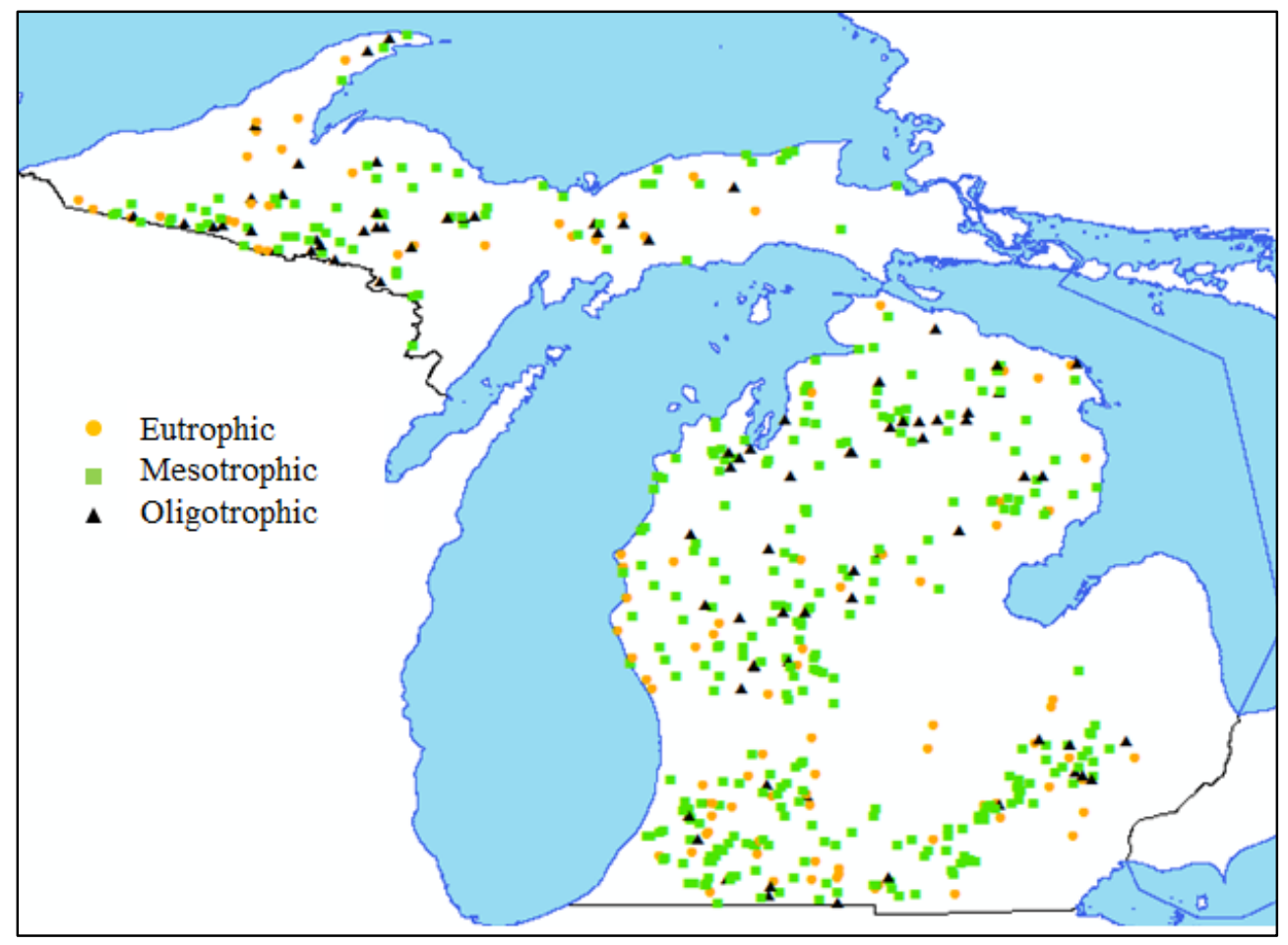

Figure 3.5. Spatial distribution of eutrophic, mesotrophic, and oligotrophic lakes in the MSU dataset. 
We grouped the NHD and MSU dataset by climate and lake size to compare lake size distributions (Figure 3.6 and Table 3.3). The NHD did not contain trophic state data and so the datasets could not be compared across trophic states. A larger number of lakes in the NHD are in the Upper Peninsula and more lakes in the MSU dataset are located in the Lower Peninsula. The NHD also has a smaller minimum lake surface area, and larger maximum surface area, than the MSU dataset. Despite the observed differences, the MSU dataset does adequately represent the spatial distribution and size distribution of the larger sample contained in the NHD.

Table 3.4 Naming convention, description, and number of lakes $(\mathrm{N})$ for the 27 lake groups. Lake groups that were modeled and which round they were modeled in are shown in the 'Modeled' column. Superscripts denote round 1 or round 2 modeling.

\begin{tabular}{|c|c|c|c|}
\hline Group Name & Description & $\mathrm{N}$ & Modeled \\
\hline UP-Sm-E & Upper Peninsula, Small, Eutrophic & 14 & $\mathrm{Y}^{1}$ \\
\hline UP-Sm-M & Upper Peninsula, Small, Mesotrophic & 39 & $\mathrm{~N}$ \\
\hline UP-Sm-O & Upper Peninsula, Small, Oligotrophic & 24 & $\mathrm{~N}$ \\
\hline UP-Md-E & Upper Peninsula, Medium, Eutrophic & 8 & $Y^{2}$ \\
\hline UP-Md-M & Upper Peninsula, Medium, Mesotrophic & 29 & $\mathrm{~N}$ \\
\hline UP-Md-O & Upper Peninsula, Medium, Oligotrophic & 10 & $\mathrm{~N}$ \\
\hline UP-Lg-E & Upper Peninsula, Large, Eutrophic & 10 & $\mathrm{Y}^{2}$ \\
\hline UP-Lg-M & Upper Peninsula, Large Mesotrophic & 25 & $\mathrm{Y}^{2}$ \\
\hline UP-Lg-O & Upper Peninsula, Large, Oligotrophic & 11 & $\mathrm{Y}^{2}$ \\
\hline NLP-Sm-E & Northern Lower Peninsula, Small, Eutrophic & 1 & $\mathrm{Y}^{1}$ \\
\hline NLP-Sm-M & Northern Lower Peninsula, Small, Mesotrophic & 41 & $\mathrm{~N}$ \\
\hline NLP-Sm-O & Northern Lower Peninsula, Small, Oligotrophic & 8 & $\mathrm{~N}$ \\
\hline NLP-Md-E & Northern Lower Peninsula, Medium, Eutrophic & 13 & $\mathrm{~N}$ \\
\hline NLP-Md-M & Northern Lower Peninsula, Medium, Mesotrophic & 27 & $\mathrm{~N}$ \\
\hline NLP-Md-O & Northern Lower Peninsula, Medium, Oligotrophic & 5 & $\mathrm{~N}$ \\
\hline NLP-Lg-E & Northern Lower Peninsula, Large, Eutrophic & 9 & $\mathrm{~N}$ \\
\hline NLP-Lg-M & Northern Lower Peninsula, Large. Mesotrophic & 33 & $\mathrm{~N}$ \\
\hline NLP-Lg-O & Northern Lower Peninsula, Large Oligotrophic & 8 & $\mathrm{Y}^{2}$ \\
\hline SLP-Sm-E & Southern Lower Peninsula, Small, Eutrophic & 13 & $\mathrm{Y}^{1}$ \\
\hline SLP-Sm-M & Southern Lower Peninsula, Small, Mesotrophic & 49 & $\mathrm{Y}^{1}$ \\
\hline SLP-Sm-O & Southern Lower Peninsula, Small, Oligotrophic & 7 & $\mathrm{Y}^{1}$ \\
\hline SLP-Md-E & Southern Lower Peninsula, Medium, Eutrophic & 17 & $\mathrm{~N}$ \\
\hline SLP-Md-M & Southern Lower Peninsula, Medium, Mesotrophic & 49 & $\mathrm{Y}^{2}$ \\
\hline SLP-Md-O & Southern Lower Peninsula, Medium, Oligotrophic & 6 & $\mathrm{~N}$ \\
\hline SLP-Lg-E & Southern Lower Peninsula, Large, Eutrophic & 18 & $\mathrm{Y}^{1}$ \\
\hline SLP-Lg-M & Southern Lower Peninsula, Large, Mesotrophic & 39 & $\mathrm{~N}$ \\
\hline SLP-Lg-O & Southern Lower Peninsula, Large, Oligotrophic & 4 & $\mathrm{Y}^{2}$ \\
\hline
\end{tabular}



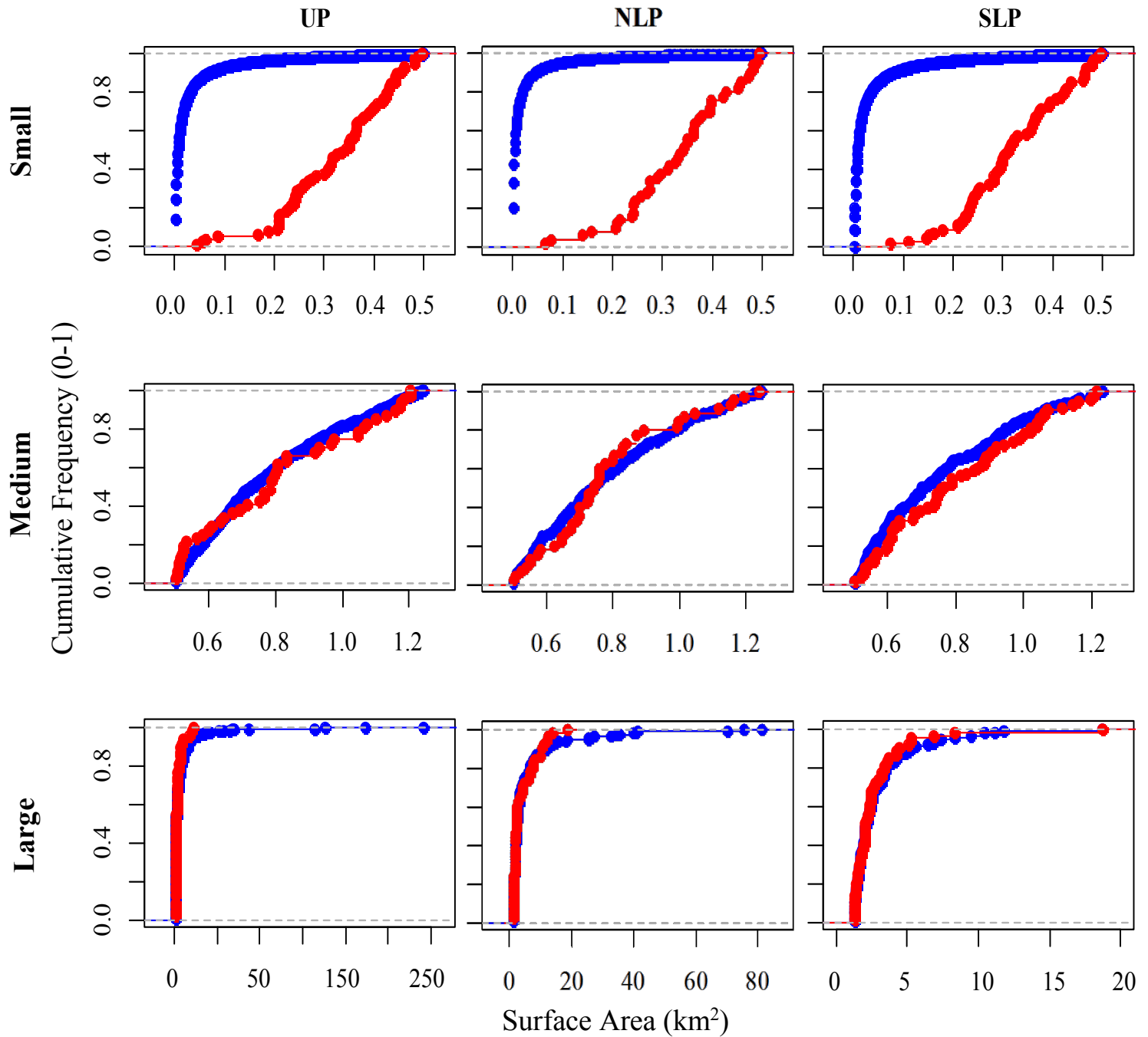

- MSU - NHD

Figure 3.6. Cumulative frequency distributions of lake surface area by size group (rows) and climate groups (columns) for the MSU dataset and NHD. The climate groups are in the Upper Peninsula (UP), northern Lower Peninsula (NLP), and southern Lower Peninsula (SLP)). Note the different surface area scales among the large lake groups.

\subsection{Lake Model}

FLake is a physically-based, freshwater lake model that predicts lake temperature and mixing as well as ice cover and energy fluxes $(32,33,34)$. The main uses of the model to date have been for representing the effect of lakes in numerical weather prediction and as a stand-alone lake model. The model is intended to be used without calibration because it 
may reduce the model's predictive capability (33). The model is driven by both meteorological data and lake properties including: solar radiation, air temperature, air humidity, wind speed, cloudiness, latitude, depth, fetch, and extinction coefficient. Secchi depth was used to determine the extinction coefficient using the relationship that the extinction coefficient is 1.7 divided by Secchi depth in meters (53). The model outputs of interest to this study are surface and mean water temperature, but other outputs include sensible and latent heat flux, sediment heat exchange, convective heat flux, and ice and snow cover.

The model divides the lake into two layers in which the upper layer is completely mixed and is confined by the thermocline which is described using the self-similarity concept $(54,55)$. The thermocline shape is determined using a single equation that calculates the shape coefficient as a function of depth and time. As wind speed increases, the thickness of the upper layer deepens and the shape of the thermocline remains the same. The heat budget for the entire water column is governed by the following equation:

$$
D\left(\frac{d \bar{\theta}}{d t}\right)=\frac{1}{\rho_{w} c_{w}}\left[Q_{s}+I_{s}-Q_{b}-I(D)\right]
$$

where $\bar{\theta}$ is mean temperature, $t$ is time, $\mathrm{D}$ is the maximum depth, $\rho_{\mathrm{w}}$ is the density of water, $\mathrm{c}_{\mathrm{w}}$ is the specific heat of water, $\mathrm{Q}$ is the turbulent heat flux, and $\mathrm{I}$ is the radiation heat flux. Subscripts of $s$ and $b$ denote the lake surface and bottom, respectively. The traditional components of the lake heat budget that make up $\mathrm{Q}_{\mathrm{s}}$ are the latent and sensible heat exchange with the atmosphere. $I_{s}$ is made up of incoming solar radiation and longwave radiation emitted by the atmosphere, and longwave radiation emitted by the lake surface. $\mathrm{Q}_{\mathrm{b}}$ is the heat exchange with the sediments. For a more detailed description of the lake parameterization scheme see Mironov (33).

\subsection{Sensitivity Analysis}

A sensitivity analysis was conducted for FLake using Allequash Lake (see section 3.5.1 below) and the modeled climate data obtained for the northern validation site (see section 3.5.1 below). Each of the climate model input parameters was varied individually, and the model was run keeping all other variables constant. Climate input variables were increased and decreased by $10 \%$ and $50 \%$ to determine the effects of different inputs on surface and mean water temperature predictions (Table 3.5). The extinction coefficient was increased and decreased by $50 \%$ and the model was run without varying any climate variables. All of the values in Table 3.5 could realistically exist in the natural world; however, combinations of the varied and unvaried parameters may not. Furthermore, each of the climate input parameters were varied by $\pm 10 \%$ and $\pm 50 \%$, but the amount of natural variability that these changes comprise is different for each climate variable (Table 3.6). For example, the change in the mean solar radiation from a $50 \%$ increase makes up $61 \%$ of the standard deviation of the original dataset, while for the same increase in air temperature the difference in means only makes up approximately $21 \%$ of the standard deviation of the original dataset. 
Table 3.5. Descriptive statistics of varied climate data for the sensitivity analysis.

\begin{tabular}{ccccccc}
\hline $\begin{array}{c}\text { Climate } \\
\text { Parameter }\end{array}$ & Statistic & $\pm 0 \%$ & $+10 \%$ & $-10 \%$ & $+50 \%$ & $-50 \%$ \\
\hline \multirow{3}{*}{$\begin{array}{c}\text { Solar Radiation } \\
\left(\mathrm{W} / \mathrm{m}^{2}\right)\end{array}$} & Minimum & 3.1 & 3.4 & 2.8 & 4.7 & 1.6 \\
& Maximum & 367.9 & 404.7 & 331.1 & 551.9 & 184.0 \\
& Mean & 114.9 & 126.4 & 103.4 & 172.4 & 57.5 \\
Standard deviation & 93.8 & 103.2 & 84.4 & 140.7 & 46.9 \\
\hline Air Temperature & Minimum & -22.7 & -25.0 & -20.5 & -34.1 & -11.4 \\
$\left({ }^{\circ} \mathrm{C}\right)$ & Maximum & 22.8 & 25.1 & 20.5 & 34.2 & 11.4 \\
& Mean & 4.5 & 5.0 & 4.1 & 6.8 & 2.3 \\
& Standard deviation & 10.5 & 11.5 & 9.4 & 15.7 & 5.2 \\
\hline \multirow{2}{*}{ Air Humidity } & Minimum & 3.3 & 3.6 & 3.0 & 5.0 & 1.7 \\
$(\mathrm{mb})$ & Maximum & 46.2 & 50.8 & 41.6 & 69.3 & 23.1 \\
& Mean & 20.3 & 22.3 & 18.3 & 30.4 & 10.2 \\
& Standard deviation & 10.8 & 11.9 & 9.7 & 16.2 & 5.4 \\
\hline Wind Speed & Minimum & 0.1 & 0.1 & 0.1 & 0.2 & 0.1 \\
$(\mathrm{~m} / \mathrm{s})$ & Maximum & 10.7 & 11.8 & 9.6 & 16.1 & 5.4 \\
& Mean & 4.0 & 4.4 & 3.6 & 5.9 & 2.0 \\
& Standard deviation & 1.8 & 2.0 & 1.6 & 2.7 & 0.9 \\
\hline & Minimum & 0.0 & 0.0 & 0.0 & 0.0 & 0.0 \\
Cloudiness & Maximum & 1.0 & 1.0 & 0.9 & 1.0 & 0.5 \\
$(0-1)$ & Mean & 0.8 & 0.9 & 0.8 & 1.3 & 0.4 \\
& Standard deviation & 0.2 & 0.2 & 0.2 & 0.3 & 0.1 \\
\hline
\end{tabular}

Table 3.6. Change of varied climate parameters means relative to the standard deviation in the original dataset for each climate input.

\begin{tabular}{lcccc}
\hline & \multicolumn{4}{c}{ Change in means relative to standard deviation (\%) } \\
\hline \multicolumn{1}{c}{ Parameter } & $10 \%$ & $-10 \%$ & $50 \%$ & $-50 \%$ \\
\hline Solar Radiation & 12 & 12 & 61 & 61 \\
Air Temperature & 5 & 4 & 22 & 21 \\
Air Humidity & 19 & 19 & 94 & 94 \\
Wind Speed & 22 & 22 & 100 & 100 \\
Cloudiness & 50 & 0 & 100 & 100 \\
\hline
\end{tabular}




\subsection{Model Validation}

The model's mean and surface water temperature predictions were first validated using observed meteorological conditions from 1998 through 1999. We then conducted a second validation using modeled past climate data from 1998 through 1999 to determine how well the combined climate and lake models predicted lake temperatures. Validation was conducted using regression-based equivalence testing for six lakes located in northern Wisconsin and four lakes in southern Wisconsin.

\subsubsection{Validation Lake Data}

Lakes were chosen for validation based on location, availability of long-term water temperature and meteorological data, and variability of surface area, depth, and trophic state (Table 3.7). The locations of the northern and southern validation sites are shown in Figure 3.7. Data from 1998 through 1999 for the ten validation lakes were obtained from the North Temperate Lakes-Long-Term Ecological Research Network (56). The water temperature measurements were taken at approximately each meter from the surface to the maximum depth for each lake except Lake Wingra, where measurements extended only to the mean depth. The daily mean temperature of the water column was calculated using weighted averages based on each lake's morphology (57). The morphology for Fish Lake was not available, so the morphology of Crystal Lake was used as a proxy based on similarities in the lake bathymetry. For Lake Wingra, the arithmetic mean was used to calculate the mean water temperature, which may have resulted in an overestimate of the mean temperature.

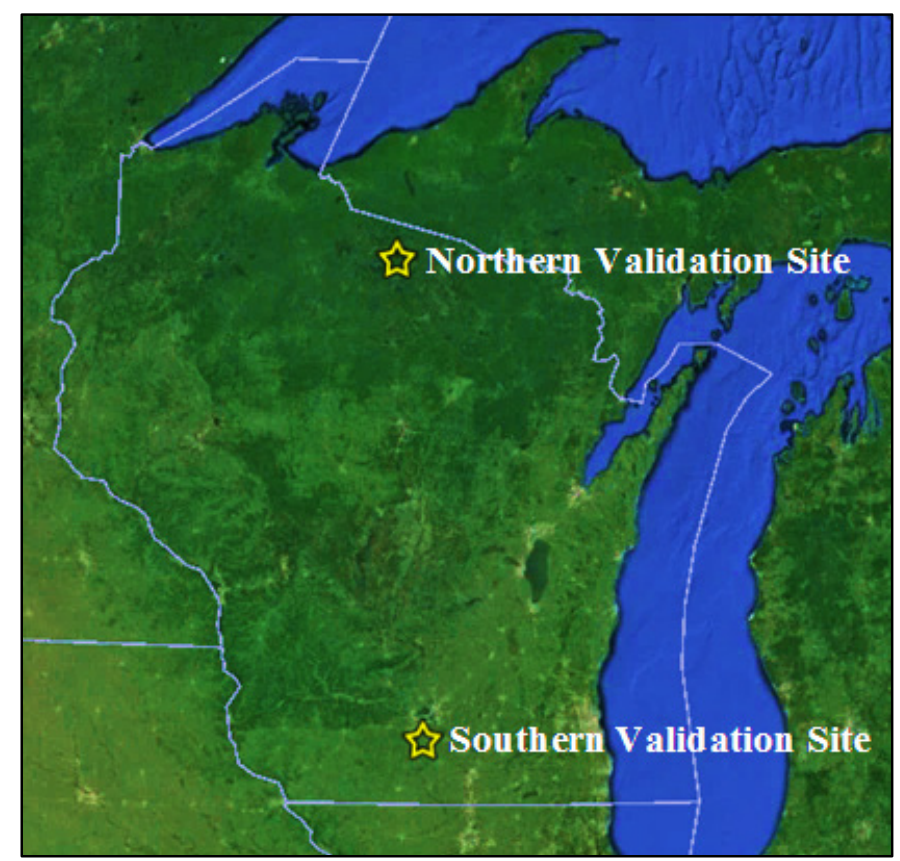

Figure 3.7. Map of the location of the northern and southern validation sites in Wisconsin (Google Earth Map Data: NOAA, Landsat, 58. For image permissions see Appendix D, 59). 
Table 3.7. Summary of lake property data for validation lakes.

\begin{tabular}{lcccccc}
\hline Lake & Latitude & $\begin{array}{c}\text { Area } \\
\left(\mathrm{km}^{2}\right)\end{array}$ & $\begin{array}{c}\text { Max } \\
\text { Depth } \\
(\mathrm{m})\end{array}$ & $\begin{array}{c}\text { Extinction } \\
\text { Coefficient } \\
(1 / \mathrm{m})\end{array}$ & $\begin{array}{c}\text { Fetch } \\
(\mathrm{m})\end{array}$ & $\begin{array}{c}\text { Validation } \\
\text { Site }\end{array}$ \\
\hline Crystal Bog & 46.008 & 0.01 & 2.5 & 1.2 & 68 & Northern \\
Crystal Lake & 46.003 & 0.38 & 20.4 & 0.2 & 785 & Northern \\
Big Muskellunge Lake & 46.021 & 3.63 & 21.3 & 0.3 & 2380 & Northern \\
Sparkling Lake & 46.008 & 0.64 & 20.0 & 0.3 & 755 & Northern \\
Allequash Lake & 46.038 & 1.64 & 8.0 & 0.6 & 1030 & Northern \\
Trout Lake & 46.029 & 15.65 & 35.7 & 0.4 & 3107 & Northern \\
Fish Lake & 43.287 & 0.80 & 18.9 & 0.8 & 1550 & Southern \\
Lake Mendota & 43.099 & 39.61 & 25.3 & 0.6 & 7503 & Southern \\
Lake Wingra & 43.053 & 1.36 & 6.7 & 2.6 & 1800 & Southern \\
Lake Monona & 43.063 & 13.60 & 22.5 & 0.8 & 5000 & Southern \\
\hline
\end{tabular}

\subsubsection{Validation Meteorological Data}

\section{Observed Meteorological Data}

Daily observed meteorological conditions from 1998 through 1999 were obtained for each validation site. Solar radiation, air temperature, air humidity, and wind speed data were obtained from the North Temperate Lakes-Long-term Ecological Research Network $(60,61)$. Woodruff Airport data were used for lakes at the northern validation site, and data compiled from three observation stations in Madison, WI were used for lakes at the southern validation site (Table 3.7). Fetch was determined by identifying the predominant wind direction at each location and measuring the longest corresponding distance across each lake in GIS.

\section{Modeled Meteorological Data}

Downscaled past (1998-1999) and future (2020-2099) meteorological data were obtained from the United States Geological Survey (USGS) Regional Climate Viewer (62). The Regional Climate Viewer produces climate data at $15 \mathrm{~km}$ resolution for the eastern United States (62) from a variety of global circulation models. The MPI ECHAM5 climate model (63) with the IPCC A2 emissions scenario (31) was selected to model meteorological conditions for the validation period (1998-1999) as well as for future climate conditions (2020-2099). The A2 emission scenario is one of the highest emission rate scenarios. In this scenario, population continues to increase to over 10 billion by $2050, \mathrm{CO}_{2}$ emissions are expected to increase to $870 \mathrm{ppm}$ by the end of the $21^{\text {st }}$ century, methane and nitrous oxide concentrations are expected to increase, and sulfur dioxide increases to a peak in 2050 and then gradually decreases. The MPI ECHAM5 climate model was evaluated with 21 other climate models and was shown to have a lower overall error of more than 10\% compared to the typical model error and $30 \%$ to $40 \%$ less error than the least accurate models in the region where the study site is located $(64,65)$. The typical model error is the median root square error of all of the models for a given meteorological variable (64). 


\subsubsection{Validation Statistics}

To validate the lake model, we used regression-based equivalence testing. Regression is often used to validate lake models by plotting model predictions and observed data against each other to develop a linear regression. Ideally the slope would equal 1 and the intercept would be equal to 0 if there is complete agreement between model predictions and observed data. Regression-based equivalence testing evaluates the similarity of the regression slope to 1 and intercept to 0 . The traditional null and alternative hypotheses are reversed so that the null hypothesis is that the slope and intercept are different from 1 and 0 , respectively, and the alternative hypothesis is that the slope and intercept are equal to 1 and 0 , respectively (66). A regression model is developed for observed and predicted data, and if the slope and intercept fall within the region of similarity, which is based on a-priori values and the significance level, the null hypothesis is rejected.

We used R statistical software (67) and the R package "equivalence" (68) to conduct equivalence testing to validate FLake. The equivalence package uses a bootstrap approach to develop alternative regressions using subsets of the data and determines whether the slope and intercept fall within the predetermined regions of similarity for each regression generated in the bootstrap. To reject the null hypothesis of dissimilarity, the slope and intercept must fall within the region of similarity for at least $95 \%$ of the iterations.

The regions of similarity for the lake temperature output using the observed meteorological data were $\pm 15 \%$ for the slope and $\pm 1.0^{\circ} \mathrm{C}$ for the intercept. Looser criteria were used to assess the FLake model outputs when driven by modeled meteorological data to accommodate added uncertainty from using modeled meteorological data. The regions of similarity for lake temperature using the modeled climate inputs were $\pm 20 \%$ and $\pm 4.0^{\circ} \mathrm{C}$ for the slope and intercept, respectively. The bootstrap test was iterated 1000 times for each lake and a significance level of 0.05 was used for all statistical tests.

\subsection{Modeling Approach}

We used FLake and modeled future climate data to predict lake temperatures from 2020 to 2099. A set of 13 lake groups were selected for modeling that captured grouping extremes and allowed us to compare lake responses across climates, lake sizes, and trophic states. A prototype lake was developed for each of the selected 13 lake groups and used for modeling future conditions. The midpoint of the latitude range corresponding to each climate group was used for model inputs. For each of the prototype lakes, the model was run on a daily time step for the years 2020 to 2099. The model predictions were analyzed for long-term trends and differences among lake groups. The changes in the period when surface water temperatures were predicted to be above minimum and optimal growth temperatures for cyanobacteria were also analyzed for trends by lake group for the years 2020 and 2099.

\subsubsection{Prototype Lake Development and Characteristics}

One prototype lake was developed for each lake group by averaging the lake characteristics of all lakes within the group. The fetch of the prototype lake was approximated by the square root of the surface area (69). The prototype lake was used to 
model future conditions to represent the response of all the lakes in the group for a given lake type.

We selected a set of seven lake groups from the 27 combinations of climate, size, and trophic state for the first round modeling. One small eutrophic lake from each climate group (UP-Sm-E, NLP-Sm-E, and SLP-Sm-E) was modeled to compare results across climates. Similarly, one small, one medium, and one large eutrophic lake in the warmest climate group (SLP-Sm-E, SLP-Md-E, and SLP-Lg-E) was modeled to compare the effect of lake size. Finally, eutrophic, mesotrophic, and oligotrophic lakes, all small and from the southern-most climate group (SLP-Sm-E, SLP-Sm-M, and SLP-Sm-O) were modeled to compare trophic states.

Based on a lack of differences among the lakes selected for the first round of modeling, another set of six lakes were modeled to capture more of the extremes of the lake groups. The following lake groups were modeled in the second round: one large, oligotrophic lake in each climate group (UP-Lg-O, NLP-Lg-O, and SLP-Lg-O); one large eutrophic, mesotrophic, and oligotrophic lake in the Upper Peninsula (UP-Lg-E, UP-Lg$\mathrm{M}$, and UP-Lg-O); and one small, medium, and large eutrophic lake in the Upper Peninsula (UP-Sm-E, UP-Med-E, UP-Lg-E). The characteristics of the thirteen modeled prototype lakes are shown in Table 3.8. Note that some lakes did not have mean depth data which may have resulted in a skewed mean depth for lake groups. An interesting characteristic of the prototype lakes developed from the MSU dataset is that lakes in the small size class tend to have steeper basin slopes than large lakes (Table 3.8).

Table 3.8. Summary of prototype lake characteristics for each modeled lake group. Superscripts in the mean depth column indicate the number of lakes in the set that did not have mean depth data. NA indicates that there were no data available for the group.

\begin{tabular}{lcccccc}
\hline Lake Group & $\mathrm{N}$ & $\begin{array}{c}\text { Surface } \\
\text { Area } \\
\left(\mathrm{km}^{2}\right)\end{array}$ & $\begin{array}{c}\text { Mean } \\
\text { Depth } \\
(\mathrm{m})\end{array}$ & $\begin{array}{c}\text { Maximum } \\
\text { Depth } \\
(\mathrm{m})\end{array}$ & $\begin{array}{c}\text { Secchi } \\
\text { Depth } \\
(\mathrm{m})\end{array}$ & $\begin{array}{c}\text { Fetch } \\
(\mathrm{m})\end{array}$ \\
\hline UP-Sm-E & 14 & 0.3 & $3.6^{3}$ & 10.0 & 1.4 & 576 \\
UP-Md-E & 8 & 0.8 & $2.7^{1}$ & 6.7 & 1.1 & 913 \\
UP-Lg-E & 10 & 5.0 & $3.1^{2}$ & 7.6 & 1.3 & 2233 \\
UP-Lg-M & 25 & 5.1 & $4.0^{2}$ & 11.5 & 0.6 & 2266 \\
UP-Lg-O & 11 & 2.4 & 6.2 & 17.8 & 0.3 & 1547 \\
NLP-Sm-E & 1 & 0.4 & NA & 7.6 & 0.9 & 608 \\
NLP-Lg-O & 8 & 4.1 & $6.5^{1}$ & 21.0 & 0.3 & 2034 \\
SLP-Sm-E & 13 & 0.4 & $3.5^{4}$ & 9.9 & 0.9 & 600 \\
SLP-Sm-M & 49 & 0.3 & $4.7^{10}$ & 11.8 & 0.6 & 571 \\
SLP-Sm-O & 7 & 0.3 & $6.0^{3}$ & 16.1 & 0.4 & 549 \\
SLP-Md-E & 17 & 0.8 & $3.9^{2}$ & 10.3 & 1.4 & 893 \\
SLP-Lg-E & 18 & 3.5 & $3.7^{2}$ & 9.4 & 1.8 & 1877 \\
SLP-Lg-O & 4 & 2.7 & 6.2 & 28.7 & 4.5 & 1642 \\
\hline
\end{tabular}




\subsection{Trend Analysis}

The modeled climate data and lake modeling results were analyzed for trends using two procedures. First, the data were analyzed for trend using seasonal decomposition by loess smoothing (70). Seasonal decomposition is used to determine and remove seasonality from a time series dataset to reveal underlying trends. These methods were applied using the "stl" function in the R package "stats" (67). The seasonal component was removed and loess smoothing was then applied to the detrended data. Finally, the long-term trend was determined for the seasonal component and merged with the smoothed data.

The second method used for trend analysis was a combination of the Mann-Kendall trend test $(71,72)$ and the Theil-Sen approach for slope estimation $(73,74)$. The MannKendall test is a non-parametric test used to determine whether data have a significant monotonic upward or downward trend over time. The Theil-Sen approach is a nonparametric method of estimating the slope of a trend by determining the median slope through all possible pairs of points for the model predictions over time. However, neither the Theil-Sen approach nor the Mann-Kendall test is applicable to autocorrelated data such as environmental data with seasonal and inter-annual variation (75). Applying a prewhitening procedure can remove autocorrelation, but at the risk of reducing the statistical significance and magnitude of real trends. Pre-whitening is a term used to describe the process of removing systematic noise from data to analyze underlying trends.

The approach proposed by S. Yue et al. (76) illustrates that the effect of removing autocorrelation on the estimate of the magnitude of the trend far exceeds the effect of removing the trend on the estimate of autocorrelation. Therefore, they propose the following method: 1) determine the slope of the trend using the Theil-Sen approach, and if the slope of the trend is significantly different from zero it is assumed to be linear and removed from the series; 2) calculate and remove the autocorrelation coefficient from the detrended series; 3 ) merge the detrended data with autocorrelation removed with the linear trend determined using the Theil-Sen approach; and 4) apply the Mann-Kendall test to the merged data to determine the significance of the trend. These methods were applied using the R statistical software package "zyp" (77). The slope of the trend was determined using monthly averaged data from 2020 to 2099 for all climate data and modeled lake groups to accommodate the computing power of the $\mathrm{R}$ statistical software. The long-term trend for each season was determined using daily data for each modeled lake group.

Lake model surface temperature predictions in 2020 and 2099 were analyzed to determine the change in the period when surface temperature was predicted to be above minimum and optimum growth temperatures for cyanobacteria as a function of climate, lake size, and trophic state. For each year, we determined the number of days that the surface water temperature was predicted to be above minimum growth temperatures, $T_{\min }$ $\left(15^{\circ} \mathrm{C}\right)(14,15$, $)$ and the number of days the temperature is above optimal growth temperatures, $\mathrm{T}_{\mathrm{opt}}\left(25^{\circ} \mathrm{C}\right)(14,15)$. The changes in the number of days above $\mathrm{T}_{\min }$ and $\mathrm{T}_{\mathrm{opt}}$ were compared across climates, lakes sizes, and trophic states to determine if any relationships existed and to determine the susceptibility of lakes to future cyanobacteria growth. 


\section{Results}

\subsection{Sensitivity Analysis}

The sensitivity of the model's surface and mean water temperature predictions to modeled solar radiation, air temperature, air humidity, wind speed, cloudiness, and extinction coefficient were tested using observations at Allequash Lake (Table 3.5) to illustrate the effect of varying parameters by $\pm 10 \%$ and $\pm 50 \%$. The modeled surface (Figure 4.1) and mean (Figure 4.2) water temperature predictions appear to be most sensitive to solar radiation, air temperature, and air humidity. Although surface and mean water temperature predictions appear to be sensitive to the same parameters, modeled surface temperature predictions are much more variable than mean temperature predictions, which have a smoother response to varied climate inputs because of the lesser influence of the meteorological conditions at depth. There is also a seasonal component to the sensitivity of the lake model predictions for all varied parameters. In summer, the model is more sensitive to varied inputs than in winter months (Figure 4.1 and Figure 4.2). 

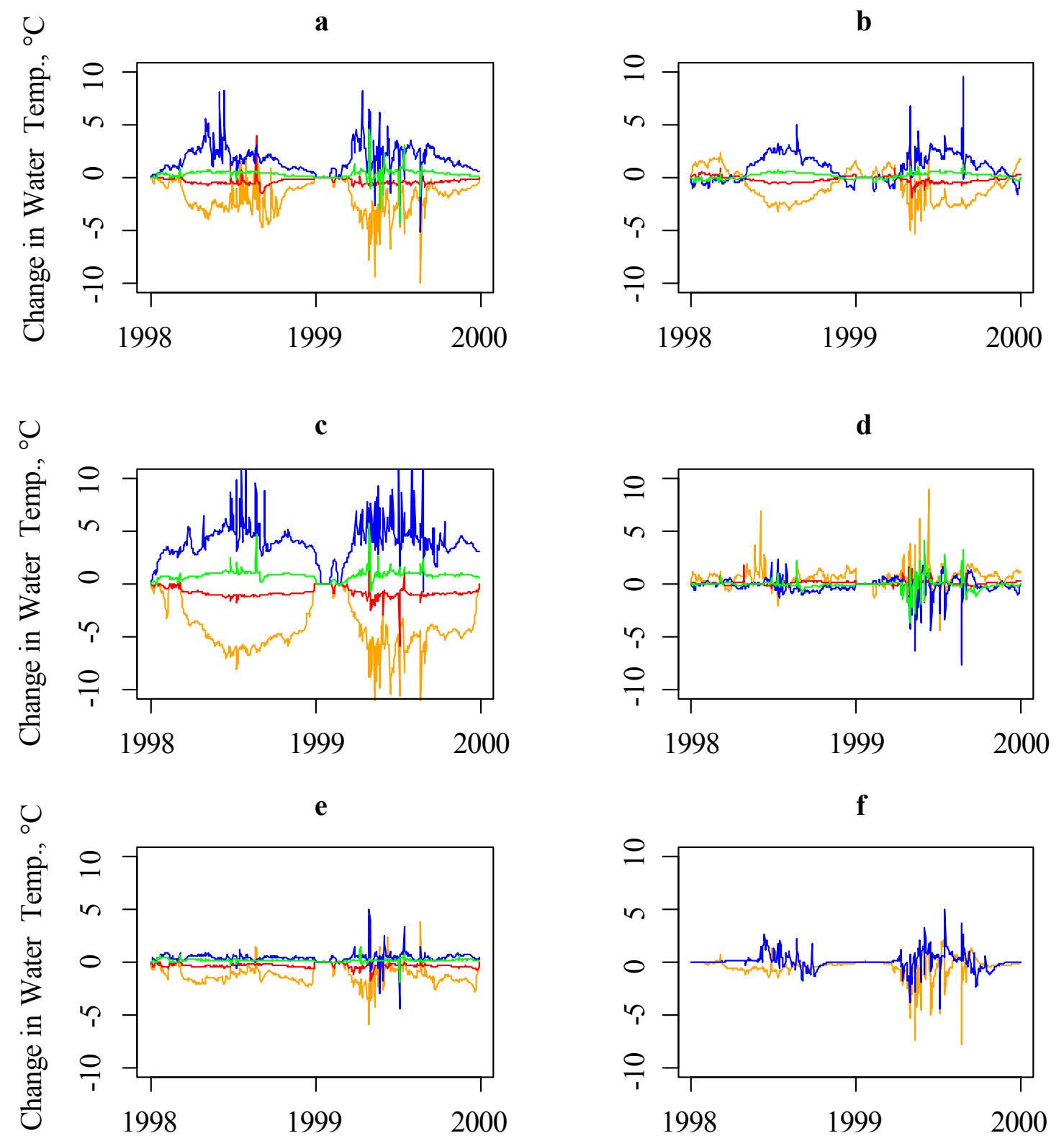

Years

$--50 \%--10 \%-+50 \%-+10 \%$

Figure 4.1. Response of surface water temperature predictions to varied modeled climate inputs and extinction coefficient including: a) solar radiation, b) air temperature, c) air humidity, d) wind speed, e) cloudiness, and f) extinction coefficient for Allequash Lake. 

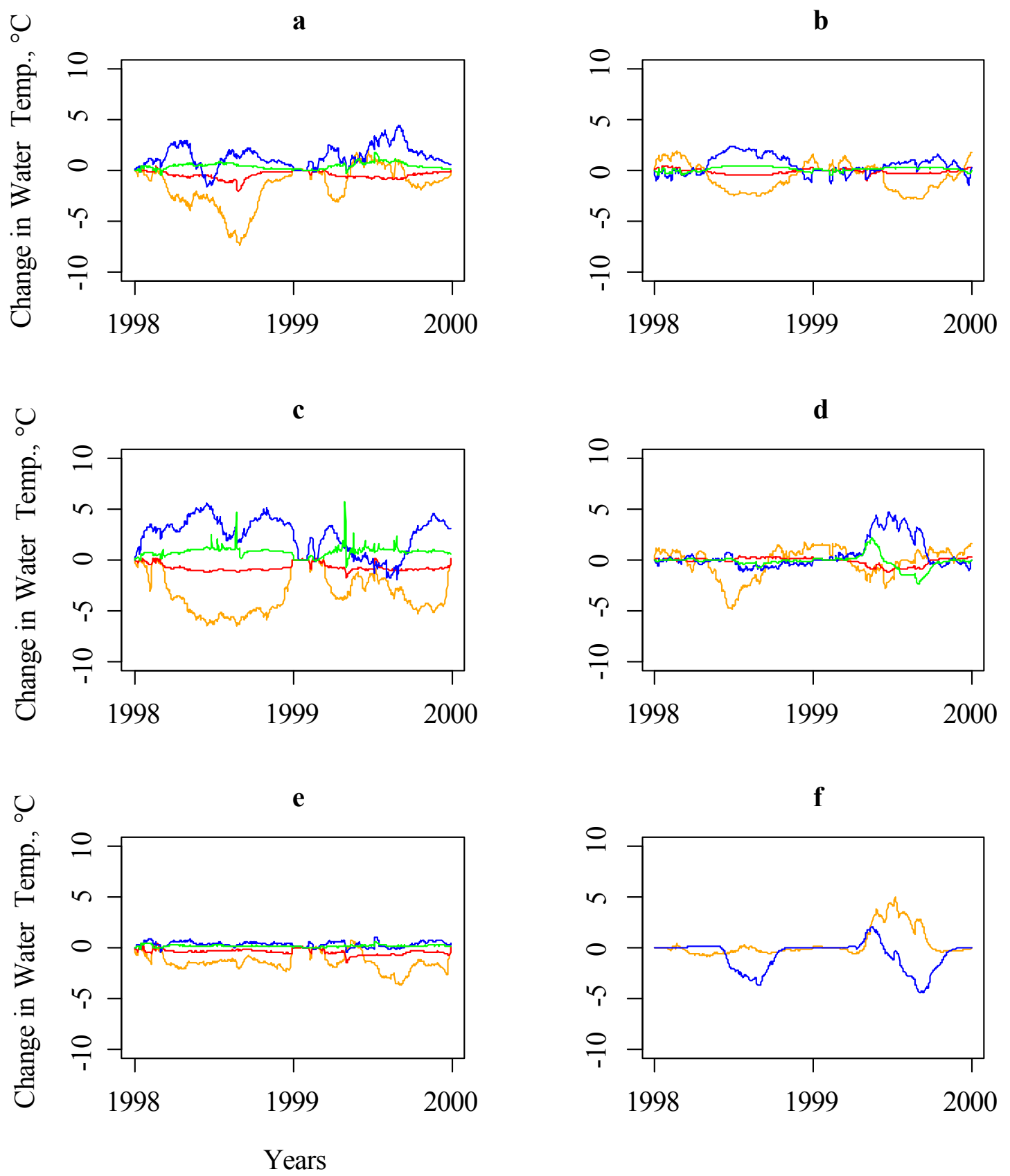

Figure 4.2. Response of mean water temperature predictions to varied modeled climate inputs and extinction coefficient including: a) solar radiation, b) air temperature, c) air humidity, d) wind speed, e) cloudiness, and f) extinction coefficient for Allequash Lake. 


\subsection{Modeled Meteorological Data}

Plots of the difference between modeled and observed meteorological data from 1998 through 1999 illustrate the accuracy of the climate model (Figure 4.3). The errors were large for solar radiation, air temperature, and air humidity (Table 4.1). The differences between modeled and observed climate data were larger in warmer months for solar radiation and air humidity. The climate model deviation from observed conditions does not appear to vary much between the northern and southern validations sites.

Table 4.1. Climate model and observed means with root mean squared error (RMSE) for solar radiation, air temperature, air humidity, and wind speed for the northern and southern validation sites from 1998 through 1999.

\begin{tabular}{|c|c|c|c|c|c|c|}
\hline \multirow{3}{*}{$\begin{array}{l}\text { Climate } \\
\text { Parameter }\end{array}$} & \multicolumn{3}{|c|}{ Northern Validation Site } & \multicolumn{3}{|c|}{ Southern Validation Site } \\
\hline & \multicolumn{2}{|c|}{ Mean } & \multirow{2}{*}{ RMSE } & \multicolumn{2}{|c|}{ Mean } & \multirow{2}{*}{ RMSE } \\
\hline & Observed & Modeled & & Observed & Modeled & \\
\hline Solar & & & & & & \\
\hline $\begin{array}{l}\text { Radiation } \\
\left(\mathrm{W} / \mathrm{m}^{2}\right)\end{array}$ & 147.5 & 114.9 & 97.3 & 160.4 & 131.9 & 109.0 \\
\hline Air & & & & & & \\
\hline $\begin{array}{l}\text { Temperature } \\
\left({ }^{\circ} \mathrm{C}\right)\end{array}$ & 6.2 & 4.5 & 6.3 & 9.5 & 7.9 & 6.0 \\
\hline $\begin{array}{l}\text { Air Humidity } \\
(\mathrm{mb})\end{array}$ & 8.6 & 20.3 & 13.6 & 10.5 & 23.2 & 14.8 \\
\hline $\begin{array}{l}\text { Wind Speed } \\
(\mathrm{m} / \mathrm{s})\end{array}$ & 2.6 & 4.0 & 2.6 & 3.3 & 4.4 & 2.8 \\
\hline
\end{tabular}



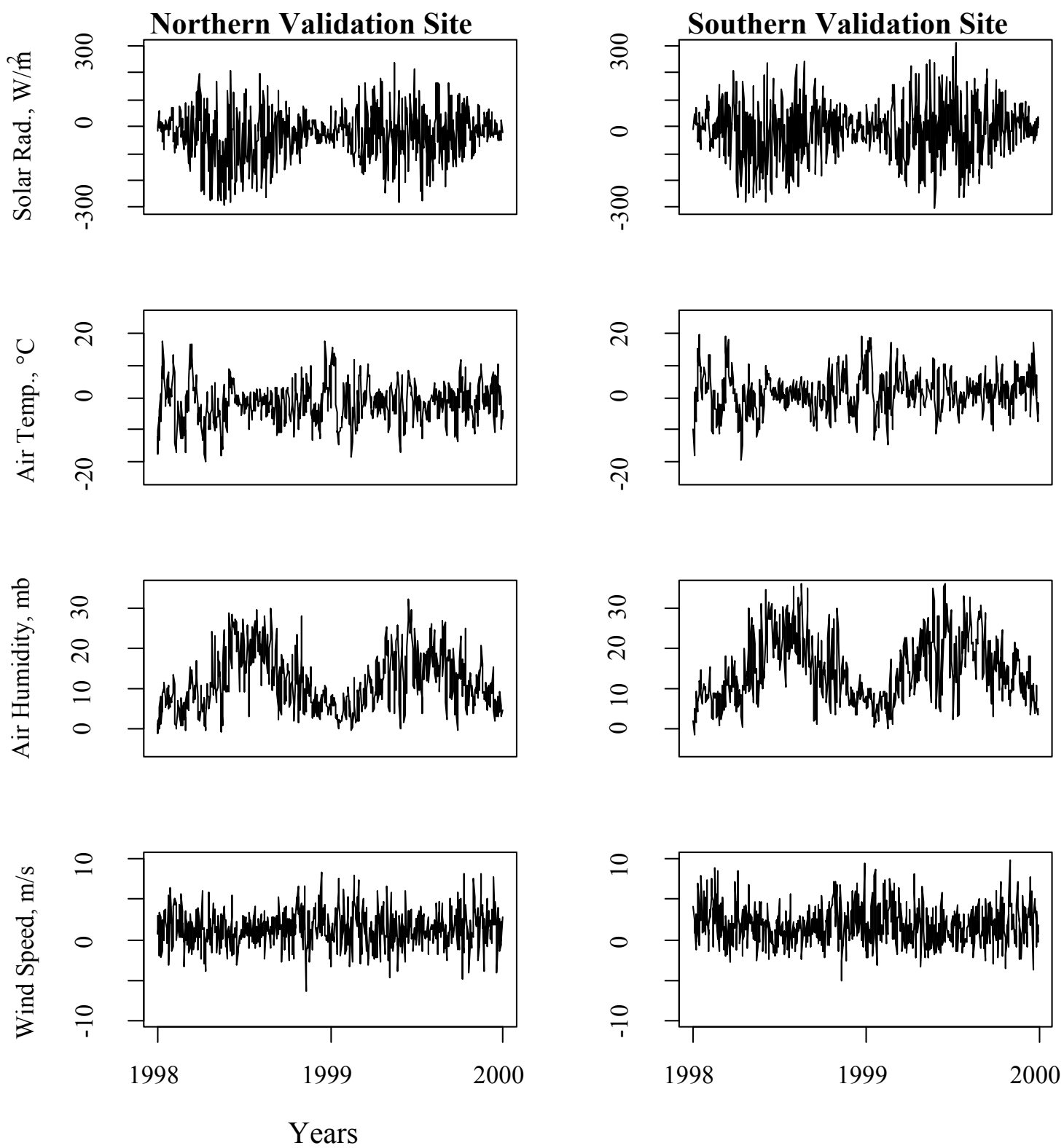

Figure 4.3. Difference between modeled and observed (modeled - observed) meteorological data for the northern (left column) and southern (right column) validation sites in Wisconsin from 1998 through 1999. Climate variables (solar radiation, air temperature, air humidity, and wind speed) are shown by row.

\subsection{Validation}

FLake's ability to predict surface and mean water temperatures was tested for 10 lakes. The model was found to be valid using the criteria described in section 3.5 and observed meteorological data for both mean and surface water temperature for Allequash 
Lake, Crystal Lake, and Crystal Bog. The model predictions were valid for surface water temperature but not for mean water temperature for Big Muskellunge Lake, Sparkling Lake, Fish Lake, Lake Monona, and Lake Mendota. For Lake Wingra and Trout Lake, the model was not valid for either mean or surface water temperatures (Table 4.2). For supporting material see Appendix B.

The model validation was repeated using the modeled climate data for 1998 and 1999. Using the looser criteria, the lake model predictions were valid for predicting surface water temperature for all lakes except Crystal Bog. The model was found to be valid for mean water temperature for all lakes except Big Muskellunge Lake, Lake Wingra, Lake Monona, and Lake Mendota. The intercept showed that the lake model over-predicts when using modeled climate inputs for all lakes; the bias ranged from $3.4^{\circ} \mathrm{C}$ to $5.1^{\circ} \mathrm{C}$. Results of all equivalence tests are shown in Table 4.2 and Appendix B.

Table 4.2. Summary of validation results for mean $\left(T_{m}\right)$ and surface $\left(T_{s}\right)$ water temperature using observed and modeled climate data. Validation entry results are shaded for cases that are not valid.

\begin{tabular}{|c|c|c|c|}
\hline \multirow{3}{*}{ Lake } & \multirow{3}{*}{ Parameter } & $\begin{array}{c}\text { Observed Climate } \\
\text { Data }\end{array}$ & $\begin{array}{l}\text { Modeled Climate } \\
\text { Data }\end{array}$ \\
\hline & & Valid & Valid \\
\hline & & $\mathrm{Y} / \mathrm{N}$ & $\mathrm{Y} / \mathrm{N}$ \\
\hline \multirow{2}{*}{ Allequash Lake } & $\mathrm{T}_{\mathrm{s}}$ & $\mathrm{Y}$ & $\mathrm{Y}$ \\
\hline & $\mathrm{T}_{\mathrm{m}}$ & $\mathrm{Y}$ & $\mathrm{Y}$ \\
\hline \multirow{2}{*}{$\begin{array}{l}\text { Big Muskellunge } \\
\text { Lake }\end{array}$} & $\mathrm{T}_{\mathrm{s}}$ & $\mathrm{Y}$ & $\mathrm{Y}$ \\
\hline & $\mathrm{T}_{\mathrm{m}}$ & $\mathrm{N}$ & $\mathrm{N}$ \\
\hline \multirow{2}{*}{ Crystal Lake } & $\mathrm{T}_{\mathrm{s}}$ & $\mathrm{Y}$ & $\bar{Y}$ \\
\hline & $\mathrm{T}_{\mathrm{m}}$ & $\mathrm{Y}$ & $\mathrm{Y}$ \\
\hline \multirow{2}{*}{ Crystal Bog } & $\mathrm{T}_{\mathrm{s}}$ & Y & $\mathrm{N}$ \\
\hline & $\mathrm{T}_{\mathrm{m}}$ & $\mathrm{Y}$ & $\mathrm{Y}$ \\
\hline \multirow{2}{*}{ Sparkling Lake } & $T_{s}$ & $\mathrm{Y}$ & $\mathrm{Y}$ \\
\hline & $\mathrm{T}_{\mathrm{m}}$ & $\mathrm{N}$ & $\mathrm{Y}$ \\
\hline \multirow{2}{*}{ Trout Lake } & $\mathrm{T}_{\mathrm{s}}$ & $\mathrm{N}$ & $\bar{Y}$ \\
\hline & $\mathrm{T}_{\mathrm{m}}$ & $\mathrm{N}$ & $\mathrm{Y}$ \\
\hline \multirow{2}{*}{ Fish Lake } & $\mathrm{T}_{\mathrm{s}}$ & Y & Y \\
\hline & $\mathrm{T}_{\mathrm{m}}$ & $\mathrm{N}$ & $\mathrm{Y}$ \\
\hline \multirow{2}{*}{ Lake Wingra } & $\mathrm{T}_{\mathrm{s}}$ & $\mathrm{N}$ & Y \\
\hline & $\mathrm{T}_{\mathrm{m}}$ & $\mathrm{N}$ & $\mathrm{N}$ \\
\hline \multirow{2}{*}{ Lake Monona } & $\mathrm{T}_{\mathrm{s}}$ & $\mathrm{Y}$ & $\mathrm{Y}$ \\
\hline & $\mathrm{T}_{\mathrm{m}}$ & $\mathrm{N}$ & $\mathrm{N}$ \\
\hline \multirow{2}{*}{ Lake Mendota } & $\mathrm{T}_{\mathrm{s}}$ & Y & Y \\
\hline & $\mathrm{T}_{\mathrm{m}}$ & $\mathrm{N}$ & $\mathrm{N}$ \\
\hline
\end{tabular}




\subsection{Trend Analysis}

\subsubsection{Seasonal Decomposition}

Seasonal decomposition was first applied to all of the input climate variables for the Upper Peninsula, northern Lower Peninsula, and southern Lower Peninsula. Similar trends were observed for each variable among climates. The seasonally decomposed trends for solar radiation, air temperature, air humidity, wind speed, and cloudiness is illustrated using data from the northern Lower Peninsula in Figure 4.4. There appears to be a clear overall increasing trend in air temperature and air humidity while solar radiation, wind speed, and cloudiness seem to remain relatively constant over the modeled period (Figure 4.4) or decrease.

Seasonal decomposition was also applied to surface water temperature predictions for each of the modeled lake groups to illustrate long-term trends. The seasonally decomposed trends were similar across the modeled lake groups. Differences in the intercepts of the trends were observed among lakes in the Upper Peninsula, northern Lower Peninsula, and southern Lower Peninsula, while no differences were apparent among size or trophic state classes (Figure 4.5). Small, eutrophic lakes illustrate differences in trends among climate regions (Figure 4.5a). Eutrophic lakes in the southern Lower Peninsula illustrate differences among lake size classes (Figure 4.5b), and the results for large lakes in the Upper Peninsula illustrate differences among trophic states (Figure 4.5c). 

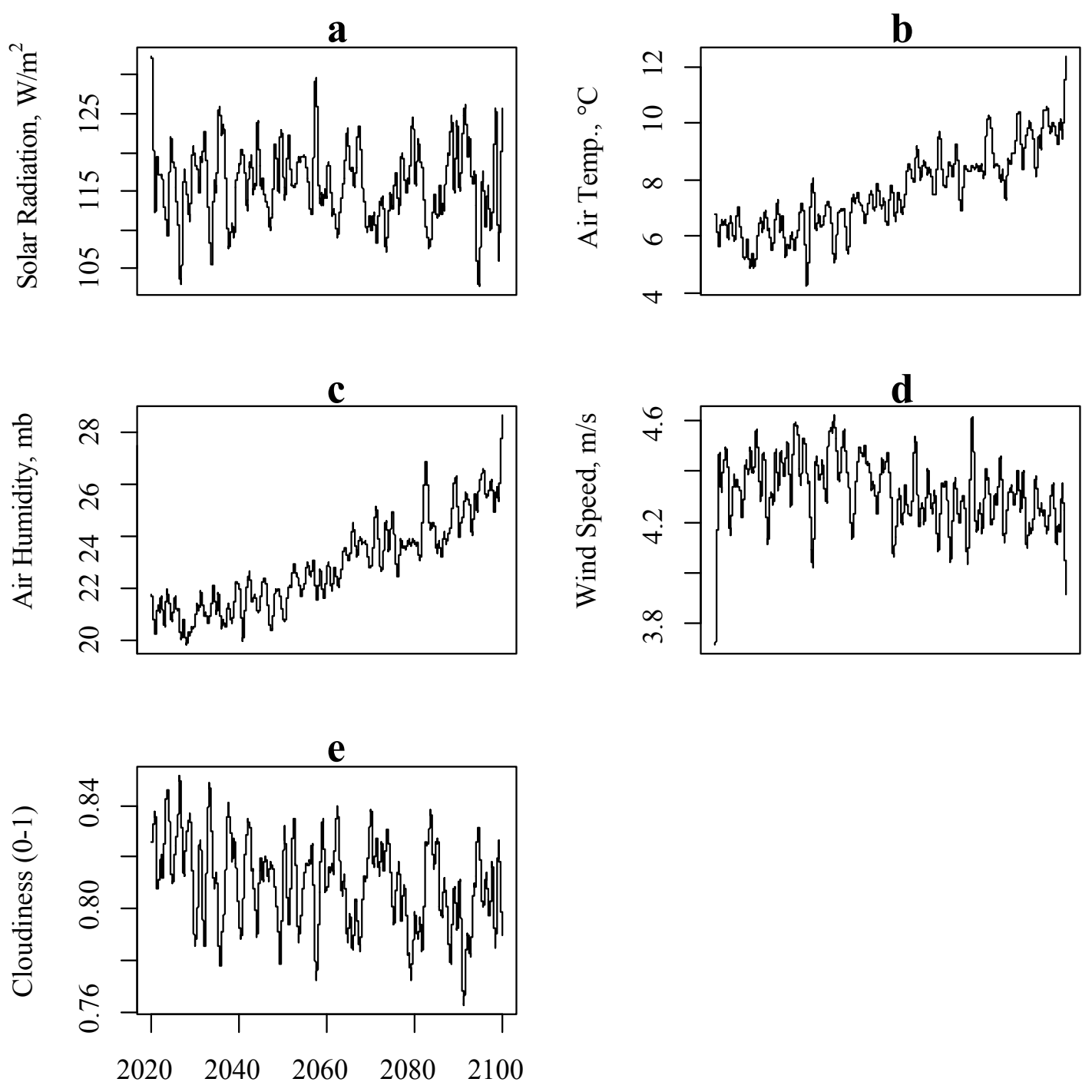

Years

Figure 4.4 Seasonally decomposed trends in (a) solar radiation, (b) air temperature, (c) air humidity, (d) wind speed, (e) and cloudiness in the northern Lower Peninsula from 2020 to 2099. 

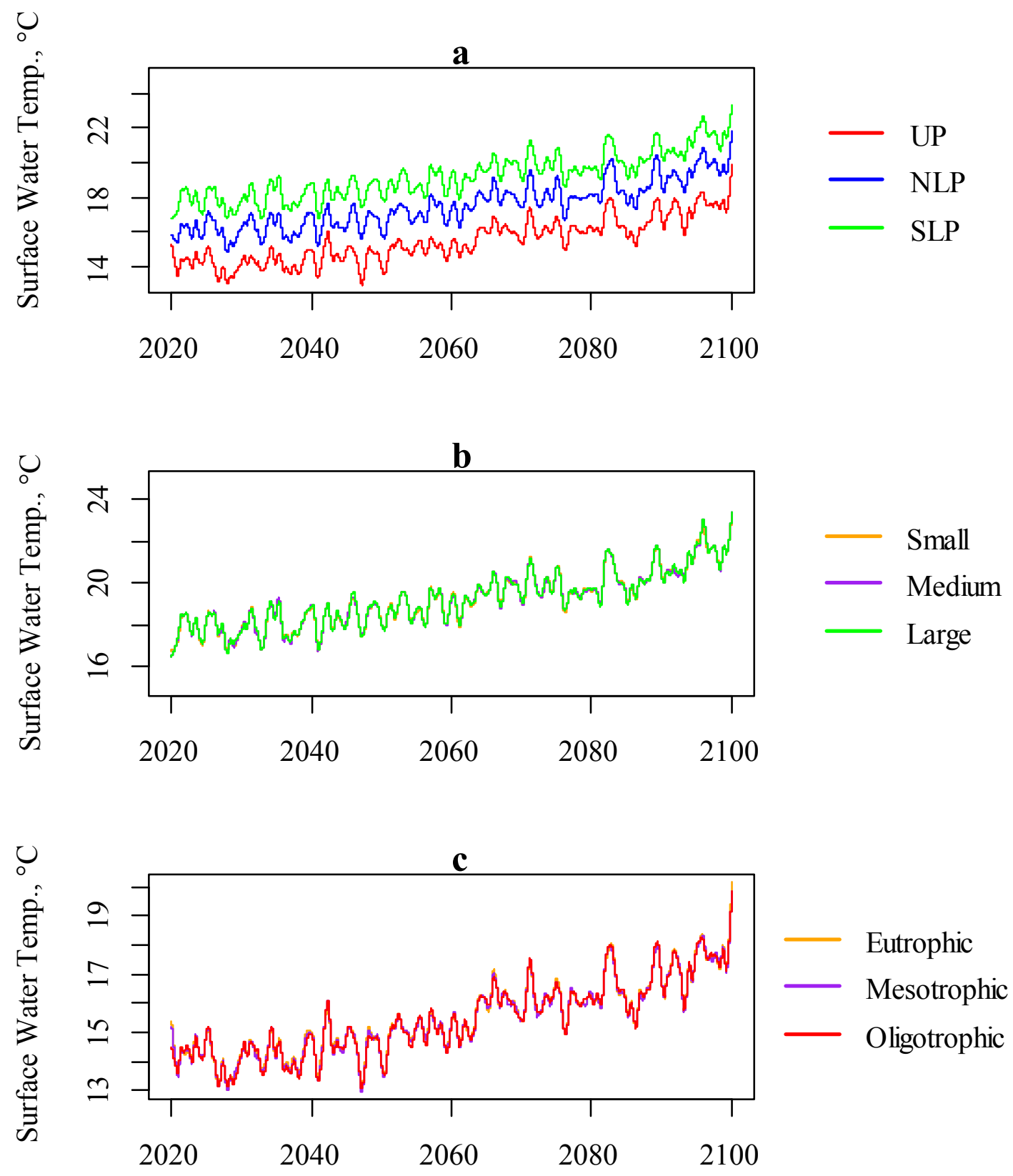

Figure 4.5. Seasonally decomposed trends from 2020 to 2099 for: (a) small, eutrophic lakes in the Upper Peninsula (UP-Sm-E), northern Lower Peninsula (NLP-Sm-E), and southern Lower Peninsula (SLP-Sm-E); (b) small, medium and large eutrophic lakes in the southern Lower Peninsula (SLP-Sm-E, SLP-Md-E, and SLP-Lg-E); (c) large eutrophic (UP-Lg-E), mesotrophic (UP-Lg-M), and oligotrophic lakes (UP-Lg-O) in the Upper Peninsula. 


\subsubsection{Slope Estimation}

The Theil-Sen slope was estimated for each climate parameter in each climate region. Trends were significant for each of the following meteorological variables in all three climate regions: air temperature, air humidity, and cloudiness (Table 4.3). There was also a significant trend in wind speed in the Upper Peninsula (Table 4.3). The confidence intervals for the estimated trend in air temperature and humidity were compared between climate regions, and no statistical differences were observed. A summary of the mean long-term change in air temperature, air humidity, and cloudiness for all climate regions is reported in Table 4.4 .

Table 4.3 Estimates of slope, $95 \%$ confidence intervals for the slope, intercept, and total change from 2020 to 2099 for each climate parameter in the Upper Peninsula (UP), northern Lower Peninsula (NLP), and southern Lower Peninsula (SLP). Significant trends are noted with an asterisk $(*)$.

\begin{tabular}{|c|c|c|c|c|c|}
\hline Location & $\begin{array}{c}\text { Slope } \\
\text { (unit/decade) }\end{array}$ & $\begin{array}{c}\text { CIUpper } \\
\text { (unit/decade) }\end{array}$ & $\begin{array}{c}\mathrm{CI}_{\text {Lower }} \\
\text { (unit/decade) }\end{array}$ & $\begin{array}{c}\text { Intercept } \\
\text { (unit) }\end{array}$ & $\begin{array}{c}\text { Total } \\
\text { Change }\end{array}$ \\
\hline \multicolumn{6}{|c|}{ Solar Radiation $\left(\mathrm{W} / \mathrm{m}^{2}\right)$} \\
\hline UP & -0.2 & 0.1 & -1.6 & 118.0 & $\overline{-1.3}$ \\
\hline NLP & 0.4 & 0.2 & -1.1 & 123.4 & 3.3 \\
\hline SLP & 0.4 & 0.2 & -1.2 & 130.6 & 3.4 \\
\hline \multicolumn{6}{|c|}{ Air Temperature $\left({ }^{\circ} \mathrm{C}\right)$} \\
\hline$\overline{\mathrm{UP}}$ & 0.5 & 0.8 & 0.3 & 5.5 & $4.3^{*}$ \\
\hline NLP & 0.5 & 0.8 & 0.3 & 7.7 & $4.3^{*}$ \\
\hline SLP & 0.5 & 0.7 & 0.3 & 9.0 & $4.1^{*}$ \\
\hline \multicolumn{6}{|c|}{ Air Humidity (mb) } \\
\hline UP & 0.6 & 0.8 & 0.4 & 19.1 & $4.8^{*}$ \\
\hline NLP & 0.7 & 0.9 & 0.4 & 21.0 & $5.4^{*}$ \\
\hline SLP & 0.7 & 1.0 & 0.4 & 23.4 & $5.8^{*}$ \\
\hline \multicolumn{6}{|c|}{ Wind Speed $(\mathrm{m} / \mathrm{s})$} \\
\hline UP & 0.0 & 0.0 & -0.1 & 4.5 & $-0.2^{*}$ \\
\hline NLP & 0.0 & 0.0 & 0.0 & 4.5 & -0.1 \\
\hline SLP & 0.0 & 0.0 & -0.1 & 4.8 & -0.2 \\
\hline \multicolumn{6}{|c|}{ Cloudiness (\%) } \\
\hline UP & -0.3 & -0.1 & -0.5 & 0.8 & $\overline{-2.2^{*}}$ \\
\hline NLP & -0.4 & -0.2 & -0.7 & 0.8 & $-3.5^{*}$ \\
\hline SLP & -0.4 & -0.1 & -0.6 & 0.8 & $-3.0 *$ \\
\hline
\end{tabular}


Table 4.4. Mean change in air temperature, air humidity, and cloudiness between 2020 and 2099 for all climate regions. An asterisk (*) identifies trends that were statistically significant.

Parameter

\begin{tabular}{lc}
\hline Solar Radiation $\left(\mathrm{W} / \mathrm{m}^{2}\right)$ & 1.8 \\
Air Temperature $\left({ }^{\circ} \mathrm{C}\right)$ & $4.3^{*}$ \\
Air Humidity $(\mathrm{mb})$ & $5.3^{*}$ \\
Wind Speed $(\mathrm{m} / \mathrm{s})$ & -0.2 \\
Cloudiness $(\%)$ & $-2.9^{*}$ \\
\hline
\end{tabular}

The annual and seasonal trends in surface water temperature from 2020 to 2099 were significant for all modeled lake groups (Table 4.5). For all lake groups, the largest seasonal increase in surface water temperature was observed in spring and the smallest increase was in winter. No statistical differences in long-term trends of surface temperature were identified among any of the groups regardless of location, size, or trophic state (Table 4.5). However, across all lake groups, the long-term trend in winter was different from spring, summer, and fall while the long-term trend in fall was not statistically different from summer (Table 4.6). The long-term trend in fall was different from spring with the exception of three lake groups: small eutrophic and mesotrophic lakes and medium eutrophic lakes in the southern Lower Peninsula (SLP-Sm-E, SLP-Sm$\mathrm{M}$, and SLP-Md-E, respectively), but there was no obvious relationship between this result and climate, lake size, or trophic state. Fall increases in surface temperature were greater than summer increases in all groups except: small, eutrophic lakes in the Upper Peninsula (UP-Sm-E); large eutrophic, mesotrophic, and oligotrophic lakes in the Upper Peninsula (UP-Lg-E, UP-Lg-M, and UP-Lg-O, respectively); and large oligotrophic lakes in the northern Lower Peninsula (NLP-Lg-O).

Table 4.5 Estimates of slope, $95 \%$ confidence intervals for the slope, intercept, and total change in surface water temperature from 2020 to 2099 are reported for each modeled lake group for the entire period. All trends (slopes) were significant at $\alpha=0.05$.

\begin{tabular}{lccccc}
\hline Group & $\begin{array}{c}\text { Slope } \\
\left({ }^{\circ} \mathrm{C} / \text { decade }\right)\end{array}$ & $\begin{array}{c}\text { CIUpper } \\
\left({ }^{\circ} \mathrm{C} / \text { decade }\right)\end{array}$ & $\begin{array}{c}\mathrm{CI}_{\text {Lower }} \\
\left({ }^{\circ} \mathrm{C} / \text { decade }\right)\end{array}$ & $\begin{array}{c}\text { Intercept } \\
\left({ }^{\circ} \mathrm{C}\right)\end{array}$ & $\begin{array}{c}\text { Total } \\
\text { Change }\left({ }^{\circ} \mathrm{C}\right)\end{array}$ \\
\hline UP-Sm-E & 0.5 & 0.7 & 0.3 & 13.9 & 3.8 \\
UP-Md-E & 0.5 & 0.7 & 0.3 & 13.8 & 3.8 \\
UP-Lg-E & 0.5 & 0.7 & 0.3 & 13.6 & 3.8 \\
UP-Lg-M & 0.5 & 0.7 & 0.3 & 14.0 & 3.8 \\
UP-Lg-O & 0.5 & 0.7 & 0.3 & 13.8 & 3.8 \\
NLP-Sm-E & 0.5 & 0.7 & 0.3 & 15.6 & 4.0 \\
NLP-Lg-O & 0.5 & 0.7 & 0.3 & 16.0 & 3.9 \\
SLP-Sm-E & 0.5 & 0.7 & 0.3 & 17.6 & 3.8 \\
SLP-Sm-M & 0.5 & 0.7 & 0.3 & 17.5 & 3.8 \\
SLP-Sm-O & 0.5 & 0.7 & 0.2 & 17.8 & 3.8 \\
SLP-Md-E & 0.5 & 0.7 & 0.3 & 17.6 & 3.8 \\
SLP-Lg-M & 0.5 & 0.7 & 0.3 & 17.5 & 3.9 \\
SLP-Lg-O & 0.5 & 0.7 & 0.3 & 18.2 & 3.9 \\
\hline
\end{tabular}


Table 4.6 Estimates of slope, 95\% confidence intervals for the slope, intercept, and change in surface water temperature from 2020 to 2099 are reported for each modeled lake group for each season. All trends were significant at $\alpha=0.05$. (Table continued on the next page.)

\begin{tabular}{|c|c|c|c|c|c|c|}
\hline Group & Season & $\begin{array}{c}\text { Slope } \\
\left({ }^{\circ} \mathrm{C} / \text { decade }\right) \\
\end{array}$ & $\begin{array}{c}\mathrm{CI}_{\text {Upper }} \\
\left({ }^{\circ} \mathrm{C} / \text { decade }\right)\end{array}$ & $\begin{array}{c}\mathrm{CI}_{\text {Lower }} \\
\left({ }^{\circ} \mathrm{C} / \text { decade }\right) \\
\end{array}$ & $\begin{array}{c}\text { Intercept } \\
\left({ }^{\circ} \mathrm{C}\right)\end{array}$ & $\begin{array}{c}\text { Total } \\
\text { Change } \\
\left({ }^{\circ} \mathrm{C}\right)\end{array}$ \\
\hline \multirow{4}{*}{ UP-Sm-E } & Fall & 0.05 & 0.06 & 0.05 & 11.0 & 3.2 \\
\hline & Spring & 0.08 & 0.09 & 0.07 & 15.3 & 4.9 \\
\hline & Summer & 0.06 & 0.06 & 0.05 & 25.7 & 3.6 \\
\hline & Winter & 0.03 & 0.03 & 0.02 & 2.5 & 1.6 \\
\hline \multirow{4}{*}{ UP-Md-E } & Fall & 0.06 & 0.07 & 0.05 & 10.9 & 3.6 \\
\hline & Spring & 0.08 & 0.09 & 0.07 & 15.7 & 4.7 \\
\hline & Summer & 0.06 & 0.06 & 0.05 & 25.5 & 3.6 \\
\hline & Winter & 0.03 & 0.03 & 0.03 & 2.2 & 1.7 \\
\hline \multirow{4}{*}{ UP-Lg-E } & Fall & 0.06 & 0.06 & 0.05 & 10.9 & 3.4 \\
\hline & Spring & 0.08 & 0.09 & 0.07 & 15.7 & 4.7 \\
\hline & Summer & 0.06 & 0.06 & 0.05 & 25.6 & 3.6 \\
\hline & Winter & 0.03 & 0.03 & 0.03 & 2.3 & 1.7 \\
\hline \multirow{4}{*}{ UP-Lg-M } & Fall & 0.05 & 0.06 & 0.04 & 11.3 & 3.2 \\
\hline & Spring & 0.08 & 0.09 & 0.07 & 14.8 & 5.0 \\
\hline & Summer & 0.06 & 0.09 & 0.05 & 25.5 & 3.6 \\
\hline & Winter & 0.03 & 0.03 & 0.02 & 2.6 & 1.5 \\
\hline \multirow{4}{*}{ UP-Lg-O } & Fall & 0.05 & 0.06 & 0.05 & 12.6 & 3.2 \\
\hline & Spring & 0.09 & 0.09 & 0.08 & 13.4 & 5.3 \\
\hline & Summer & 0.06 & 0.06 & 0.05 & 25.1 & 3.6 \\
\hline & Winter & 0.02 & 0.03 & 0.02 & 3.1 & 1.3 \\
\hline \multirow{4}{*}{ NLP-Sm-E } & Fall & 0.06 & 0.07 & 0.05 & 13.3 & 3.5 \\
\hline & Spring & 0.08 & 0.08 & 0.07 & 17.5 & 5.0 \\
\hline & Summer & 0.06 & 0.06 & 0.05 & 27.1 & 3.6 \\
\hline & Winter & 0.03 & 0.04 & 0.03 & 4.2 & 2.0 \\
\hline \multirow{4}{*}{ NLP-Lg-O } & Fall & 0.05 & 0.06 & 0.05 & 15.0 & 3.2 \\
\hline & Spring & 0.09 & 0.10 & 0.09 & 15.5 & 5.7 \\
\hline & Summer & 0.06 & 0.06 & 0.05 & 26.9 & 3.5 \\
\hline & Winter & 0.02 & 0.03 & 0.02 & 5.2 & 1.4 \\
\hline \multirow{4}{*}{ SLP-Sm-E } & Fall & 0.06 & 0.07 & 0.06 & 14.7 & 3.8 \\
\hline & Spring & 0.08 & 0.09 & 0.07 & 19.3 & 4.7 \\
\hline & Summer & 0.05 & 0.06 & 0.05 & 28.6 & 3.4 \\
\hline & Winter & 0.03 & 0.03 & 0.02 & 6.7 & 1.7 \\
\hline \multirow{4}{*}{ SLP-Sm-M } & Fall & 0.06 & 0.07 & 0.05 & 14.7 & 3.7 \\
\hline & Spring & 0.08 & 0.08 & 0.07 & 19.3 & 4.7 \\
\hline & Summer & 0.05 & 0.06 & 0.05 & 28.5 & 3.4 \\
\hline & Winter & 0.03 & 0.03 & 0.02 & 6.7 & 1.6 \\
\hline
\end{tabular}




\begin{tabular}{|c|c|c|c|c|c|c|}
\hline Group & Season & $\begin{array}{c}\text { Slope } \\
\left({ }^{\circ} \mathrm{C} / \text { decade }\right)\end{array}$ & $\begin{array}{c}\mathrm{CI} \text { Upper } \\
\left({ }^{\circ} \mathrm{C} / \text { decade }\right)\end{array}$ & $\begin{array}{c}\mathrm{CI}_{\text {Lower }} \\
\left({ }^{\circ} \mathrm{C} / \text { decade }\right)\end{array}$ & $\begin{array}{c}\text { Intercept } \\
\left({ }^{\circ} \mathrm{C}\right)\end{array}$ & $\begin{array}{c}\text { Total } \\
\text { Change } \\
\left({ }^{\circ} \mathrm{C}\right) \\
\end{array}$ \\
\hline \multirow{4}{*}{ SLP-Sm-O } & Fall & 0.06 & 0.07 & 0.05 & 15.5 & 3.6 \\
\hline & Spring & 0.08 & 0.09 & 0.08 & 18.6 & 5.1 \\
\hline & Summer & 0.05 & 0.05 & 0.05 & 28.4 & 3.2 \\
\hline & Winter & 0.03 & 0.03 & 0.02 & 6.9 & 1.6 \\
\hline \multirow{4}{*}{ SLP-Md-E } & Fall & 0.06 & 0.07 & 0.05 & 14.4 & 3.7 \\
\hline & Spring & 0.08 & 0.08 & 0.07 & 19.5 & 4.7 \\
\hline & Summer & 0.06 & 0.06 & 0.05 & 28.7 & 3.4 \\
\hline & Winter & 0.03 & 0.03 & 0.03 & 6.5 & 1.8 \\
\hline \multirow{4}{*}{ SLP-Lg-M } & Fall & 0.06 & 0.07 & 0.05 & 14.5 & 3.5 \\
\hline & Spring & 0.08 & 0.09 & 0.07 & 19.4 & 4.8 \\
\hline & Summer & 0.06 & 0.06 & 0.05 & 28.7 & 3.5 \\
\hline & Winter & 0.03 & 0.03 & 0.03 & 6.5 & 1.8 \\
\hline \multirow{4}{*}{ SLP-Lg-O } & Fall & 0.06 & 0.06 & 0.05 & 16.7 & 3.4 \\
\hline & Spring & 0.09 & 0.10 & 0.08 & 17.5 & 5.5 \\
\hline & Summer & 0.05 & 0.06 & 0.05 & 28.1 & 3.3 \\
\hline & Winter & 0.02 & 0.02 & 0.02 & 7.4 & 1.2 \\
\hline
\end{tabular}

Table 4.7. Summary of mean change in surface water temperature for all modeled lake groups from 2020 to 2099.

\begin{tabular}{lc}
\hline Season & $\begin{array}{r}\text { Mean Change in Surface Water } \\
\text { Temperature }\left({ }^{\circ} \mathrm{C}\right)\end{array}$ \\
\hline Fall & 3.5 \\
Spring & 5.0 \\
Summer & 3.5 \\
Winter & 1.6 \\
All & 3.8 \\
\hline
\end{tabular}

\subsubsection{Cyanobacteria Growing Period}

The change in the number of days the surface water temperature was above minimum and optimal temperatures for cyanobacteria growth were compared for the years 2020 and 2099 for each modeled lake group (Figure 4.6). Climate region had the greatest effect on changes in periods of both minimum and optimum growth temperatures. Periods of growth increased as latitude decreased for minimum growth temperatures and increased as latitude increased for optimum growth temperatures.

The increase in the period when temperatures were above minimum growth conditions was greatest for medium lakes, closely followed by large lakes, and small lakes showed the lowest change (Figure 4.6). The change in period when temperature was above optimum conditions as a function of lake size was not consistent among climates and trophic states. Medium lakes showed the greatest increase, closely followed by large lakes, and small lakes showed the lowest change for eutrophic lakes in the Upper 
Peninsula, while the change in the period decreased with lake size for eutrophic lakes in the southern Lower Peninsula (Figure 4.6). The change in period when temperature was above minimum conditions across lake trophic state was affected by climate region and lake size. Mesotrophic lakes showed the lowest increase, while eutrophic and oligotrophic lakes were higher for large lakes in the Upper Peninsula (Figure 4.6). This result was inversed for small lakes in the southern Lower Peninsula (Figure 4.6). The change in period when temperature was above optimum conditions across lake trophic state was also dependent on climate and lake size. For large lakes in the Upper Peninsula, the increase in the period increases with water clarity, while for small lakes in the southern Lower Peninsula the greatest change was observed for oligotrophic lakes, followed by eutrophic and then mesotrophic lakes (Figure 4.6).

Analyzing trends between lake properties using the data for all modeled lake groups revealed interactive effects on the change in the period when temperature is above minimum and optimal growth temperatures. Using the data for all modeled lake groups, an increasing trend was observed in the days when temperature were above minimum growth temperatures increases as latitude and size decreases (Figure 4.7a,b). An increasing trend was observed in the days when temperatures were above optimum growth temperatures with decreasing latitude and increasing lake size (Figure 4.8a,b). In all cases the minimum and optimum temperature periods increased with increasing water clarity (Figure 4.7c and Figure 4.8c). 

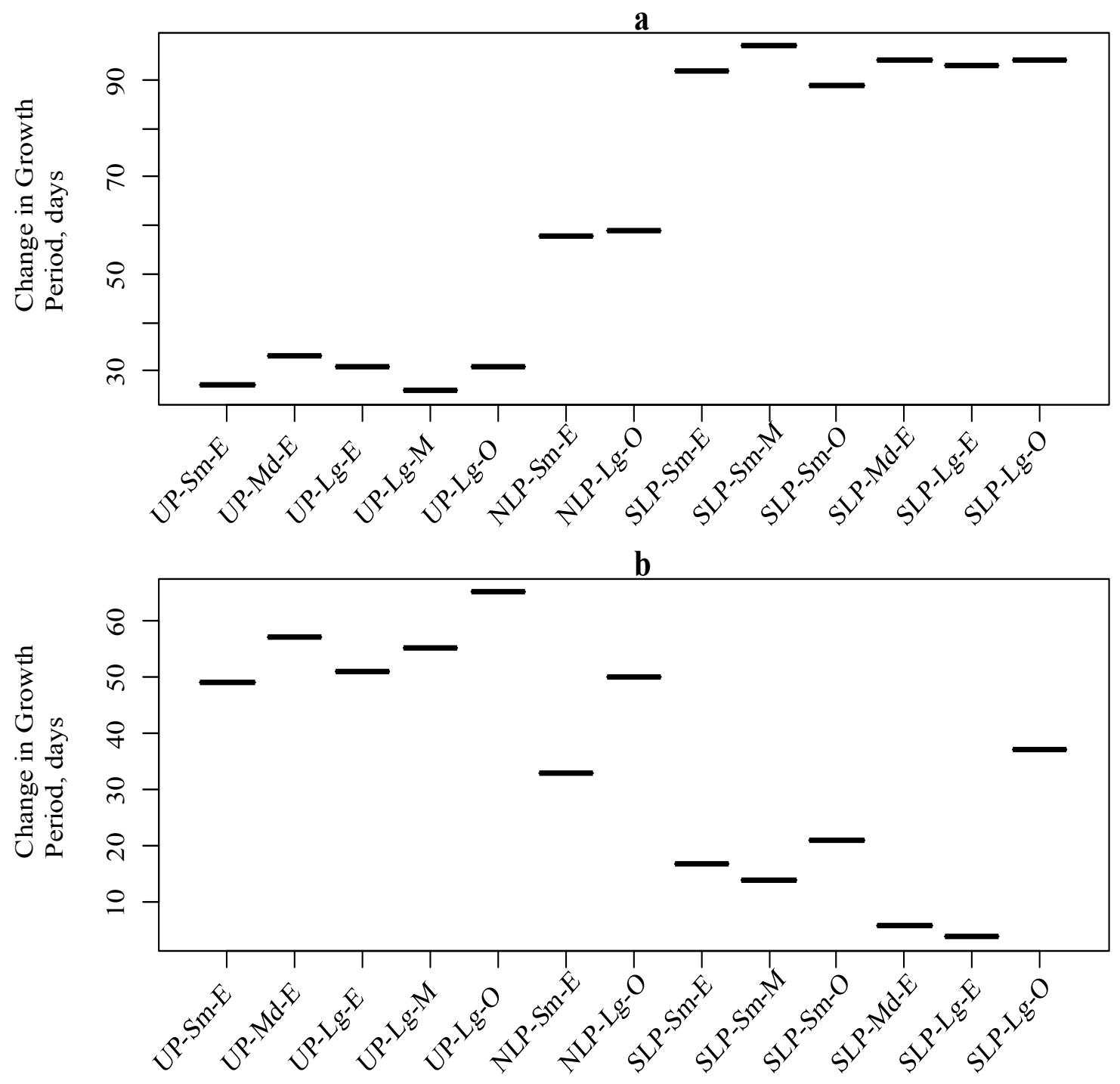

Figure 4.6. Summary of changes in number of days with surface temperature above a) $\mathrm{T}_{\min }\left(15^{\circ} \mathrm{C}\right)$ and $\mathrm{b}$ ) $\mathrm{T}_{\mathrm{opt}}\left(25^{\circ} \mathrm{C}\right)$ from 2020 to 2099 for each modeled lake group. 

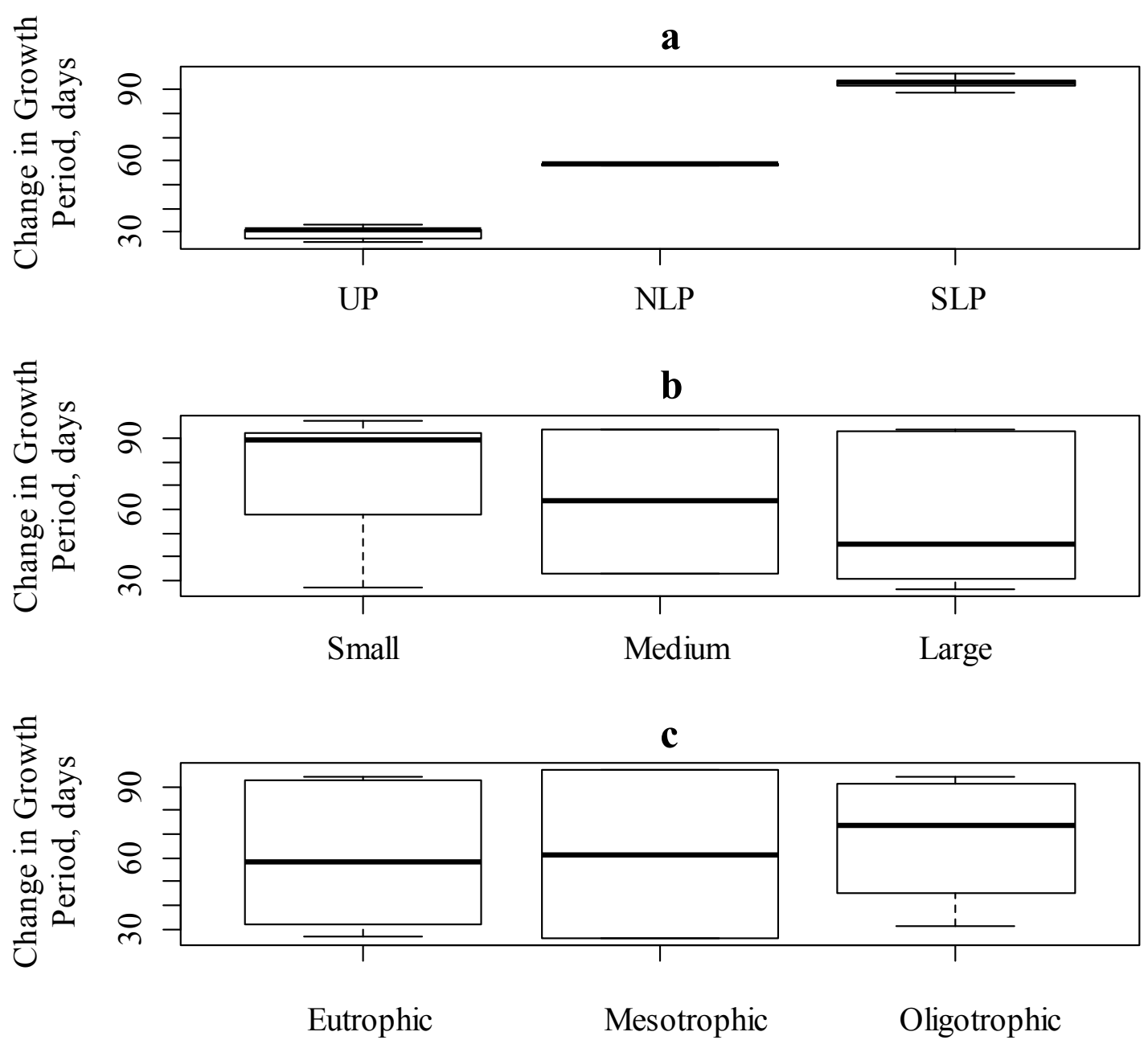

Figure 4.7. Change in the number of days when surface water temperature is above $\mathrm{T}_{\min }\left(15^{\circ} \mathrm{C}\right)$ between 2020 and 2099 as a function of a) climate, b) lake size, and c) trophic state. 

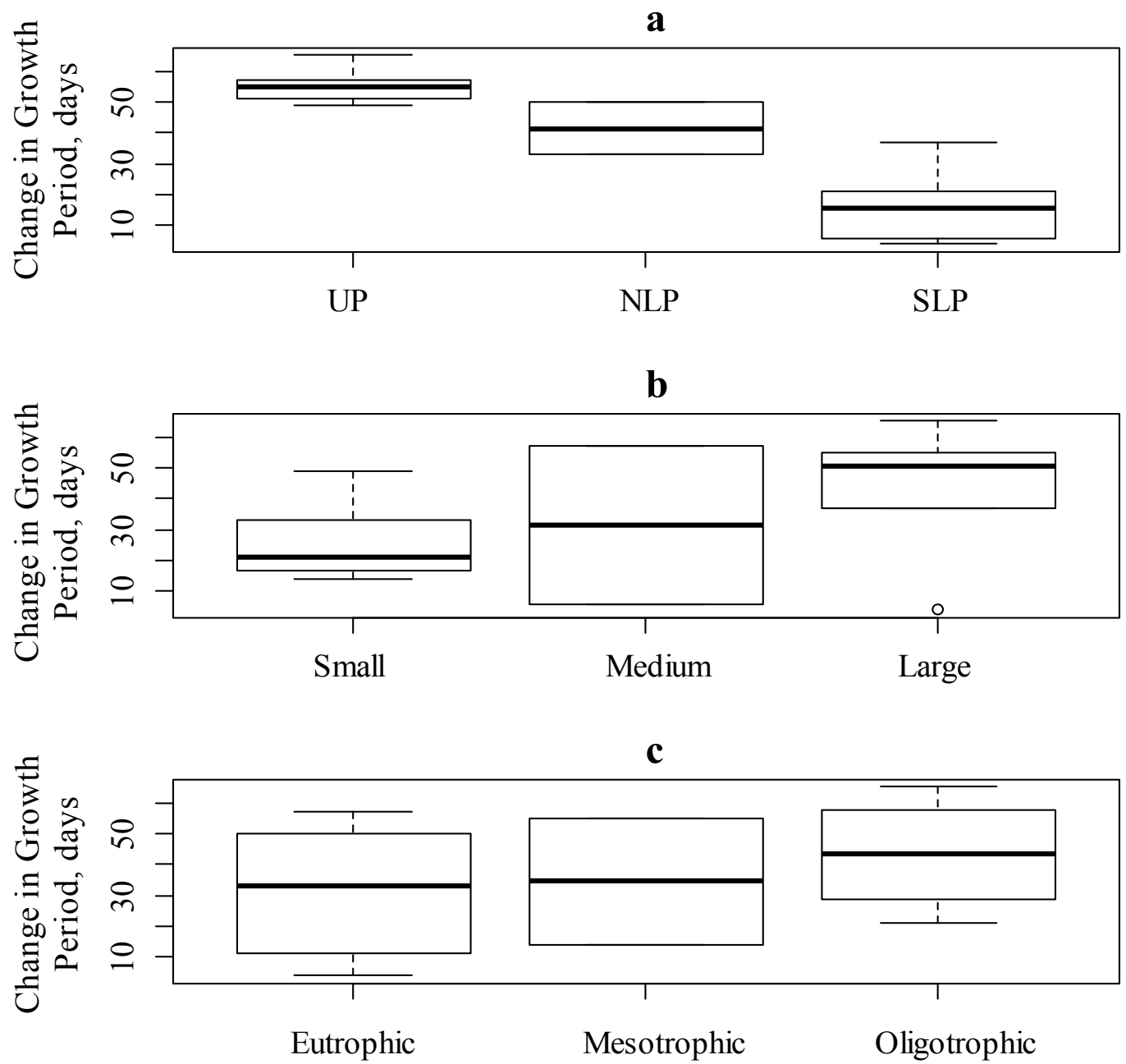

Figure 4.8. Change in the number of days when surface water temperature is above $\mathrm{T}_{\text {opt }}\left(25^{\circ} \mathrm{C}\right)$ between 2020 and 2099 as a function of a) climate, b) lake size, and c) trophic state.

\section{Discussion}

\subsection{Sensitivity Analysis}

The sensitivity analysis aided us in identifying the relative effects of meteorological drivers and water transparency on the model predictions. The model predictions showed the largest response to changes in air humidity, and the response of surface water temperature predictions is much more variable than the response of mean temperature predictions. This result is likely due to the exposure of the surface of the lake to the atmosphere, resulting in a more immediate response to external conditions compared to the rest of the water column. The method used to conduct the sensitivity analysis may have resulted in a misrepresentation of the relative effects of meteorological inputs on lake model predictions. Inputs were varied one at a time, but in the natural world this would not be the case. Most climate parameters do not vary independently and have a 
combined effect on the lake heat budget. Each of the climate input parameters were varied by $\pm 10 \%$ and $\pm 50 \%$, but the amount of natural variability that these changes comprise is different for each climate variable (Table 3.6). The sensitivity analysis showed that the model is most sensitive to air humidity inputs, which would mainly affect latent heat fluxes. Latent heat fluxes do affect surface heat exchange, but are typically relatively small factors in the heat budget in comparison to sensible heat and radiation fluxes. The relative magnitude of the effect may have been skewed because input parameters were not co-varied.

\subsection{Modeled Meteorological Data}

The ability of the dynamically downscaled global climate model used in this study to reproduce observed conditions during the two year validation period was limited. The variability of model error was large for all climate variables and is not constant across seasons for solar radiation and air humidity. The climate model error appears to be relatively constant from year to year in the two years of simulation; however, there were not enough data to make a definitive conclusion.

\subsection{Validation}

The results of the validation of FLake using observed meteorological data showed that the model performed well for predicting surface water temperature. Reasons for the poorer fit for Lake Wingra and Trout Lake using observed climate data inputs may be that these lakes deviate from the model assumptions or other contributing factors were not represented in the model. For example, approximately $75 \%$ of the Lake Wingra watershed is urbanized and receives large amounts of phosphorus through surface runoff (78) and Trout Lake receives significant ground-water exchanges (79).

The lake model was valid for predicting mean water temperatures using observed meteorological data for only 3 out of 10 lakes. Based on this result, we do not recommend using FLake to predict mean water temperatures in absolute terms without lake-specific calibration. While being unable to model mean temperature limits the applicability of the model for determining climate impacts on aquatic organisms, this guidance is in line with the model developers' focus on surface water temperature (33).

The lake model was valid using modeled meteorological data to predict surface water temperature (9 of 10 lakes) but not mean temperature (6 of 10 lakes). These results were similar to the validation results using observed meteorological data, and indicate that modeled meteorological inputs allow FLake to predict surface water temperatures with reasonable accuracy. However, the looser validation criteria for the modeled climate data allowed for increased bias (greater than $1^{\circ} \mathrm{C}$ ) in FLake predictions.

The response of the model predictions to humidity, coupled with the relatively high errors in humidity between the modeled and observed climate data indicate that the bias in the model predictions was mainly caused by inaccurate humidity predictions from the climate model. $\mathrm{A} \pm 10 \%$ change in air humidity altered surface and mean water temperature predictions by $2^{\circ} \mathrm{C}$ (Figure 4.1 and Figure 4.2 ). A $10 \%$ increase in air humidity increased the mean air humidity by $2 \mathrm{mb}$, and a $50 \%$ increase in air humidity increased the mean air humidity by $10 \mathrm{mb}$ (Table 3.5). Climate model humidity predictions exceeded observations by up to $30 \mathrm{mb}$ during the summer months (Figure 4.3) which may have drastically altered the latent heat flux. Although the latent heat flux 
is a relatively small component of surface heat exchange, increased air humidity can favor condensation instead of evaporation, and increase the heat flux into the lake. While air humidity was exaggerated by the inaccurate climate model predictions, it is likely that the bias was also linked to error in other climate model parameters such as air temperature and solar radiation.

\subsection{Trend Analysis}

A strong increasing trend in surface water temperature was observed from 2020 to 2099 for all modeled lake groups. The seasonally decomposed trend in surface water temperature for all modeled groups closely followed trends in air temperature. This is likely because air temperature plays a key role in lake surface heat exchange through sensible and latent heat fluxes. There were no observable differences in the trends in lake surface temperature for different lake sizes or trophic states, but there was an observable difference in the intercept among climate groups. Because there were no statistical differences in the modeled climates used to drive the lake model predictions, the differences in the intercepts of surface temperature trends may have been a function of the latitudes used as model inputs, and the sensitivity of the model to latitude should be tested. Our results agree with findings from studies using both contemporary evidence and lake models $(28,28,35)$. Similar studies found that surface water temperature trends closely followed local air temperatures with no detectable differences in trends across lake morphologies or trophic states $(28,28,35)$. Additionally, maximum surface water temperatures were found to be most affected by air temperature, dew point temperature, and solar radiation (28).

The results of this study were surprising given our knowledge that surface heat exchange is controlled, in part, by lake surface area $(18,19)$ and that water clarity can affect radiation reflection in the lake (21). Similarly, location affects atmospheric conditions and we expected to see differences in climate and surface water temperature trends among the three climate regions. Our main explanation for the lack of differences in surface temperature responses among climates was that there were no differences in air temperature trends among the climate regions. It is unclear if the lack of difference in air temperature trends was real or a product of model error. The Great Lakes act as a buffer for local air temperatures and reduce the regional temperature range $(80,81)$, and so air temperatures may not actually vary much throughout Michigan's Upper and Lower Peninsula. However, the results of the sensitivity analysis showed that the climate model has considerable error, which may have muted the differences in temperature among the climate regions.

\subsection{Ecological Implications}

The results of the slope estimation showed that the greatest predicted increase in surface water temperature occurred in spring, followed by summer and fall which resulted in longer periods of minimum and optimum growth conditions for cyanobacteria. Change in the period when the surface water temperature was predicted above minimum and optimum growing conditions between 2020 and 2099 varied by climate, lake size, and trophic state. Using the data for all modeled lake groups, the number of days when lake temperatures were above minimum growth temperatures increased as latitude and size decreased, and increased with increasing water clarity. Lakes in the southern Lower 
Peninsula are subject to warmer temperatures and increased solar radiation earlier in the year than more northern climate regions, allowing lakes to reach minimum growth temperatures earlier in the spring. Furthermore, small lakes are able to warm more quickly than large lakes. The link between longer periods above minimum growth temperature in oligotrophic lakes was likely due to the higher transmission through and absorption of solar radiation in the clearer waters. Based on these results, it follows that small, oligotrophic lakes in the southern Lower Peninsula will be most at risk for cyanobacteria blooms because of the large number of days above the minimum water temperature.

The change in number of days when temperatures were above optimum growth temperature decreased with decreasing latitude and increased with increasing size and water clarity. The effect of climate was unexpected, as it would seem that the effect of climate on sustained minimum and optimum temperatures would be the same. However, because we are considering the change in the growth period, this result reflects large number of days when surface temperatures are already above optimum growth temperatures in the more southern regions. The increased period for optimal growth temperatures in the colder Upper Peninsula was greater because of the relatively low number of days at the onset of the modeling period in comparison to more southern climate regions. The implication is that lakes in the Upper Peninsula will experience a much greater change in risk of cyanobacteria blooms than present, while the risk will be only slightly elevated in the southern part of the state.

The increasing effect on the change in the period supporting optimum growth conditions with increasing lake size is more straightforward. Large lakes tend to uptake more heat and remain stratified for longer into the summer than small lakes. Although they do not meet minimum growth temperatures as quickly as small lakes, large lakes are able to absorb more heat and release heat a slower rate as summer approaches fall resulting in longer periods of time when temperatures are above optimum growing conditions than small lakes.

Validation using modeled climate data showed that lake model surface temperatures were over-predicted by an average of approximately $4^{\circ} \mathrm{C}$. This likely resulted in an overestimate of the change in the time period for minimum and optimum growth conditions. However, our results were used to indicate relative importance of climate, size, and trophic state, despite modeling errors that limit the use of the absolute periods within minimum and optimal growing temperatures.

\subsection{Limitations and Future Work}

The results of this study are limited by a number of factors that should be considered when interpreting the outcomes. These limitations also present opportunities for future work that will improve and expand our results. First, we must be mindful of our current ability to model lakes and climate. We demonstrated the accuracy of a regionally downscaled global climate model and a lake model, as well as the impact of accuracy of the climate model on the accuracy of the lake model predictions. The effect of the variability and magnitude of climate model error on error in the lake model predictions is apparent from the validation and sensitivity analysis results. As downscaling methods for regional climate models are further developed, these methods can be reapplied to increase

the certainty of the lake model predictions. With improved climate and lake model 
predictions, these results may be strengthened. It may also produce the ability to detect differences between lake types not detected herein and therefore help refine management practices for the future.

The lake model used in this study also has limitations. This study attempted to determine the response of a variety of lake types with a very limited amount of observed data for validation and model inputs. Because of the relatively high error rates during validation, we chose not to use FLake to predict mean water temperatures under future conditions. A study with the primary focus of validating FLake using lakes with a variety of physical and chemical properties would help to better define the limits and applicability of the model in terms of lake characteristics. Future work quantifying the uncertainty from the coupled climate and lake model would be another way to improve our analysis and strengthen the results using methods such as Monte Carlo simulations (82) that capture concurrent variability over time.

FLake is a simplified bulk model that is meant to be used without lake-specific calibration, which limits the user's ability to adjust the model parameters to achieve better results. One option for improving lake model results would be to identify the bounds of the model's applicability for different lake types and alter the sampling scheme to accommodate those results. Another potential avenue for model improvement may be to expand the self-similarity concept applied to the thermocline and hypolimnion to include other possible shapes of the temperature-depth curve. Other options to improve the accuracy of future predictions would be to choose a lake model that better captures lake processes with more complexity, such as one-dimensional finite-difference models $(37,38,39,40)$ or a three-dimensional hydrodynamic model $(83)$.

Using prototype lakes to represent lake groups allowed us to extrapolate our results to a larger number of lakes. This, in turn, would make the results more applicable for management applications as they are not for specific lakes, but categories of lakes with similar characteristics. In contrast, using prototype lakes eliminated our ability to calibrate the model and validate the accuracy of model predictions. Other disadvantages included the bias in the lake size distribution of the MSU dataset that may have resulted in an overestimate of the size of the prototype lake size for small lakes and an underestimate in the size of large lakes in comparison to the actual lake population in Michigan. Additionally, the small lakes in the MSU dataset tend to have steeper basin slopes than large lakes, creating a bias in the morphology of the prototype lakes.

The effects of increasing surface water temperatures have a much larger scope than what was presented here, which focused on effects on algal growth. Increasing surface water temperatures have implications for ice duration, mixing regime, duration of stratification, and food web structure that which can affect the ecology in a lake. The results of this study lay the groundwork for further investigation into effects of climate change on a large number of lake properties, including hypolimnetic temperatures, mixing, ice cover, and lake ecology. Future work on these topics will help us better characterize lakes' physical responses to climate change and subsequent ecological effects. 


\section{Conclusions}

A one-dimensional, bulk lake model was selected and validated to model the impacts of climate change on the surface water temperature of Michigan's inland lakes from 2020 to 2099. Lake model predictions were analyzed for long-term trends, and potential effects on cyanobacteria growth were identified. The lake model FLake accurately reproduced surface water temperatures without calibration; however, it did not pass validation criteria for predicting mean water temperature using either observed or modeled climate data. The comparison of modeled and observed climate data showed that the regionally downscaled global climate model used in this study produced highly variable error. We found that FLake was especially sensitive to solar radiation, air temperature, and air humidity and this highlighted the importance of accurate climate model data for accurate lake model predictions.

Seasonal decomposition and slope estimation showed long-term trends for each of the climate parameters and for lake surface temperature predictions. Positive trends in air temperature and humidity were significant, as was a slightly decreasing trend in cloud cover. Long-term trends in surface water temperature were significant for all groups, and there were no statistical differences in slopes among the modeled lake groups. The intercepts of the trends among climate groups increased as the latitude decreased. Significant differences in long-term trends were identified among seasons, and for all modeled lake groups the long-term trend from 2020 to 2099 was most gradual in winter and steepest in spring.

Analysis of the change in the period of minimum and optimal growth temperatures for cyanobacteria between 2020 and 2099 showed that climate region will play a key role in determining the risk of future cyanobacteria growth. The predicted change in the number of days when surface water temperature was above the minimum growth temperature increased as latitude decreased. Conversely, the predicted change in the number of days when surface water temperature was predicted to be above optimum growth temperatures increased as latitude increased. When considering the effects of lake size and trophic state, the largest increase in the period with surface temperatures above minimum growth temperature was predicted for small, oligotrophic lakes in the southern Lower Peninsula. The largest increase in the period with surface temperatures above optimum growth temperature was predicted for large, oligotrophic lakes in the Upper Peninsula.

Through this study we provided an approach for large scale lake studies, quantitative validation, and trend analysis. This study also supports a more holistic understanding of climate change effects on small lakes and the results can be used to inform the development of plans to prevent or mitigate algal growth in lakes that will be at greater risk in future climates. 


\section{References}

1. P. Murdoch, J. Baron, T. Miller, Potential effects of climate change on surface-water quality in North America. Journal of the American Water Resources Association 36, 347-366 (2000).

2. J. Downing et al., The global abundance and size distribution of lakes, ponds, and impoundments. Limnology and Oceanography 51, 2388-2397 (2006).

3. J. Downing, Emerging global role of small lakes and ponds: little things mean a lot. Limnetica 29 (2010).

4. O. Petchey et al., Environmental warming alters food-web structure and ecosystem function. Nature 402, 69-72 (1999).

5. D. Schindler, S. Bayley, B. Parker, The effects of climatic warming on the properties of boreal lakes and streams at the Experimental Lakes Area, northwestern Ontario. Limnology and Oceanography 41, 1004-1017 (1996).

6. N. Poff, M. Brinson, J. Day, "Aquatic ecosystems and global climate change." Pew Center on Global Climate Change, Arlington, VA 44 (2002).

7. M. Daufresne, K. Lengfellner, U. Sommer, Global warming benefits the small in aquatic ecosystems. Proceedings of the National Academy of Sciences 106, 1278812793 (2009).

8. G. Yvon-Durocher et al., Warming alters the size spectrum and shifts the distribution of biomass in freshwater ecosystems. Global Change Biology 17, 1681-1694 (2011).

9. J. Brett, 10 Environmental Factors and Growth. Fish physiology 8, 599-675 (1979).

10. G. Rhee, I. Gotham, The effect of environmental factors on phytoplankton growth: temperature and the interactions of temperature with nutrient limitation. Limnology and Oceanography 26, 635-648 (1981).

11. P. White et al., The effect of temperature and algal biomass on bacterial production and specific growth rate in freshwater and marine habitats. Microbial Ecology 21, 99118 (1991).

12. B. De Stasio, T. Golemgeski, D. Livingstone, Temperature as a driving factor in aquatic ecosystems: Distributions, stratification patterns, metabolism, and effects of climate changes. Encyclopedia of Inland Waters. (2009), 690-698.

13. S. Kosten et al., Warmer climates boost cyanobacterial dominance in shallow lakes. Global Change Biology 18, 118-126 (2012).

14. R. Robarts, T. Zohary, Temperature effects on photosynthetic capacity, respiration, and growth rates of bloom-forming cyanobacteria. New Zealand Journal of Marine and Freshwater Research 21, 391-399 (1987).

15. A. Konopka, Allan, T. Brock, Effect of temperature on blue-green algae (cyanobacteria) in Lake Mendota. Applied and Environmental Microbiology 36, 572576 (1978).

16. H. Paerl, J. Huisman, Climate change: a catalyst for global expansion of harmful cyanobacterial blooms. Environmental Microbiology Reports 1, 27-37 (2009).

17. W. Carmichael, Health effects of toxin-producing cyanobacteria: The CyanoHABs. Human and ecological risk assessment: An International Journal 7, 1393-1407 (2001). 
18. R. Ragotzkie, Ed., "Lakes" in Heat Budgets of Lakes. (Springer, New York, 1978), pp. 1-19.

19. S. Chapra, Surface water-quality modeling. (Waveland press, Illinois, 2014), pp. 560600 .

20. W. Bailey, T. Oke, W. Rouse, Surface Climates of Canada. (McGill-Queen's PressMQUP, Vol. 4, 1997).

21. K. Menken, P. Brezonik, M. Bauer, Influence of chlorophyll and colored dissolved organic matter (CDOM) on lake reflectance spectra: Implications for measuring lake properties by remote sensing. Lake and Reservoir Management 22, 179-190 (2006).

22. E. Gorham, Morphometric control of annual heat budgets in temperate lakes. University of Minnesota Department of Botany, (1964).

23. D. Stannard et al., Figure 2a: Energy Balance of a water body in "Evapotranspiration from marsh and open-water sites at Upper Klamath Lake, Oregon, 2008-2010”. (US Geological Survey, Report No. 2013-5014, 2013).

24. L. Winslow et al., Small lakes show muted climate change signal in deepwater temperatures. Geophysical Research Letters 42, 355-361 (2015).

25. B. De Stasio, et al., Potential effects of global climate change on small northtemperate lakes: Physics, fish, and plankton. Limnology and Oceanography 41, 11361149 (1996).

26. J. Imberger, J. Patterson, "Dynamic Reservoir Simulation Model- DYRESM: 5." Transport Models for Inland and Coastal Waters, Academic Press New York. 1981. Proceedings of a Symposium on Predictive Ability, Berkeley, California, 310-361, 12 (1980).

27. M. Riley, H. Stefan, Dynamic lake water quality simulation model "MINLAKE", (University of Minnesota Digital Conservancy, 1987).

28. H. Stefan et al., Simulated long-term temperature and dissolved oxygen characteristics of lakes in the north-central United States and associated fish habitat limits. Limnology and Oceanography 41, 1124-1135 (1996).

29. X. Fang, H. Stefan, Simulations of climate effects on water temperature, dissolved oxygen, and ice and snow covers in lakes of the contiguous United States under past and future climate scenarios. Limnology and Oceanography 54, 2359-2370 (2009).

30. M. Hondzo, H. Stefan, Lake water temperature simulation model. Journal of Hydraulic Engineering 119, 1251-1273 (1993).

31. N. Nakicenovic, R. Swart. "Special report on emissions scenarios." Cambridge University Press (2000).

32. D. Mironov, "Parameterization of lakes in numerical weather prediction. Part 1: Description of a lake model." German Weather Service, Offenbach am Main, Germany (2003).

33. D. Mironov, "Parameterization of lakes in numerical weather prediction. Description of a lake model." COSMO Technical Report No. 11, Deutscher Wetterdienst, Offenbach am Main, Germany (2008).

34. D. Mironov et al., Implementation of the lake parameterisation scheme FLake into the numerical weather prediction model COSMO. Boreal Environ. Res 15, 218-230 (2010). 
35. G. Kirillin, Modeling the impact of global warming on water temperature and seasonal mixing regimes in small temperate lakes. Boreal Environ. Res 15, 279-293 (2010).

36. J. Magnuson et al., Potential effects of climate changes on aquatic systems: Laurentian Great Lakes and Precambrian Shield Region. Hydrological processes 11, 825-871 (1997).

37. V. Stepanenko et al., First steps of a lake model intercomparison Project: lakemiP. Boreal Environ. Res 15, 191-202 (2010).

38. V. Stepanenko et al., A one-dimensional model intercomparison study of thermal regime of a shallow, turbid midlatitude lake. Geoscientific Model Development 6, 1337-1352 (2013).

39. F. Peeters et al., Modeling 50 years of historical temperature profiles in a large central European lake. Limnology and Oceanography 47, 186-197 (2002).

40. K. Jöhnk, L. Umlauf, Modelling the metalimnetic oxygen minimum in a medium sized alpine lake. Ecological Modelling 136, 67-80 (2001).

41. S. Goyette, N. McFarlane, G. Flato, Application of the Canadian Regional Climate Model to the Laurentian Great Lakes region: Implementation of a lake model. Atmosphere-Ocean 38, 481-503 (2000).

42. S. Hostetler, G. Bates, F. Giorgi, Interactive coupling of a lake thermal model with a regional climate model. Journal of Geophysical Research: Atmospheres 98, 50455057 (1993).

43. V. Stepanenko, V. Lykosov, Numerical Modeling of the Heat and Moisture Transport in a Lake-Soil System. Russian Meteorology and Hydrology 3, 69 (2005).

44. S. Golosov et al., Climate change impact on thermal and oxygen regime of shallow lakes. Tellus A 64 (2012).

45. A. Martynov, L. Sushama, R. Laprise, Simulation of temperate freezing lakes by onedimensional lake models: performance assessment for interactive coupling with regional climate models. Boreal Environ. Res 15, 143-164 (2010).

46. W. Thiery et al., Understanding the performance of the FLake model over two African Great Lakes. Geoscientific Model Development 7, 317-337 (2014).

47. K. Cheruvelil et al., Multi-scaled drivers of ecosystem state: quantifying the importance of the regional spatial scale. Ecological Applications 23, 1603-1618 (2013).

48. J. Simley, W. Carswell Jr., “The national map — hydrography.” US Geological Survey Fact Sheet 3054.4 (2009).

49. T. Hoar, D. Nychka, "Statistical downscaling of the Community Climate System Model (CCSM) monthly temperature and precipitation projections" IMAGe/NCAR, (2008).

50. NCAR GIS Program, Climate Change Scenarios, version 2.0 (2012). Accessed http://www.gisclimatechange.org. Accessed April 21,2015.

51. NCAR community, (2004). Community Climate System Model, version 3.0., NCAR/UCAR. http://www.cesm.ucar.edu/models/ccsm3.0/

52. R. Carlson, A trophic state index for lakes. Limnology and oceanography 22, 361-369 (1977). 
53. H. Poole, W. Atkins, Photo-electric measurements of submarine illumination throughout the year. Journal of the Marine Biological Association of the United Kingdom (New Series) 16, 297-324 (1929).

54. W. Munk, E. Anderson, Notes on the theory of the thermocline. J. Mar. Res. 3, 276295 (1948).

55. S. Kitaigorodskii, Y. Miropolsky, On the theory of the open ocean active layer. Izv. Akad. Nauk SSSR. Fizika Atmosfery i Okeana 6, 178-188 (1970).

56. Center for Limnology; NTL LTER, North Temperate Lakes LTER: Physical limnology of primary study lakes 1981 - current. Long-term Ecological Research Network (2012).http://dx.doi.org/10.6073/pasta/4531d88a9edbe2f36fd7158f0dd 33e71 Accessed September 4, 2015

57. D. Robertson et al., North Temperate Lakes LTER Morphometry and Hypsometry data for core study lakes." Long-term Ecological Research Network (2014). http://dx.doi.org/10.6073/pasta/1d15f38aaf14110714add6230ef78bd8 Accessed September 4, 2015

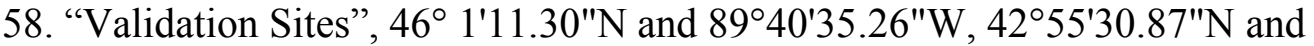
89²6'3.32"W. Google Earth, April 9, 2013. March 1, 2016.

59. Google Permissions. "Using Google Maps, Google Earth and Street View." December 17, 2015. https://www.google.com/permissions/geoguidelines.html. April 24, 2016.

60. Center for Limnology; NTL LTER, North Temperate Lakes LTER meteorological data - Woodruff Airport 1989 - current. Long-term Ecological Research Network (1991). http://dx.doi.org/10.6073/pasta/27ae6de56ea1 1 f0395b1a8fe3895e3c4 Accessed September 4, 2015

61. L. Anderson, D. Robertson, Additional daily meteorological data for Madison Wisconsin (1884-2010). Long-term Ecological Research Network (2013). http://dx.doi.org/10.6073/pasta/d24595d3c620b2da26a5af7052ed8fa5 Accessed September 4, 2015

62. S. Hostetler, J. Alder, A. Allan. "Dynamically downscaled climate simulations over North America: Methods, evaluation, and supporting documentation for users" US Geological Survey (2011).

63. E. Roeckner et al., The atmospheric general circulation model ECHAM5. Part I: model description" Tech. Rep. Max Planck Institute for Meteorology (2003).

64. P. Gleckler, K. Taylor, C. Doutriaux, Performance metrics for climate models. Journal of Geophysical Research: Atmospheres 113 (2008).

65. G. Meehl et al., The WCRP CMIP3 multimodel dataset: A new era in climate change research. Bulletin of the American Meteorological Society 88, 1383-1394 (2007).

66. A. Robinson, R. Duursma, J. Marshall, A regression-based equivalence test for model validation: shifting the burden of proof. Tree physiology 25, 903-913 (2005).

67. R Core Team, R: A language and environment for statistical computing. R Foundation for Statistical Computing, Vienna, Austria (2015).

68. A. Robinson, "equivalence: Provides Tests and Graphics for Assessing Tests of Equivalence." R package version 0.7.1. (2016).

69. E. Gorham, F. Boyce, Influence of lake surface area and depth upon thermal stratification and the depth of the summer thermocline. Journal of Great Lakes Research 15, 233-245 (1989). 
70. R. Cleveland et al., STL: A seasonal-trend decomposition procedure based on loess. Journal of Official Statistics 6, 3-73 (1990).

71. H. Mann, Nonparametric tests against trend. Econometrica: Journal of the Econometric Society (1945), 245-259.

72. M. Kendall, Multivariate analysis. (Griffin, 1975).

73. P. Sen, Estimates of the regression coefficient based on Kendall's tau. Journal of the American Statistical Association 63, 1379-1389 (1968).

74. H. Thiel, "A rank-invariant method of linear and polynomial regression analysis, Part 3." Proceedings of Koninalijke Nederlandse Akademie van Weinenschatpen A., 53 (1950).

75. M. Bayazit, B. Önöz, To prewhiten or not to prewhiten in trend analysis?. Hydrological Sciences Journal 52, 611-624 (2007).

76. S. Yue, et al., The influence of autocorrelation on the ability to detect trend in hydrological series. Hydrological Processes 16, 1807-1829 (2002).

77. D. Bronaugh, A. Werner. "zyp: Zhang+ Yue-Pilon trends package." R package version 09-01 (2013).

78. R. Waschbusch, W. Selbig, R. Bannerman, "Sources of phosphorus in stormwater and street dirt from two urban residential basins in Madison, Wisconsin, 199495." National Conference on Tools for Urban Water Resource Management and Protection proceedings, 2000 DIANE Publishing (1993).

79. USGS, " Trout Lake, Wisconsin: A Water, Energy, and Biogeochemical Budgets Program Site." U.S. Department of the Interior U.S. Geological Survey Fact Sheet, 161-199 (2000).

80. R. Scott, F. Huff, Lake effects on climatic conditions in the Great Lakes Basin. (Illinois State Water Survey, 1997).

81. M. Notaro et al., Influence of the Laurentian Great Lakes on Regional Climate." Journal of Climate 26, 789-804 (2013).

82. D. Landau, K. Binder, "A guide to Monte Carlo simulations in statistical physics." Cambridge university press (2014).

83. B. Hodges et al., Modeling basin-scale internal waves in a stratified lake. Limnology and Oceanography 45, 1603-1620 (2000) 


\section{Appendices}

\section{A. Lakes and Classifications}

Table A.1 reports the lake name, surface area, secchi depth, maximum depth, and mean depth for each of the 517 lakes in the study area (47). The lake data are reported by lake group. There are 27 lake groups based on climate, size, and trophic state. An entry of 'NA' indicates that there was no data available.

Table A.1. Summary of lake property data for the 545 lakes in the study by lake group.

\begin{tabular}{lcccc}
\hline Name & $\begin{array}{c}\text { Surface Area } \\
\left(\mathrm{km}^{2}\right)\end{array}$ & $\begin{array}{c}\text { Secchi Depth } \\
(\mathrm{m})\end{array}$ & $\begin{array}{c}\text { Max } \\
\text { Depth } \\
(\mathrm{m})\end{array}$ & $\begin{array}{c}\text { Mean } \\
\text { Depth } \\
(\mathrm{m})\end{array}$ \\
\hline \multicolumn{4}{c}{ Group1: Upper Peninsula, Small, Eutrophic } \\
\hline Sunken Lake & 0.30 & 1.83 & 6.40 & 3.40 \\
Bass Lake & 0.41 & 0.76 & 6.40 & 2.10 \\
Six mile Lake & 0.40 & 1.68 & 7.01 & 3.00 \\
Pickerel Lake & 0.28 & 1.98 & 18.59 & 5.50 \\
Pole Creek Lake & 0.36 & 0.61 & 3.05 & 1.50 \\
Dana Lake & 0.34 & 1.68 & 7.62 & $\mathrm{NA}$ \\
Ashford Lake & 0.06 & 1.37 & 12.19 & $\mathrm{NA}$ \\
Trout Lake & 0.24 & 0.76 & 2.13 & $\mathrm{NA}$ \\
Little Oxbow Lake & 0.39 & 1.52 & 18.29 & 4.90 \\
Taylor Lake & 0.45 & 1.37 & 12.19 & 5.10 \\
Boot Lake & 0.43 & 1.76 & 9.14 & 3.60 \\
Kaks Lake & 0.24 & 1.52 & 6.71 & 2.50 \\
Culhane Lake & 0.42 & 1.37 & 14.94 & 4.50 \\
Pike Lake & 0.33 & 1.52 & 15.55 & 3.30 \\
\hline Group 2:Upper Peninsula, Small, Mesotrophic & & \\
\hline Crooked Lake & 0.39 & 3.20 & 8.53 & 3.80 \\
Pickerel Lake & 0.38 & 3.66 & 21.95 & 7.80 \\
KP Lake & 0.44 & 3.66 & 7.62 & 3.50 \\
Section One Lake & 0.24 & 2.74 & 8.23 & 2.50 \\
Bass Lake & 0.19 & 2.74 & 6.10 & NA \\
Emerald Lake & 0.25 & 3.35 & 10.67 & 3.00 \\
Gaylanta Lake & 0.45 & 3.05 & 15.24 & 3.50 \\
Dixon Lake & 0.32 & 3.81 & 9.14 & 4.10 \\
Lake Twentyseven & 0.43 & 3.20 & 6.71 & 3.60 \\
Hoffman Lake & 0.48 & 3.96 & 9.14 & 2.60 \\
Tomahawk Lake & 0.17 & 3.02 & 9.75 & NA \\
Shoepac Lake & 0.21 & 2.74 & 28.65 & NA \\
Lost Lake & 0.42 & 3.35 & 5.18 & 1.50 \\
\hline & & & & \\
\hline
\end{tabular}




\begin{tabular}{|c|c|c|c|c|}
\hline Name & $\begin{array}{c}\text { Surface Area } \\
\left(\mathrm{km}^{2}\right)\end{array}$ & $\begin{array}{l}\text { Secchi Depth } \\
\text { (m) }\end{array}$ & $\begin{array}{c}\text { Max } \\
\text { Depth } \\
(\mathrm{m})\end{array}$ & $\begin{array}{c}\text { Mean } \\
\text { Depth } \\
(\mathrm{m})\end{array}$ \\
\hline Lancaster Lake & 0.21 & 3.35 & 17.37 & 8.20 \\
\hline Mary Lake & 0.35 & 3.35 & 25.30 & 6.50 \\
\hline Hamilton Lake & 0.31 & 3.96 & 9.14 & 3.30 \\
\hline Rock Lake & 0.35 & 2.29 & 9.14 & 3.60 \\
\hline Carney Lake & 0.46 & 3.05 & 10.67 & 4.00 \\
\hline Camp Seven Lake & 0.21 & 3.81 & 10.67 & 5.00 \\
\hline Little Smoky Lake & 0.35 & 3.05 & 6.10 & 3.10 \\
\hline Unnamed & 0.35 & 2.44 & 15.24 & 3.90 \\
\hline Allen Lake & 0.32 & 3.05 & 7.62 & 4.50 \\
\hline Gibson Lake & 0.37 & 2.44 & 7.01 & 2.70 \\
\hline Anderson Lake & 0.21 & 3.96 & 9.14 & 2.40 \\
\hline Pike Lake & 0.37 & 3.96 & 9.14 & 3.70 \\
\hline Moraine Lake & 0.37 & 3.96 & 6.10 & 2.10 \\
\hline Eel Lake & 0.21 & 3.66 & 7.62 & 2.70 \\
\hline Island Lake & 0.09 & 2.01 & 12.19 & NA \\
\hline County Line Lake & 0.28 & 2.90 & 13.72 & 5.40 \\
\hline Deer Lake & 0.32 & 3.20 & 13.41 & 4.50 \\
\hline Sporley Lake & 0.31 & 3.35 & 12.80 & 6.40 \\
\hline Bobcat Lake & 0.36 & 2.13 & 5.49 & 2.00 \\
\hline Hannah Webb Lake & 0.26 & 3.81 & 10.67 & 4.00 \\
\hline Snyder Lake & 0.25 & 3.20 & 5.18 & 1.90 \\
\hline McClure Storage Basin & 0.42 & 2.44 & 14.60 & 4.60 \\
\hline Wolf Lake & 0.46 & 2.44 & 3.96 & 1.60 \\
\hline Perch Lake & 0.38 & 2.44 & 15.24 & 5.60 \\
\hline Muskrat Lakes & 0.04 & 2.44 & 7.93 & NA \\
\hline Unnamed & 0.06 & 3.05 & 7.32 & NA \\
\hline \multicolumn{5}{|c|}{ Group 3:Upper Peninsula, Small, Oligotrophic } \\
\hline Cub Lake & 0.23 & 5.18 & 7.01 & 2.90 \\
\hline Shupac Lake & 0.43 & 7.92 & 29.57 & 8.70 \\
\hline Heart Lake & 0.27 & 4.72 & 35.66 & 9.80 \\
\hline Big Bass Lake & 0.26 & 5.79 & 10.06 & 3.50 \\
\hline Lake Fifteen & 0.37 & 4.27 & 16.76 & 9.40 \\
\hline Ess Lake & 0.48 & 5.18 & 15.55 & 5.10 \\
\hline Stager Lake & 0.44 & 5.18 & 16.76 & 5.80 \\
\hline Camp Lake & 0.40 & 4.27 & 17.07 & 5.50 \\
\hline Unnamed & 0.22 & 4.88 & 7.62 & 4.10 \\
\hline Long Lake & 0.24 & 6.10 & 32.00 & 9.60 \\
\hline Dinner Lake & 0.44 & 4.02 & 12.19 & 3.80 \\
\hline Imp Lake & 0.37 & 5.94 & 26.21 & 9.60 \\
\hline
\end{tabular}




\begin{tabular}{|c|c|c|c|c|}
\hline Name & $\begin{array}{c}\text { Surface Area } \\
\left(\mathrm{km}^{2}\right)\end{array}$ & $\begin{array}{l}\text { Secchi Depth } \\
\text { (m) }\end{array}$ & $\begin{array}{c}\text { Max } \\
\text { Depth } \\
\text { (m) }\end{array}$ & $\begin{array}{c}\text { Mean } \\
\text { Depth } \\
(\mathrm{m})\end{array}$ \\
\hline Edey Lake & 0.33 & 4.88 & 9.14 & 2.90 \\
\hline Silver Lake & 0.44 & 4.27 & 7.01 & 2.80 \\
\hline Fish Lake & 0.49 & 4.27 & 12.19 & 5.00 \\
\hline Unnamed & 0.21 & 4.27 & 19.81 & 4.60 \\
\hline Bass Lake & 0.31 & 7.01 & 23.77 & 9.90 \\
\hline Little Shag Lake & 0.43 & 4.88 & 10.67 & 5.50 \\
\hline Johnson Lake & 0.32 & 4.27 & 13.72 & 5.90 \\
\hline Unnamed & 0.50 & 4.27 & 10.67 & 2.50 \\
\hline Norway Lake & 0.21 & 5.99 & 6.10 & 2.60 \\
\hline Big Lake & 0.48 & 4.72 & 10.36 & 1.30 \\
\hline Lake Arfelin & 0.23 & 4.88 & 10.67 & 5.10 \\
\hline Emily Lake & 0.24 & 4.27 & 27.43 & 7.40 \\
\hline \multicolumn{5}{|c|}{ Group 4:Upper Peninsula, Medium, Eutrophic } \\
\hline Lake May & 0.77 & 1.83 & 6.10 & 2.30 \\
\hline Brule Lake & 0.98 & 0.91 & 6.10 & 3.30 \\
\hline Paint Lake & 0.96 & 1.68 & 4.57 & NA \\
\hline Winslow Lake & 1.05 & 1.98 & 6.10 & 2.80 \\
\hline Ruth Lake & 0.81 & 1.83 & 10.97 & 3.40 \\
\hline Bob Lake & 0.53 & 1.26 & 4.57 & 2.30 \\
\hline Lake Roland & 1.05 & 1.83 & 12.19 & 4.10 \\
\hline Thayer Lake & 0.52 & 1.52 & 3.05 & 1.00 \\
\hline \multicolumn{5}{|c|}{ Group 5:Upper Peninsula, Medium, Mesotrophic } \\
\hline Lake Manuka & 0.64 & 2.74 & 8.23 & 1.60 \\
\hline Big Lake & 0.50 & 3.78 & 24.69 & 7.30 \\
\hline Unnamed & 1.13 & 3.96 & 24.38 & 6.80 \\
\hline Unnamed & 0.92 & 2.13 & 4.57 & NA \\
\hline Lake Emma & 0.80 & 3.05 & 3.05 & 1.00 \\
\hline Buck Lake & 0.61 & 2.74 & 9.14 & 3.40 \\
\hline Lake Mary & 1.06 & 3.91 & 14.63 & 6.30 \\
\hline Swan Lake & 0.65 & 2.44 & 6.10 & 4.40 \\
\hline Frenchman Lake & 0.75 & 2.13 & 6.10 & 2.10 \\
\hline James Lake & 0.83 & 2.74 & 3.05 & 1.60 \\
\hline Fire Lake & 0.51 & 2.74 & 12.19 & 3.30 \\
\hline Petes Lake & 0.78 & 3.81 & 11.28 & 4.10 \\
\hline Moosehead Lake & 0.58 & 2.74 & 11.89 & 4.60 \\
\hline Clearwater Lake & 0.72 & 2.44 & 3.05 & 2.10 \\
\hline Marion Lake & 1.20 & 3.35 & 12.19 & 3.70 \\
\hline Shag Lake & 0.79 & 3.96 & 9.10 & 4.60 \\
\hline Bass Lake & 0.80 & 2.59 & 5.49 & 2.60 \\
\hline
\end{tabular}




\begin{tabular}{lcccc}
\hline Name & $\begin{array}{c}\text { Surface Area } \\
\left(\mathrm{km}^{2}\right)\end{array}$ & $\begin{array}{c}\text { Secchi Depth } \\
(\mathrm{m})\end{array}$ & $\begin{array}{c}\text { Max } \\
\text { Depth } \\
(\mathrm{m})\end{array}$ & $\begin{array}{c}\text { Mean } \\
\text { Depth } \\
(\mathrm{m})\end{array}$ \\
\hline Horseshoe Lake & 0.53 & 2.74 & 7.32 & 2.60 \\
Unnamed & 0.83 & 3.96 & 28.96 & 7.30 \\
Lake Sainte Kathryn & 0.67 & 2.29 & 7.62 & 3.10 \\
Deer Lake & 1.07 & 2.92 & 21.95 & NA \\
Monocle Lake & 0.69 & 2.74 & 16.76 & 6.50 \\
Gemini Lakes & 0.51 & 2.59 & 6.10 & 2.70 \\
Ross Lake & 0.79 & 2.77 & 6.10 & 3.00 \\
Lake Keewaydin & 0.53 & 2.29 & 7.60 & 2.90 \\
Kingston Lake & 0.51 & 2.90 & 5.50 & $\mathrm{NA}$ \\
Pike Lake & 1.17 & 2.13 & 13.11 & 4.70 \\
Bodi Lake & 1.19 & 2.13 & 14.63 & 3.50 \\
Lake Fanny Hooe & 0.93 & 3.96 & 12.19 & 6.40 \\
\hline
\end{tabular}

Group 6:Upper Peninsula, Medium, Oligotrophic

Name Surface Area Secchi Depth

\begin{tabular}{lcccc} 
& $(\mathrm{sq} . \mathrm{km})$ & $(\mathrm{m})$ & $\begin{array}{c}\text { (m) } \\
(\mathrm{m})\end{array}$ \\
\hline Opal Lake & 0.51 & 5.18 & 12.19 & 4.60 \\
Avery Lake & 1.18 & 7.01 & 27.43 & 8.90 \\
Lake Nettie & 1.20 & 4.53 & 14.02 & 3.70 \\
Indian Lake & 0.80 & 5.03 & 10.97 & 4.60 \\
Island Lake & 0.76 & 5.50 & 17.53 & 5.90 \\
Golden Lake & 1.10 & 8.65 & 30.48 & 8.00 \\
Lake Ellen & 0.57 & 4.57 & 18.29 & 6.90 \\
Colwell Lake & 0.52 & 4.72 & 7.62 & 4.60 \\
Unnamed & 1.16 & 5.49 & 24.38 & 8.20 \\
Bass Lake & 0.60 & 4.11 & 22.56 & 8.30 \\
\hline Group 7:Upper Peninsula, Large, Eutrophic & & \\
\hline Grand Lake & 23.57 & 1.81 & 7.62 & 2.70 \\
Alke Paradise & 7.76 & 1.51 & 5.18 & $\mathrm{NA}$ \\
Unnamed & 2.81 & 0.91 & 9.40 & 3.00 \\
Tamarack Lake & 1.34 & 1.22 & 4.57 & 3.48 \\
Langford Lake & 1.95 & 1.51 & 3.05 & 2.10 \\
Chaney Lake & 2.01 & 1.83 & 6.10 & 2.20 \\
McDonald Lake & 1.87 & 1.22 & 3.05 & 1.00 \\
Nawakwa Lake & 1.79 & 1.37 & 10.67 & 3.00 \\
Prickett Lake & 3.11 & 1.22 & 17.07 & 5.67 \\
Otter Lake & 3.64 & 1.37 & 8.84 & 4.80 \\
\hline Growp 8:Uppr Penis & Large, & &
\end{tabular}

Group 8:Upper Peninsula, Large, Mesotrophic

Lake Margrethe

7.79

3.51

19.81

4.70 


\begin{tabular}{|c|c|c|c|c|}
\hline Name & $\begin{array}{c}\text { Surface Area } \\
\left(\mathrm{km}^{2}\right)\end{array}$ & $\begin{array}{l}\text { Secchi Depth } \\
\text { (m) }\end{array}$ & $\begin{array}{c}\text { Max } \\
\text { Depth } \\
\text { (m) }\end{array}$ & $\begin{array}{c}\text { Mean } \\
\text { Depth } \\
(\mathrm{m})\end{array}$ \\
\hline Manistee Lake & 3.54 & 2.77 & 5.49 & 2.20 \\
\hline East Twin Lake & 3.32 & 2.13 & 7.62 & 2.00 \\
\hline Otsego Lake & 8.15 & 3.20 & 7.01 & 3.00 \\
\hline Beaver Lake & 2.74 & 3.51 & 23.47 & 8.50 \\
\hline Rush Lake & 1.72 & 3.05 & 10.10 & 2.20 \\
\hline Long Lake & 21.64 & 2.51 & 7.62 & 3.20 \\
\hline Gulliver Lake & 3.56 & 2.26 & 8.53 & 3.50 \\
\hline Stanley Lake & 1.29 & 3.05 & 11.89 & 3.30 \\
\hline Iron Lake & 1.58 & 2.13 & 13.72 & 3.00 \\
\hline Sunset Lake & 2.15 & 3.66 & 16.46 & 5.00 \\
\hline Lake Emily & 1.32 & 2.44 & 9.75 & 3.40 \\
\hline Round Lake & 1.96 & 3.96 & 17.07 & 5.80 \\
\hline Duck Lake & 2.49 & 2.90 & 7.60 & 4.10 \\
\hline Little African Lake & 6.81 & 2.51 & 9.14 & 2.95 \\
\hline Little Lake & 1.86 & 3.96 & 15.24 & 4.20 \\
\hline Cable Lake & 1.34 & 2.77 & 9.14 & 3.20 \\
\hline Bond Falls Flowage & 8.65 & 3.05 & 8.50 & NA \\
\hline Au Train Lake & 3.42 & 2.29 & 9.14 & 3.62 \\
\hline Greenwood Reservoir & 3.90 & 2.44 & 9.14 & 3.70 \\
\hline Unnamed & 17.30 & 3.35 & 21.95 & NA \\
\hline $\begin{array}{l}\text { Dead River Storage } \\
\text { Basin }\end{array}$ & 11.08 & 3.66 & 18.00 & 9.50 \\
\hline Muskallonge Lake & 3.19 & 2.51 & 6.10 & 2.90 \\
\hline Rice Lake & 2.65 & 2.59 & 2.74 & 1.10 \\
\hline Lac La Belle & 4.88 & 2.74 & 11.58 & 6.50 \\
\hline \multicolumn{5}{|c|}{ Group 9:Upper Peninsula, Large, Oligotrophic } \\
\hline Bear Lake & 1.27 & 5.53 & 18.29 & 8.50 \\
\hline Big Bear Lake & 1.39 & 4.27 & 10.97 & 4.70 \\
\hline Thumb Lake & 2.06 & 7.77 & 46.33 & 9.50 \\
\hline Lake Esau & 1.29 & 5.03 & 8.84 & 4.10 \\
\hline Long Lake & 1.54 & 7.24 & 18.59 & 7.10 \\
\hline Lake Antoine & 3.00 & 4.57 & 7.62 & 3.60 \\
\hline Unnamed & 1.71 & 4.88 & 21.34 & 6.20 \\
\hline Skeels Lake & 1.92 & 4.57 & 15.20 & 4.50 \\
\hline Glimmerglass Lake & 3.48 & 7.01 & 18.29 & 7.20 \\
\hline Lake Gratiot & 5.89 & 4.72 & 21.34 & 8.10 \\
\hline Lake Medora & 2.79 & 4.27 & 9.14 & 4.40 \\
\hline
\end{tabular}

Group 10:Northern Lower Peninsula, Small, Eutrophic

Brownlee Lake

0.37
1.98

36.44

7.62 


\begin{tabular}{|c|c|c|c|c|}
\hline Name & $\begin{array}{l}\text { Surface Area } \\
\qquad\left(\mathrm{km}^{2}\right)\end{array}$ & $\begin{array}{l}\text { Secchi Depth } \\
\text { (m) }\end{array}$ & $\begin{array}{c}\text { Max } \\
\text { Depth } \\
\text { (m) }\end{array}$ & $\begin{array}{c}\text { Mean } \\
\text { Depth } \\
(\mathrm{m})\end{array}$ \\
\hline \multicolumn{5}{|c|}{ Group 11:Northern Lower Peninsula, Small, Mesotrophic } \\
\hline Half Moon Lake & 0.26 & 2.82 & 21.34 & 6.90 \\
\hline Sand Lake & 0.24 & 2.01 & 4.57 & 1.80 \\
\hline Twin Lakes & 0.46 & 2.44 & 5.79 & 2.70 \\
\hline Winfield Lake & 0.48 & 2.29 & 17.37 & 5.20 \\
\hline Lake Montcalm & 0.34 & 3.52 & 20.40 & 9.10 \\
\hline Horseshoe Lake & 0.39 & 2.44 & 13.41 & 7.40 \\
\hline Brockway Lake & 0.07 & 2.51 & 7.93 & NA \\
\hline School Section Lake & 0.49 & 2.90 & 10.06 & 3.10 \\
\hline Crystal Lake & 0.29 & 2.13 & 10.36 & 4.10 \\
\hline Townline Lake & 0.31 & 3.66 & 15.85 & 5.40 \\
\hline Hillsview Lake & 0.40 & 2.29 & 12.19 & 3.50 \\
\hline Unnamed & 0.47 & 3.35 & 6.71 & 3.40 \\
\hline Bergess Lake & 0.24 & 3.20 & 14.63 & 4.60 \\
\hline Merrill Lake & 0.34 & 3.35 & 8.23 & 2.60 \\
\hline Pleiness Lake & 0.40 & 3.20 & 11.60 & NA \\
\hline Idlewild Lake & 0.42 & 2.90 & 6.71 & 2.70 \\
\hline Tiff Lake & 0.30 & 2.51 & 12.19 & NA \\
\hline Five Lake & 0.48 & 2.01 & 20.42 & 3.20 \\
\hline Unnamed & 0.21 & 3.66 & 15.85 & NA \\
\hline Todd Lake & 0.33 & 2.44 & 15.24 & 6.50 \\
\hline Windover Lake & 0.28 & 3.66 & 20.73 & 4.50 \\
\hline Hackert Lake & 0.49 & 3.51 & 4.88 & 2.00 \\
\hline Sunrise Lake & 0.31 & 3.51 & 20.12 & 7.50 \\
\hline Unnamed & 0.27 & 3.05 & 18.29 & NA \\
\hline Harper Lake & 0.34 & 3.96 & 18.29 & 5.50 \\
\hline Lake Four & 0.24 & 2.44 & 12.19 & NA \\
\hline Canfield Lake & 0.14 & 3.02 & 8.84 & NA \\
\hline Berry Lake & 0.28 & 3.35 & 8.53 & 3.10 \\
\hline Goose Lake & 0.40 & 2.74 & 4.27 & 1.20 \\
\hline Round Lake & 0.36 & 2.44 & 4.57 & 1.50 \\
\hline Long Lake & 0.27 & 2.74 & 4.57 & 1.90 \\
\hline Grousehaven Lake & 0.35 & 2.74 & 16.46 & 6.70 \\
\hline Devoe Lake & 0.48 & 2.13 & 16.15 & 6.20 \\
\hline Vaughn Lake & 0.46 & 3.05 & 19.81 & 6.50 \\
\hline Bass Lake & 0.38 & 2.59 & 5.79 & 1.90 \\
\hline East Lake & 0.38 & 2.26 & 6.10 & 2.00 \\
\hline Herendeene Lake & 0.16 & 3.02 & 11.28 & NA \\
\hline Cedar Lake & 0.21 & 3.35 & 18.59 & 7.50 \\
\hline
\end{tabular}




\begin{tabular}{|c|c|c|c|c|}
\hline Name & $\begin{array}{c}\text { Surface Area } \\
\left(\mathrm{km}^{2}\right)\end{array}$ & $\begin{array}{l}\text { Secchi Depth } \\
\text { (m) }\end{array}$ & $\begin{array}{c}\text { Max } \\
\text { Depth } \\
\text { (m) }\end{array}$ & $\begin{array}{c}\text { Mean } \\
\text { Depth } \\
(\mathrm{m})\end{array}$ \\
\hline Wilson Lake & 0.36 & 2.74 & 14.33 & 3.50 \\
\hline Ellsworth Lake & 0.43 & 3.05 & 12.80 & 5.20 \\
\hline Saint Clair Lake & 0.24 & 3.05 & 9.75 & 3.10 \\
\hline \multicolumn{5}{|c|}{ Group 12:Northern Lower Peninsula, Small, Oligotrophic } \\
\hline Englewright Lake & 0.22 & 5.03 & 20.12 & 5.70 \\
\hline Baptist Lake & 0.33 & 4.57 & 19.81 & 6.80 \\
\hline Cowden Lake & 0.45 & 4.27 & 15.24 & 5.10 \\
\hline Brush Lake & 0.08 & 4.88 & 8.23 & NA \\
\hline Diamond Lake & 0.24 & 4.27 & 18.29 & 5.10 \\
\hline Arnold Lake & 0.49 & 6.10 & 25.91 & NA \\
\hline Lake George & 0.37 & 4.11 & 14.63 & 8.30 \\
\hline North Lake & 0.35 & 4.27 & 28.04 & 7.30 \\
\hline \multicolumn{5}{|c|}{ Group 13:Northern Lower Peninsula, Medium, Eutrophic } \\
\hline Rainbow Lake & 0.68 & 1.98 & 6.71 & 1.50 \\
\hline Stony Lake & 1.12 & 1.83 & 13.11 & 6.60 \\
\hline Robinson Lake & 0.54 & 1.26 & 9.14 & 5.50 \\
\hline Diamond Lake & 0.76 & 1.65 & 7.62 & 2.70 \\
\hline Boyles Creek & 1.16 & 1.83 & 22.30 & 4.90 \\
\hline Ross Lake & 1.02 & 1.83 & 5.79 & NA \\
\hline Lincoln Lake & 0.70 & 1.22 & 4.00 & NA \\
\hline Lincoln Lake & 0.70 & 1.22 & 4.00 & NA \\
\hline Hicks Lake & 0.65 & 1.07 & 10.06 & 3.10 \\
\hline Cranberry Lake & 0.66 & 1.37 & 6.10 & 2.40 \\
\hline Hardwood Lake & 0.73 & 1.22 & 10.67 & 3.40 \\
\hline Indian Lake & 0.87 & 1.98 & 4.57 & NA \\
\hline George Lake & 0.76 & 1.68 & 27.43 & 6.20 \\
\hline \multicolumn{5}{|c|}{ Group 14:Northern Lower Peninsula, Medium, Mesotrophic } \\
\hline Duck Lake & 0.87 & 3.96 & 19.80 & NA \\
\hline Muskellunge Lake & 0.55 & 2.44 & 11.28 & 5.60 \\
\hline Bills Lake & 0.80 & 3.81 & 27.43 & 5.70 \\
\hline Little Whitefish Lake & 0.73 & 3.35 & 13.11 & 5.50 \\
\hline Kimball Lake & 0.59 & 2.13 & 16.15 & NA \\
\hline Pickerel Lake & 1.24 & 2.44 & 22.25 & 7.80 \\
\hline McLaren Lake & 1.05 & 3.35 & 21.34 & 6.90 \\
\hline Blue Lake & 0.90 & 2.74 & 15.24 & NA \\
\hline Coldwater Lake & 1.16 & 2.44 & 19.81 & 9.90 \\
\hline East Lake & 0.83 & 2.44 & 15.55 & NA \\
\hline Stevenson Lake & 0.55 & 2.13 & 14.33 & 4.10 \\
\hline School Section Lake & 0.76 & 3.05 & 7.93 & 3.40 \\
\hline
\end{tabular}




\begin{tabular}{lcccc}
\hline Name & $\begin{array}{c}\text { Surface Area } \\
\left(\mathrm{km}^{2}\right)\end{array}$ & $\begin{array}{c}\text { Secchi Depth } \\
(\mathrm{m})\end{array}$ & $\begin{array}{c}\text { Max } \\
\text { Depth } \\
(\mathrm{m})\end{array}$ & $\begin{array}{c}\text { Mean } \\
\text { Depth } \\
(\mathrm{m})\end{array}$ \\
\hline Pratt Lake & 0.76 & 3.05 & 8.53 & 3.00 \\
Bass Lake & 1.19 & 3.96 & 13.72 & 3.10 \\
Long Lake & 0.84 & 3.20 & 23.17 & 4.40 \\
Londo Lake & 0.73 & 2.44 & 4.27 & 1.80 \\
Sand Lake & 0.99 & 2.44 & 7.62 & 2.30 \\
West Londo Lake & 0.80 & 2.90 & 4.88 & 2.10 \\
Clear Lake & 0.83 & 3.56 & 15.24 & 3.50 \\
Unnamed & 0.74 & 2.29 & 9.40 & 2.00 \\
Cedar Lake & 0.58 & 2.44 & 2.44 & 1.00 \\
Cedar Hedge Lake & 0.78 & 3.20 & 20.12 & 5.80 \\
Brown Bridge Pond & 0.69 & 2.59 & 8.84 & 3.40 \\
Jewell Lake & 0.75 & 2.59 & 10.36 & 1.80 \\
Cedar Lake & 1.00 & 3.05 & 14.02 & 8.00 \\
Lake of the Woods & 0.70 & 2.44 & 4.27 & 1.50 \\
Susan Lake & 0.51 & 2.69 & 4.57 & 1.80 \\
\hline Group 15:Northern Lower Peninsula, Medium, Oligotrophic & \\
\hline Clear Lake & 0.50 & 5.18 & 9.14 & 3.10 \\
Nichols Lake & 0.62 & 4.57 & 15.24 & 4.90 \\
Unnamed & 0.65 & 5.18 & 20.73 & 9.00 \\
Lake George & 0.52 & 4.11 & 7.62 & 2.80 \\
Pine Lake & 0.67 & 5.33 & 15.24 & 6.20 \\
\hline Group 16:Northern Lower & & &
\end{tabular}

\begin{tabular}{lcccc}
\hline Group 16:Northern Lower Peninsula, Large, Eutrophic \\
\hline White Lake & 10.43 & 1.98 & 21.30 & 6.90 \\
White Lake & 10.43 & 1.98 & 21.30 & 6.90 \\
Fremont Lake & 3.34 & 1.68 & 26.82 & 9.90 \\
Tamarack Lake & 1.28 & 0.76 & 5.18 & 1.50 \\
Pentwater Lake & 1.98 & 1.98 & 12.30 & NA \\
Pentwater Lake & 1.98 & 1.98 & 12.30 & NA \\
Round Lake & 2.19 & 1.52 & 3.05 & 1.40 \\
Hamlin Lake & 19.00 & 1.98 & 23.99 & 4.50 \\
Sixmile Lake & 1.50 & 1.83 & 9.40 & 4.00 \\
\hline Group 17:Northern Lower Peninsula, Large, Mesotrophic & \\
\hline Big Blue Lake & 1.36 & 3.35 & 15.24 & 3.80 \\
Croton Dam Pond & 5.02 & 2.77 & 12.19 & 2.70 \\
Hardy Dam Pond & 12.75 & 3.05 & 33.50 & 9.40 \\
Rogers Dam Pond & 1.36 & 2.13 & 9.14 & NA \\
Unnamed & 1.91 & 2.76 & 12.80 & 4.00 \\
Unnamed & 6.89 & 2.59 & 14.30 & 2.10 \\
Wixom Lake & 4.22 & 3.05 & 12.19 & NA \\
\hline
\end{tabular}




\begin{tabular}{lcccc}
\hline Name & $\begin{array}{c}\text { Surface Area } \\
\left(\mathrm{km}^{2}\right)\end{array}$ & $\begin{array}{c}\text { Secchi Depth } \\
(\mathrm{m})\end{array}$ & $\begin{array}{c}\text { Max } \\
\text { Depth } \\
(\mathrm{m})\end{array}$ & $\begin{array}{c}\text { Mean } \\
\text { Depth } \\
(\mathrm{m})\end{array}$ \\
\hline Pere Marquette Lake & 2.47 & 2.29 & 11.60 & NA \\
Wolf Lake & 1.65 & 3.66 & 3.96 & 1.80 \\
Rose Lake & 1.51 & 2.38 & 9.14 & 4.70 \\
Manistee Lake & 4.23 & 2.13 & 14.90 & 7.50 \\
Lake Missaukee & 8.26 & 2.26 & 8.23 & 3.20 \\
Sage Lake & 3.15 & 2.74 & 24.38 & 5.80 \\
Hodenpyl Dam Pond & 7.52 & 3.05 & 21.30 & 7.00 \\
Little Au Sable Lake & 1.29 & 3.51 & 13.72 & 4.00 \\
Long Lake & 1.96 & 3.96 & 18.90 & 5.00 \\
Loud Dam Pond & 2.41 & 3.05 & 9.14 & 4.30 \\
Foote Dam Pond & 6.87 & 3.81 & 12.19 & 5.80 \\
Upper Herring Lake & 2.32 & 2.51 & 7.93 & 4.60 \\
Lower Herring Lake & 1.81 & 2.77 & 18.29 & 8.90 \\
Lower Herring Lake & 1.81 & 2.77 & 18.29 & 8.90 \\
Spider Lake & 1.80 & 3.96 & 10.97 & 2.80 \\
Platte Lake & 10.25 & 2.44 & 27.43 & 8.23 \\
Lake Ann & 2.03 & 3.27 & 22.86 & 9.70 \\
Bass Lake & 1.39 & 3.66 & 8.80 & 2.70 \\
Lake Skegemog & 11.20 & 2.74 & 8.84 & 3.40 \\
Lime Lake & 2.68 & 3.05 & 20.42 & 5.00 \\
Little Traverse Lake & 2.61 & 3.35 & 16.46 & 5.30 \\
Clam Lake & 1.77 & 3.05 & 8.84 & 4.00 \\
Intermediate Lake & 6.36 & 2.44 & 6.10 & 2.60 \\
Unnamed & 1.40 & 3.35 & 12.50 & 3.00 \\
Round Lake & 1.43 & 2.13 & 4.88 & 1.70 \\
Unnamed & 13.92 & 2.83 & 18.29 & 3.05 \\
\hline
\end{tabular}

\begin{tabular}{lcccc}
\hline Group 18:Northern Lower Peninsula, Large, Oligotrophic \\
\hline Horsehead Lake & 1.79 & 4.57 & 16.46 & NA \\
Fife Lake & 2.42 & 4.72 & 16.76 & 4.50 \\
Alcona Dam Pond & 3.92 & 4.42 & 12.19 & 5.00 \\
Duck Lake & 7.87 & 4.11 & 29.87 & 7.30 \\
Silver Lake & 2.46 & 6.40 & 29.26 & 6.70 \\
Long Lake & 12.01 & 7.32 & 26.20 & 7.90 \\
Boardman Lake & 1.29 & 5.79 & 22.25 & 7.90 \\
Birch Lake & 1.32 & 4.27 & 15.24 & 6.10 \\
\hline Group 19:Southern Lower Peninsula, Small, Eutrophic \\
\hline Round Lake & 0.32 & 1.98 & \\
Sand Lake & 0.39 & 1.37 & 6.71 & 2.50 \\
Morrison Lake & 0.47 & 1.68 & 7.62 & 2.60 \\
\hline
\end{tabular}




\begin{tabular}{|c|c|c|c|c|}
\hline Name & $\begin{array}{c}\text { Surface Area } \\
\left(\mathrm{km}^{2}\right)\end{array}$ & $\begin{array}{l}\text { Secchi Depth } \\
\text { (m) }\end{array}$ & $\begin{array}{c}\text { Max } \\
\text { Depth } \\
(\mathrm{m})\end{array}$ & $\begin{array}{c}\text { Mean } \\
\text { Depth } \\
(\mathrm{m})\end{array}$ \\
\hline Kenyon Lake & 0.30 & 1.98 & 8.84 & NA \\
\hline Ackley Lake & 0.26 & 1.07 & 4.57 & 1.70 \\
\hline Brandywine Lake & 0.30 & 1.22 & 7.62 & 2.90 \\
\hline Newburgh Lake & 0.38 & 0.76 & 5.50 & 2.20 \\
\hline Ruppert Lake & 0.11 & 1.76 & 8.84 & NA \\
\hline Wabascon Lake & 0.29 & 1.22 & 13.72 & 6.00 \\
\hline Blind Lake & 0.29 & 1.68 & 26.52 & NA \\
\hline Hi-Land Lake & 0.46 & 1.37 & 3.66 & NA \\
\hline Selkirk Lake & 0.37 & 1.83 & 11.89 & 3.60 \\
\hline Myers Lake & 0.36 & 1.83 & 12.50 & 3.70 \\
\hline \multicolumn{5}{|c|}{ Group 20:Southern Lower Peninsula, Small, Mesotrophic } \\
\hline Cub Lake & 0.50 & 3.96 & 13.11 & 5.60 \\
\hline Bird Lake & 0.47 & 3.05 & 19.51 & 8.30 \\
\hline Carpenter Lake & 0.15 & 3.52 & 12.19 & NA \\
\hline Bear Lake & 0.42 & 2.44 & 15.24 & 4.80 \\
\hline Cary Lake & 0.31 & 3.05 & 11.58 & 6.30 \\
\hline South Sand Lake & 0.35 & 2.26 & 9.75 & NA \\
\hline Belas Lake & 0.21 & 2.59 & 5.18 & 1.50 \\
\hline Twin Lakes & 0.25 & 3.51 & 16.50 & 5.20 \\
\hline Fish Lake & 0.46 & 3.20 & 10.97 & NA \\
\hline Deep Lake & 0.30 & 2.90 & 15.24 & 7.30 \\
\hline Killarney Lake & 0.07 & 2.13 & 5.49 & NA \\
\hline Unnamed & 0.36 & 3.35 & 13.72 & 5.70 \\
\hline Kelly Lake & 0.18 & 3.96 & 7.01 & NA \\
\hline Huzzy Lake & 0.39 & 3.20 & 10.36 & 4.60 \\
\hline Unnamed & 0.35 & 2.29 & 7.62 & 2.40 \\
\hline Paw Paw Lake & 0.50 & 3.51 & 17.10 & 7.40 \\
\hline Hogset Lake & 0.32 & 3.35 & 9.75 & NA \\
\hline Warner Lake & 0.23 & 2.74 & 9.14 & 4.10 \\
\hline Unnamed & 0.30 & 2.59 & 19.50 & 5.60 \\
\hline Unnamed & 0.37 & 2.90 & 8.23 & 3.50 \\
\hline Little Paw Paw Lake & 0.41 & 2.74 & 8.84 & NA \\
\hline Unnamed & 0.16 & 3.35 & 10.10 & 4.60 \\
\hline Rush Lake & 0.49 & 3.96 & 17.68 & 5.00 \\
\hline School Section Lake & 0.32 & 3.35 & 15.24 & 5.50 \\
\hline South Scott Lake & 0.48 & 3.96 & 16.76 & 6.10 \\
\hline North Scott Lake & 0.31 & 2.74 & 11.28 & 6.10 \\
\hline Prairie Lake & 0.36 & 2.13 & 7.32 & 4.00 \\
\hline Crooked Lake & 0.46 & 3.96 & 6.10 & 1.70 \\
\hline
\end{tabular}




\begin{tabular}{|c|c|c|c|c|}
\hline Name & $\begin{array}{l}\text { Surface Area } \\
\left(\mathrm{km}^{2}\right)\end{array}$ & $\begin{array}{l}\text { Secchi Depth } \\
\text { (m) }\end{array}$ & $\begin{array}{c}\text { Max } \\
\text { Depth } \\
\text { (m) }\end{array}$ & $\begin{array}{c}\text { Mean } \\
\text { Depth } \\
(\mathrm{m})\end{array}$ \\
\hline Little Cedar Lake & 0.30 & 3.51 & 8.23 & 3.10 \\
\hline Lake Fourteen & 0.28 & 2.13 & 6.71 & 2.20 \\
\hline Green Lake & 0.36 & 2.90 & 3.35 & 1.00 \\
\hline Lake Eleven & 0.22 & 3.35 & 9.75 & 5.30 \\
\hline Clear Lake & 0.28 & 2.13 & 16.76 & 7.50 \\
\hline Appleton Lake & 0.23 & 2.74 & 11.58 & 5.60 \\
\hline Bishop Lake & 0.44 & 3.20 & 16.46 & 2.70 \\
\hline Hall Lake & 0.23 & 3.20 & 3.66 & NA \\
\hline Lower Pettibone Lake & 0.42 & 3.05 & 12.50 & 5.80 \\
\hline Carter Lake & 0.24 & 2.74 & 7.62 & 2.60 \\
\hline Leach Lake & 0.44 & 2.59 & 12.19 & 6.50 \\
\hline Wildwood Lake & 0.48 & 2.59 & 5.18 & 2.50 \\
\hline Crooked Lake & 0.27 & 2.74 & 20.73 & NA \\
\hline Big Fish Lake & 0.43 & 2.74 & 21.34 & 5.00 \\
\hline Davison Lake & 0.23 & 3.96 & 20.42 & 7.60 \\
\hline Lake Minnawanna & 0.24 & 3.20 & 6.10 & 2.30 \\
\hline Woodard Lake & 0.28 & 3.66 & 6.71 & 2.80 \\
\hline Crockery Lake & 0.42 & 3.35 & 16.46 & 7.50 \\
\hline Baldwin Lake & 0.25 & 3.02 & 10.70 & 1.80 \\
\hline Half Moon Lake & 0.21 & 3.20 & 14.63 & NA \\
\hline Unnamed & 0.22 & 3.02 & 18.30 & 7.00 \\
\hline
\end{tabular}

\begin{tabular}{lcccc}
\hline Group 21:Southern Lower Peninsula, Small, Oligotrophic \\
\hline Lake Lavine & 0.36 & 5.79 & 21.64 & 6.50 \\
Harwood Lake & 0.48 & 4.88 & 16.76 & 7.20 \\
North Sand Lake & 0.24 & 4.78 & 12.19 & NA \\
Upper Jeptha Lake & 0.24 & 4.02 & 21.34 & NA \\
Crooked Lake & 0.33 & 4.11 & 12.19 & NA \\
Long Lake & 0.31 & 4.27 & 14.94 & 7.90 \\
Valley Lake & 0.15 & 4.27 & 13.72 & 2.48 \\
\hline Group 22:Southern Lower Peninsula, Medium, Eutrophic & \\
\hline Shavehead Lake & 1.21 & 1.52 & 21.34 & NA \\
Long Lake & 0.86 & 1.51 & 12.80 & 3.50 \\
South Lake & 0.63 & 1.37 & 5.49 & 1.30 \\
Round Lake & 0.83 & 0.61 & 8.23 & 2.30 \\
Lake of the Woods & 1.21 & 1.98 & 10.36 & 4.50 \\
Vandercook Lake & 0.59 & 1.68 & 12.80 & 7.00 \\
Maple Lake & 0.67 & 1.22 & 4.57 & 2.20 \\
Fourmile Lake & 1.04 & 1.68 & 5.49 & 1.40 \\
Duck Lake & 0.56 & 1.07 & 11.89 & 4.50 \\
\hline
\end{tabular}




\begin{tabular}{lcccc}
\hline Name & $\begin{array}{c}\text { Surface Area } \\
\left(\mathrm{km}^{2}\right)\end{array}$ & $\begin{array}{c}\text { Secchi Depth } \\
(\mathrm{m})\end{array}$ & $\begin{array}{c}\text { Max } \\
\text { Depth } \\
(\mathrm{m})\end{array}$ & $\begin{array}{c}\text { Mean } \\
\text { Depth } \\
(\mathrm{m})\end{array}$ \\
\hline Base Line Lake & 0.86 & 1.52 & 13.40 & 9.50 \\
Joslin Lake & 0.89 & 1.98 & 6.10 & 1.60 \\
Bristol Lake & 0.57 & 1.52 & 12.19 & 6.20 \\
Middle Straits Lake & 0.74 & 1.83 & 15.24 & 3.70 \\
Big Lake & 0.88 & 1.07 & 4.27 & 1.20 \\
Duncan Lake & 0.53 & 1.37 & 16.76 & 7.60 \\
Park Lake & 0.74 & 1.76 & 8.23 & NA \\
Kearsley Reservoir & 0.74 & 0.46 & 6.20 & 1.50 \\
\hline
\end{tabular}

Group 23:Southern Lower Peninsula, Medium, Mesotrophic

\begin{tabular}{|c|c|c|c|c|}
\hline Baldwins Lake & 1.06 & 3.12 & 16.76 & $\mathrm{NA}$ \\
\hline Gilead Lake & 0.56 & 2.13 & 14.94 & 5.90 \\
\hline Omena Lake & 0.53 & 2.90 & 17.07 & 5.50 \\
\hline Paradise Lake & 0.75 & 2.90 & 17.07 & 7.30 \\
\hline Stone Lake & 0.64 & 2.29 & 17.07 & 6.06 \\
\hline Donnell Lake & 0.99 & 2.90 & 19.20 & 7.60 \\
\hline Hemlock Lake & 0.61 & 2.01 & 19.81 & NA \\
\hline Clear Lake & 0.94 & 2.59 & 9.45 & 3.60 \\
\hline Pleasant Lake & 1.04 & 2.74 & 16.15 & 5.90 \\
\hline Dewey Lake & 0.90 & 2.29 & 15.24 & NA \\
\hline Oliverda Lake & 0.62 & 2.29 & 10.67 & NA \\
\hline Gravel Lake & 1.20 & 2.90 & 15.55 & 5.60 \\
\hline Cedar Lake & 1.11 & 3.35 & 25.60 & 7.30 \\
\hline Unnamed & 0.61 & 2.29 & 12.19 & 2.40 \\
\hline Sugarloaf Lake & 0.60 & 3.05 & 9.14 & 3.30 \\
\hline Gourdneck Lake & 0.89 & 2.74 & 15.85 & NA \\
\hline Lee Lake & 0.53 & 3.81 & 14.33 & 7.90 \\
\hline Eagle Lake & 0.79 & 3.51 & 3.05 & 1.52 \\
\hline Unnamed & 0.76 & 3.35 & 12.50 & 5.80 \\
\hline Van Auken Lake & 1.02 & 2.44 & 14.02 & 6.70 \\
\hline Sherman Lake & 0.60 & 3.35 & 10.97 & 4.10 \\
\hline Sugarloaf Lake & 0.72 & 2.29 & 6.10 & 1.00 \\
\hline Mill Lake & 0.53 & 3.35 & 7.62 & 1.70 \\
\hline Saddle Lake & 1.14 & 3.05 & 9.75 & 2.50 \\
\hline North Lake & 0.91 & 2.44 & 17.68 & 3.93 \\
\hline Osterhout Lake & 0.70 & 2.59 & 9.14 & 1.70 \\
\hline Eagle Lake & 0.88 & 3.35 & 17.98 & 6.50 \\
\hline South Lake & 0.82 & 3.05 & 25.30 & 5.60 \\
\hline Bruin Lake & 0.53 & 2.44 & 14.60 & 5.60 \\
\hline Base Line Lake & 1.02 & 3.51 & 19.51 & 9.50 \\
\hline
\end{tabular}




\begin{tabular}{lcccc}
\hline Name & $\begin{array}{c}\text { Surface Area } \\
\left(\mathrm{km}^{2}\right)\end{array}$ & $\begin{array}{c}\text { Sechi Depth } \\
(\mathrm{m})\end{array}$ & $\begin{array}{c}\text { Max } \\
\text { Depth } \\
(\mathrm{m})\end{array}$ & $\begin{array}{c}\text { Mean } \\
\text { Depth } \\
(\mathrm{m})\end{array}$ \\
\hline Clear Lake & 0.97 & 3.35 & 4.88 & 2.00 \\
Big Lake & 0.61 & 3.05 & 9.14 & 3.90 \\
Long Lake & 1.06 & 2.44 & 14.63 & 5.50 \\
West Crooked Lake & 0.74 & 2.29 & 5.79 & NA \\
East Crooked Lake & 1.01 & 2.44 & 12.19 & 4.00 \\
Woodland Lake & 1.05 & 2.90 & 10.67 & 2.10 \\
Wolverine Lake & 1.16 & 2.90 & 17.37 & 2.30 \\
Thompson Lake & 1.07 & 2.13 & 15.85 & 3.00 \\
Middle Lake & 0.55 & 2.29 & 9.14 & 5.90 \\
Tipsico Lake & 1.00 & 2.77 & 8.23 & 3.00 \\
Green Lake & 1.20 & 2.74 & 21.03 & 9.20 \\
Deer Lake & 0.56 & 2.44 & 19.20 & NA \\
Seven Lakes & 0.68 & 2.51 & 16.15 & NA \\
Big Pine Island Lake & 0.79 & 2.59 & 13.72 & 4.60 \\
Wolf Lake & 0.91 & 2.44 & 11.60 & NA \\
Bass Lake & 0.77 & 3.35 & 6.10 & 2.30 \\
Clifford Lake & 0.79 & 2.74 & 13.72 & 4.70 \\
Dickerson Lake & 0.92 & 2.59 & 14.63 & 5.90 \\
Murphy Lake & 0.74 & 3.05 & 12.50 & 2.00 \\
\hline Group 24:Southern Low & Peninsua & & &
\end{tabular}

\begin{tabular}{lcccc}
\hline Group 24:Southern Lower Peninsula, Medium, Oligotrophic & \\
\hline Thompson Lake & 0.60 & 4.88 & 9.14 & 4.60 \\
Fish Lake & 0.62 & 4.57 & 22.86 & 7.40 \\
Threemile Lake & 1.05 & 4.42 & 10.67 & 3.10 \\
Fish Lake & 0.61 & 4.57 & 17.07 & 9.00 \\
Cedar Island Lake & 0.68 & 4.11 & 21.95 & 8.40 \\
Camp Lake & 0.55 & 4.27 & 15.20 & 7.50 \\
\hline Group 25:Southern Lower Peninsula, Large, Eutrophic & & \\
\hline Unnamed & 1.92 & 0.74 & 7.32 & 4.00 \\
Matteson Lake & 1.27 & 1.98 & 11.58 & 4.60 \\
North Lake & 2.06 & 1.07 & 10.67 & 5.40 \\
Union Lake & 2.20 & 0.91 & 4.88 & 2.20 \\
Barton Lake & 1.36 & 1.37 & 16.20 & 6.10 \\
Austin Lake & 4.46 & 3.35 & 1.30 \\
Belleville Lake & 5.05 & 0.61 & 9.14 & 6.10 \\
Unnamed & 2.03 & 1.98 & 3.66 & $\mathrm{NA}$ \\
Unnamed & 6.88 & 0.61 & 6.10 & 3.30 \\
Kent Lake & 4.21 & 1.51 & 10.70 & 1.90 \\
Thornapple Lake & 1.69 & 1.37 & 9.45 & 5.30 \\
Stony Creek Lake & 2.02 & 0.76 & 7.01 & 2.40 \\
\hline
\end{tabular}




\begin{tabular}{lcccc}
\hline Name & $\begin{array}{c}\text { Surface Area } \\
\left(\mathrm{km}^{2}\right)\end{array}$ & $\begin{array}{c}\text { Secchi Depth } \\
(\mathrm{m})\end{array}$ & $\begin{array}{c}\text { Max } \\
\text { Depth } \\
(\mathrm{m})\end{array}$ & $\begin{array}{c}\text { Mean } \\
\text { Depth } \\
(\mathrm{m})\end{array}$ \\
\hline Lake Ponemah & 1.63 & 1.83 & 24.38 & NA \\
Morrison Lake & 1.35 & 0.76 & 10.97 & 3.90 \\
Lake Ovid & 1.50 & 0.75 & 3.05 & 2.30 \\
C S Mott Lake & 2.43 & 0.76 & 5.49 & 1.70 \\
Unnamed & 2.63 & 0.46 & 12.80 & 4.00 \\
Unnamed & 18.70 & 1.52 & 12.50 & 4.55 \\
\hline
\end{tabular}

\begin{tabular}{|c|c|c|c|c|}
\hline \multicolumn{5}{|c|}{ Group 26:Southern Lower Peninsula, Large, Mesotrophic } \\
\hline Klinger Lake & 3.36 & 2.44 & 21.95 & 6.40 \\
\hline Lake of the Woods & 1.57 & 3.35 & 23.17 & 5.90 \\
\hline Diamond Lake & 4.21 & 2.59 & 19.51 & 4.60 \\
\hline Corey Lake & 2.42 & 3.81 & 24.40 & 8.19 \\
\hline Palmer Lake & 2.95 & 2.51 & 11.28 & 4.15 \\
\hline Round Lake & 2.06 & 3.35 & 20.42 & NA \\
\hline Fishers Lake & 1.34 & 2.29 & 12.80 & 4.00 \\
\hline Devils Lake & 5.31 & 2.29 & 19.20 & 4.30 \\
\hline Fish Lake & 1.35 & 2.74 & 14.33 & 6.20 \\
\hline Sand Lake & 2.21 & 3.81 & 16.15 & 3.40 \\
\hline Magician Lake & 2.05 & 2.59 & 15.20 & 3.87 \\
\hline Vineyard Lake & 2.19 & 2.59 & 12.80 & 4.20 \\
\hline Bankson Lake & 1.47 & 3.51 & 12.80 & 4.10 \\
\hline Clark Lake & 2.33 & 3.81 & 15.24 & 3.40 \\
\hline Indian Lake & 3.20 & 3.51 & 22.90 & 8.50 \\
\hline Paw Paw Lake & 3.73 & 3.51 & 27.43 & 8.80 \\
\hline Long Lake & 2.03 & 2.74 & 17.37 & 2.60 \\
\hline Center Lake & 3.43 & 3.81 & 8.53 & 0.90 \\
\hline Unnamed & 1.35 & 3.05 & 9.14 & 1.40 \\
\hline Grass Lake & 1.43 & 3.20 & 4.00 & 0.80 \\
\hline Goguac Lake & 1.44 & 3.35 & 20.12 & 5.30 \\
\hline Unnamed & 2.42 & 2.74 & 15.24 & 4.00 \\
\hline Gull Lake & 8.29 & 2.13 & 33.53 & NA \\
\hline Whitmore Lake & 2.33 & 3.96 & 21.03 & 4.20 \\
\hline Fine Lake & 1.31 & 2.44 & 13.72 & 2.90 \\
\hline Zukey Lake & 1.74 & 3.02 & 14.63 & NA \\
\hline Pine Lake & 2.48 & 3.20 & 10.36 & 3.60 \\
\hline Crooked Lake & 2.72 & 2.26 & 14.60 & 2.20 \\
\hline Unnamed & 1.46 & 3.20 & 15.24 & NA \\
\hline Hutchins Lake & 1.53 & 2.44 & 10.36 & 3.20 \\
\hline Miner Lake & 1.33 & 3.51 & 25.30 & 7.20 \\
\hline Lake Chemung & 1.26 & 3.96 & 21.34 & 8.70 \\
\hline
\end{tabular}




\begin{tabular}{lcccc}
\hline Name & $\begin{array}{c}\text { Surface Area } \\
\left(\mathrm{km}^{2}\right)\end{array}$ & $\begin{array}{c}\text { Secchi Depth } \\
(\mathrm{m})\end{array}$ & $\begin{array}{c}\text { Max } \\
\text { Depth } \\
(\mathrm{m})\end{array}$ & $\begin{array}{c}\text { Mean } \\
\text { Depth } \\
(\mathrm{m})\end{array}$ \\
\hline Cass Lake & 5.31 & 3.35 & 37.49 & 9.10 \\
White Lake & 2.33 & 2.74 & 9.75 & 3.30 \\
Pontiac Lake & 2.56 & 2.79 & 10.36 & 1.20 \\
Unnamed & 1.85 & 2.74 & 19.51 & 3.40 \\
Lobdell Lake & 3.18 & 3.96 & 23.77 & 2.20 \\
Lake Orion & 2.00 & 2.90 & 24.40 & 5.00 \\
Wabasis Lake & 1.64 & 2.74 & 17.40 & 7.60 \\
\hline Group 27:Southern Lower Peninsula, Large, Oligotrophic & \\
\hline Orchard Lake & 3.50 & 4.27 & 33.53 & 6.70 \\
Union Lake & 1.92 & 4.57 & 33.53 & 8.70 \\
Lake Fenton & 3.56 & 4.11 & 27.43 & 6.20 \\
Lakeville Lake & 1.80 & 5.03 & 20.10 & 3.00 \\
\hline
\end{tabular}




\section{B. Validation Results}

Table B.1 is a complete summary of the regression-based equivalence testing results using observed meteorological data. For each lake, the minimum region of similarity for the slope and intercept, and the percent of bootstrap iterations where the slope and intercept fell within the region of similarity.

Table B.1. Summary of regression-based equivalence test for each validation lake using observed climate data.

\begin{tabular}{|c|c|c|c|c|c|c|c|c|c|c|c|}
\hline \multirow{3}{*}{ Lake } & \multirow{3}{*}{ Parameter } & \multicolumn{5}{|c|}{ SLOPE } & \multicolumn{5}{|c|}{ INTERCEPT } \\
\hline & & \multicolumn{2}{|c|}{$\begin{array}{l}\text { Confidence } \\
\text { Interval }\end{array}$} & \multicolumn{2}{|c|}{$\begin{array}{l}\text { Region of } \\
\text { Similarity }\end{array}$} & \multirow{2}{*}{$\begin{array}{c}\begin{array}{c}\text { Region of } \\
\text { Similarity } \\
\text { Min. }\end{array} \\
\%\end{array}$} & \multicolumn{2}{|c|}{$\begin{array}{l}\text { Confidence } \\
\text { Interval }\end{array}$} & \multicolumn{2}{|c|}{$\begin{array}{l}\text { Region of } \\
\text { Similarity }\end{array}$} & \multirow{2}{*}{$\begin{array}{c}\begin{array}{c}\text { Region of } \\
\text { Similarity } \\
\text { Min. }\end{array} \\
{ }^{\circ} \mathrm{C}\end{array}$} \\
\hline & & Lower & Upper & Lower & Upper & & Lower & Upper & Lower & Upper & \\
\hline \multirow{2}{*}{ Allequash Lake } & Ts & 0.92 & 1.03 & 0.85 & 1.15 & -0.07 & 14.59 & 15.56 & 13.70 & 15.70 & 0.87 \\
\hline & $\mathrm{Tm}$ & 0.98 & 1.15 & 0.85 & 1.15 & 0.70 & 13.67 & 14.81 & 13.12 & 15.12 & 0.17 \\
\hline \multirow{2}{*}{$\begin{array}{c}\text { Big } \\
\text { Muskellunge } \\
\text { Lake }\end{array}$} & Ts & 0.90 & 1.00 & 0.85 & 1.15 & -0.13 & 13.72 & 15.10 & 13.62 & 15.62 & -0.90 \\
\hline & $\mathrm{Tm}$ & 0.78 & 0.95 & 0.85 & 1.15 & -0.21 & 11.41 & 12.61 & 12.25 & 14.25 & -1.88 \\
\hline \multirow{2}{*}{ Crystal Lake } & Ts & 0.89 & 1.00 & 0.85 & 1.15 & -0.13 & 13.48 & 14.84 & 13.63 & 15.63 & -1.17 \\
\hline & $\mathrm{Tm}$ & 0.99 & 1.14 & 0.85 & 1.15 & 0.17 & 11.44 & 12.32 & 11.01 & 13.01 & -0.62 \\
\hline \multirow{2}{*}{ Crystal Bog } & Ts & 0.86 & 1.04 & 0.85 & 1.15 & -0.13 & 14.23 & 15.54 & 14.05 & 16.05 & -0.87 \\
\hline & $\mathrm{Tm}$ & 0.98 & 1.14 & 0.85 & 1.15 & 0.13 & 14.61 & 15.54 & 13.17 & 15.17 & 1.40 \\
\hline \multirow{2}{*}{ Sparkling Lake } & Ts & 0.90 & 1.00 & 0.85 & 1.15 & -0.11 & 13.81 & 14.95 & 13.49 & 15.49 & -0.73 \\
\hline & $\mathrm{Tm}$ & 1.12 & 1.25 & 0.85 & 1.15 & 0.27 & 11.54 & 12.23 & 10.24 & 12.24 & 0.97 \\
\hline \multirow{2}{*}{ Trout Lake } & Ts & 0.81 & 0.96 & 0.85 & 1.15 & -0.21 & 12.87 & 14.48 & 12.83 & 14.83 & -1.04 \\
\hline & $\mathrm{Tm}$ & 0.82 & 0.97 & 0.85 & 1.15 & -0.22 & 9.85 & 10.87 & 9.18 & 11.18 & 0.71 \\
\hline \multirow{2}{*}{ Fish Lake } & Ts & 0.93 & 1.09 & 0.85 & 1.15 & 0.10 & 12.99 & 14.74 & 14.78 & 16.78 & -2.72 \\
\hline & $\mathrm{Tm}$ & 0.98 & 1.19 & 0.85 & 1.15 & 0.19 & 9.84 & 10.89 & 10.79 & 12.79 & -1.96 \\
\hline \multirow{2}{*}{ Lake Wingra } & Ts & 1.00 & 1.21 & 0.85 & 1.15 & 0.19 & 14.93 & 16.33 & 16.28 & 18.28 & -2.43 \\
\hline & $\mathrm{Tm}$ & 0.59 & 0.82 & 0.85 & 1.15 & -0.39 & 11.14 & 12.57 & 15.99 & 17.99 & -5.89 \\
\hline \multirow{2}{*}{ Lake Monona } & Ts & 0.95 & 1.12 & 0.85 & 1.15 & 0.12 & 14.58 & 16.05 & 15.64 & 17.65 & -2.19 \\
\hline & $\mathrm{Tm}$ & 0.73 & 0.86 & 0.85 & 1.15 & -0.27 & 10.89 & 11.78 & 14.04 & 16.04 & -4.19 \\
\hline \multirow{2}{*}{ Lake Mendota } & Ts & 0.99 & 1.09 & 0.85 & 1.15 & 0.11 & 13.58 & 14.82 & 13.81 & 15.81 & -1.25 \\
\hline & $\mathrm{Tm}$ & 0.79 & 0.89 & 0.85 & 1.15 & -0.21 & 10.23 & 10.95 & 11.71 & 13.71 & -2.52 \\
\hline
\end{tabular}


Table B.2 is a complete summary of the regression-based equivalence testing results using modeled meteorological data. For each lake, the minimum region of similarity for the slope and intercept, and the percent of bootstrap iterations where the slope and intercept fell within the region of similarity.

Table B.2. Summary of regression-based equivalence test for each validation lake using modeled climate data.

\begin{tabular}{|c|c|c|c|c|c|c|c|c|c|c|c|}
\hline \multirow{3}{*}{ Lake } & \multirow{3}{*}{ Parameter } & \multicolumn{5}{|c|}{ SLOPE } & \multicolumn{5}{|c|}{ INTERCEPT } \\
\hline & & \multicolumn{2}{|c|}{ Confidence Interval } & \multicolumn{2}{|c|}{$\begin{array}{l}\text { Region of } \\
\text { Similarity }\end{array}$} & \multirow{2}{*}{$\begin{array}{c}\text { Region of } \\
\text { Similarity } \\
\text { Min. }\end{array}$} & \multicolumn{2}{|c|}{$\begin{array}{l}\text { Confidence } \\
\text { Interval }\end{array}$} & \multirow{2}{*}{$\begin{array}{c}\text { Region of } \\
\text { Similarity }\end{array}$} & \multicolumn{2}{|c|}{$\begin{array}{c}\text { Region of } \\
\text { Similarity Min }\end{array}$} \\
\hline & & Lower & Upper & Lower & Upper & & Lower & Upper & & Upper & ${ }^{\circ} \mathrm{C}$ \\
\hline \multirow{2}{*}{ Allequash Lake } & Ts & 0.92 & 1.12 & 0.80 & 1.20 & 0.15 & 16.33 & 18.18 & 10.70 & 18.70 & 3.52 \\
\hline & $\mathrm{Tm}$ & 0.96 & 1.21 & 0.80 & 1.20 & 0.23 & 15.19 & 16.85 & 10.12 & 18.12 & 2.74 \\
\hline $\begin{array}{l}\text { Big Muskellunge } \\
\text { Lake }\end{array}$ & Ts & 0.94 & 1.10 & 0.80 & 1.20 & 0.15 & 16.17 & 17.99 & 10.62 & 18.62 & 3.46 \\
\hline \multirow{2}{*}{ Crystal Lake } & Ts & 0.97 & 1.13 & 0.80 & 1.20 & 0.18 & 16.15 & 17.94 & 10.63 & 18.63 & 3.43 \\
\hline & $\mathrm{Tm}$ & 0.89 & 1.07 & 0.80 & 1.20 & 0.09 & 11.33 & 12.18 & 8.01 & 16.01 & -0.76 \\
\hline \multirow{2}{*}{ Crystal Bog } & Ts & 0.70 & 1.07 & 0.80 & 1.20 & -0.26 & 16.27 & 18.86 & 11.05 & 19.05 & 3.87 \\
\hline & $\mathrm{Tm}$ & 0.85 & 1.20 & 0.80 & 1.20 & 0.20 & 16.43 & 18.64 & 10.17 & 18.17 & 4.56 \\
\hline \multirow{2}{*}{ Sparkling Lake } & Ts & 0.96 & 1.16 & 0.80 & 1.20 & 0.21 & 16.18 & 18.23 & 10.49 & 18.49 & 3.78 \\
\hline & $\mathrm{Tm}$ & 0.97 & 1.16 & 0.80 & 1.20 & 0.17 & 11.37 & 12.17 & 7.24 & 15.24 & 0.93 \\
\hline \multirow{2}{*}{ Trout Lake } & Ts & 0.91 & 1.09 & 0.80 & 1.20 & 0.15 & 15.63 & 17.56 & 9.83 & 17.83 & 3.75 \\
\hline & $\mathrm{Tm}$ & 0.87 & 1.01 & 0.80 & 1.20 & -0.15 & 10.56 & 11.41 & 6.18 & 14.18 & 1.27 \\
\hline Fish Lake & $\mathrm{Tm}$ & 0.79 & 1.04 & 0.80 & 1.20 & -0.19 & 11.74 & 12.83 & 7.79 & 15.79 & 1.10 \\
\hline \multirow{2}{*}{ Lake Wingra } & Ts & 0.87 & 1.22 & 0.80 & 1.20 & 0.20 & 19.19 & 21.72 & 13.28 & 21.28 & 4.49 \\
\hline & $\mathrm{Tm}$ & 0.63 & 1.04 & 0.80 & 1.20 & -0.35 & 16.97 & 19.33 & 13.00 & 21.00 & 2.51 \\
\hline \multirow{2}{*}{ Lake Monona } & Ts & 0.92 & 1.13 & 0.80 & 1.20 & 0.14 & 19.07 & 20.82 & 12.65 & 20.65 & 4.20 \\
\hline & $\mathrm{Tm}$ & 0.51 & 0.72 & 0.80 & 1.20 & -0.47 & 12.22 & 13.45 & 11.04 & 19.04 & -2.83 \\
\hline \multirow{2}{*}{ Lake Mendota } & Ts & 0.96 & 1.13 & 0.80 & 1.20 & 0.14 & 18.27 & 19.86 & 10.81 & 18.81 & 5.08 \\
\hline & $\mathrm{Tm}$ & 0.62 & 0.77 & 0.80 & 1.20 & -0.37 & 12.00 & 12.87 & 8.71 & 16.71 & -0.70 \\
\hline
\end{tabular}




\section{Supplementary Materials}

File Name: 01_Validation_Climate_Data

Description: Daily observed and modeled meteorological data for the northern and southern validation site.

File Name: 02 Validation Lake Data

Description: Observed lake temperature data for all validation lakes.

File Name: 03_Future_Climate_Data

Description: Daily modeled meteorological data for 2020 to 2099 for each of the climate regions. 


\section{Google Earth Image Permission}

This appendix documents permission to use Google Earth copyrighted materials in a thesis. This documentation is specifically provided for Figure 3.7 in this thesis.

Important information pertaining to uses of Google Earth images in a thesis are highlighted throughout the document.

Sections not pertaining to use of Google Earth images in a thesis have been removed. To see the complete original documents, the following links can be used

Google Maps/Google Earth Additional Terms of Service:

https://www.google.com/intl/en-US_US/help/terms_maps.html

Using Google Maps, Google Earth and Street View:

https://www.google.com/permissions/geoguidelines.html

Google Terms of Service:

https://www.google.com/intl/ALL/policies/terms/index.html

\section{Google Maps/Google Earth Additional Terms of Service}

Last Modified: December 17, 2015

Thanks for using Google Maps and Google Earth ("Google Maps/Google Earth").

Google Maps/Google Earth allow you to view and use a variety of content, including map and terrain data, imagery, business listings, traffic, reviews, and other related information provided by Google, its licensors, and users (the "Content").

By accessing, downloading, or using Google Maps/Google Earth, you are agreeing to:

- the Google Terms of Service (the "Universal Terms");

- these Maps/Google Earth additional terms (the "Maps/Earth Additional Terms");

- the Google Maps/Google Earth Legal Notices (the "Legal Notices"); and

- the Google Privacy Policy (the "Privacy Policy").

Please read each of these four documents carefully, starting with the Universal Terms. The Universal Terms clarify, for example, your intellectual property ownership rights in the content you upload, and your responsibilities when using Google content or thirdparty content or when using Google Maps/Google Earth while driving. 
Collectively, we refer to the Universal Terms, the Maps/Earth Additional Terms, the Legal Notices, and the Privacy Policy as the "Agreement". The Agreement is a binding contract between you and Google regarding your use of Google Maps/Google Earth.

License. Subject to the Agreement's terms, Google grants you a non-exclusive, nontransferable license to use Google Maps/Google Earth, including features that allow you to:

- view and annotate maps;

- create KML files and map layers;

- publicly display Content with proper attribution online, in video, and in print; and

- do many other things described in the Using Google Maps, Google Earth, and Street View permissions page.

Prohibited Conduct. When using Google Maps/Google Earth, you may not (or allow those acting on your behalf to):

- redistribute or sell any part of Google Maps/Google Earth or create a new product or service based on Google Maps/Google Earth (unless you use the Google Maps/Google Earth APIs in accordance with their terms of service);

- copy the Content (unless you are otherwise permitted to do so by the Using Google Maps, Google Earth, and Street View permissions page or applicable intellectual property law, including "fair use");

- mass download or create bulk feeds of the Content (or let anyone else do so);

- use Google Maps/Google Earth to create or augment any other mapping-related dataset (including a mapping or navigation dataset, business listings database, mailing list, or telemarketing list) for use in a service that is a substitute for, or a substantially similar service to, Google Maps/Google Earth;

- use any part of Google Maps/Google Earth with other people's products or services for or in connection with real-time navigation or autonomous vehicle control, except through a specific Google-provided feature such as Android Auto or Send to Car;

- reverse engineer or attempt to extract the source code from Google Maps/Google Earth or any related software, except to the extent that this restriction is expressly prohibited by applicable law;

- remove, obscure, or alter any Google terms of service or any links to or notices of those terms, or any copyright, trademark, or other proprietary rights notices; or

- do anything inappropriate, illegal, or in violation of others' rights (including their privacy, publicity, and intellectual property rights).

Actual Conditions; Assumption of Risk. When you use Google Maps/Google Earth's map data, traffic, directions, and other Content, you may find that actual conditions differ from the map results and Content, so exercise your independent judgment and use Google Maps/Google Earth at your own risk. You're responsible at all times for your conduct and its consequences. 
Your Content in Google Maps/Google Earth. Content you upload, submit, store, send, or receive through Google Maps/Google Earth is subject to Google's Universal Terms, including the license in the section entitled "Your Content in our Services". However, content that remains exclusively local to your device (such as a locally-stored KML file) is not uploaded or submitted to Google, and is therefore not subject to that license.

Government Users. If you are using our Services on behalf of a government entity, the following terms apply:

Government Uses of Our Services. The Universal Terms section entitled "Business uses of our Services" is replaced in its entirety with the following:

"If you are using our Services on behalf of a government entity, that entity accepts these terms. Solely to the extent permitted by applicable law, regulation, or privileges and immunities, that entity will hold harmless and indemnify Google and its affiliates, officers, agents and employees from any claim, action or proceedings arising from or related to the use of the Services or violation of these terms, including any liability or expense arising from claims, losses, damages, judgements, litigation costs and legal fees."

Governing Law. For city or state government entities in the United States and European Union, the Universal Terms section regarding governing law and venue will not apply.

For United States federal government entities, the Universal Terms section regarding governing law and venue is replaced in its entirety with the following:

"This Agreement will be governed by and interpreted and enforced in accordance with the laws of the United States of America without reference to conflict of laws. Solely to the extent permitted by federal law: (A) the laws of the State of California (excluding California's conflict of laws rules) will apply in the absence of applicable federal law; and (B) any dispute arising out of or relating to this Agreement or the Services will be litigated exclusively in the federal courts of Santa Clara County, California, and the parties consent to personal jurisdiction in those courts."

U.S. Government Restricted Rights. All access or use of Google Maps/Google Earth by or for the United States federal government is subject to the "U.S. Government Restricted Rights" section in the Legal Notices. 


\section{Using Google Maps, Google Earth and Street View}

Last Modified: December 17, 2015

Thanks for considering Google Maps, Google Earth and Street View for your project! These guidelines are for non-commercial use except for the limited use cases described below; if you want to use Google Maps, Google Earth, or Street View for other commercial purposes, please contact the Google Maps for Work sales team. "Commercial purposes" means "use for sale or revenue-generating purposes".

We created this page to clarify questions we've received from users over the years regarding uses of our mapping tools in everything from marketing and promotional materials, films, television programs, books, academic journals, and much more.

Generally speaking, as long as you're following our Terms of Service and you're attributing properly, we're cool with your using our maps and imagery; in fact, we love seeing all of the creative applications of Google Maps, Google Earth and Street View! But we know you're looking for more specifics to ensure you're using our maps and imagery correctly.

As you dive into the information below, we suggest starting with the general guidelines at the top, as these will apply to all projects. Then feel free to click directly to the section that applies to you.

Below, you'll find information on:

General guidelines

$\underline{\text { Uses in print }}$

Uses on the web and in applications

\section{GENERAL GUIDELINES}

\section{The Basics}

Google Maps and Google Earth's "Content" (as defined in the Google Earth/Google Maps Additional Terms of Service) includes everything you'd find in these products: map and terrain data, imagery, business listings, traffic, reviews and other related information provided by Google, its licensors, and users.

These guidelines cover your use of the Content-with one exception. There are some particular guidelines regarding your use of Street View imagery available from both Google Maps and Google Earth. Please read the section below for instructions on how Street View imagery may or may not be used.

\section{Terms of Service}


To help you figure out whether your use of the Content is acceptable, first read the following documents:

\section{Google Terms of Service}

\section{$\underline{\text { Google Maps/Google Earth Additional Terms of Service }}$}

Your use of the Content is first and foremost governed by the licenses above.

\section{Fair Use}

Apart from any license granted to you by Google, your use of the Content may be acceptable under principles of "fair use." Fair use is a concept under copyright law in the U.S. that, generally speaking, permits you to use a copyrighted work in certain ways without obtaining a license from the copyright holder.

There are similar, although generally more limited, concepts in other countries' copyright laws, including a concept known as "fair dealing" in a number of countries. Google can't tell you if your use of the Content from our products would be fair use or would be considered fair dealing; these are legal analyses that depend on all of the specific facts of your proposed use. We suggest you speak with an attorney if you have questions regarding fair use of copyrighted works.

\section{Written permission}

Due to limited resources and high demand, we're unable to sign any letter or contract specifying that your project or use has our explicit permission. As long as you follow the guidance on this page, and attribute the Content correctly, feel free to move forward with your project.

\section{Attribution}

All uses of the Content must provide attribution to both Google and our data providers. We require clear, visible attribution when the Content is shown. You may not move the attribution to the end credits or fade it out after a few seconds.

Note that if you embed a classic map, Street View panorama or My Map; use one of our APIs on the web or in an application; or export a video or JPEG from Google Earth $\underline{\text { Pro, }}$, the necessary attribution is already baked into the map and no further credit is needed. Learn more about how to properly credit, as well as how to identify providers, on our attribution guidelines page

If you are unwilling to meet our attribution requirements, contact our data provider(s) directly to inquire about purchasing the rights to use the Content directly. You'll find provider contact information listed on their websites.

\section{Personalizing your map}


You may annotate our maps with additional information-like points, lines or labels. In fact, many of our tools have built-in features that make it easy to do just that. For example, Google My Maps lets you draw lines and shapes on a Google map. We also offer a Styled Maps API that allows you to edit the colors of individual map components (for example, changing water to purple), as well as toggle visibility for each component (for example, making roads invisible). If neither of those fit your needs, you may save an image from Google Earth and use Photoshop to add custom text labels.

While we encourage annotations, you must not significantly alter how Google Maps, Google Earth or Street View would look online. For example, you're not allowed to make any changes to the colors of the product interface or alter how imagery appears (such as adding clouds or other natural elements, blurring, etc.).

\section{USES IN PRINT}

Google Maps and Google Earth have built-in print functionality. You may print Content for non-commercial use and enlarge it (for example, a map with directions). In all uses where you will distribute printed materials that include the Content, first be sure to read the general guidelines above, especially with regard to fair use and attribution.

\begin{tabular}{|c|c|c|}
\hline Proposed use & $\begin{array}{l}\text { OK to } \\
\text { use? }\end{array}$ & Additional information \\
\hline Books & Yes & $\begin{array}{l}\text { It's fine to use a handful of images, as long as you're } \\
\text { not distributing more than } 5,000 \text { copies or using the } \\
\text { Content in guidebooks. }\end{array}$ \\
\hline Periodicals & Yes & This includes newspapers, magazines and journals. \\
\hline $\begin{array}{l}\text { Reports and } \\
\text { presentations }\end{array}$ & Yes & $\begin{array}{l}\text { This includes research papers, internal reports, } \\
\text { presentations, proposals and other related } \\
\text { professional documents. }\end{array}$ \\
\hline Guidebooks & No & $\begin{array}{l}\text { You may not use the Content as a core part of printed } \\
\text { navigational material (for example, tour books). }\end{array}$ \\
\hline $\begin{array}{l}\text { Consumer } \\
\text { goods }\end{array}$ & No & $\begin{array}{l}\text { This includes retail products or retail product } \\
\text { packaging (for example, t-shirts, beach towels, } \\
\text { shower curtains, mugs, posters, stationery, etc.). }\end{array}$ \\
\hline
\end{tabular}




\section{Print No See the advertisements section for more guidance on advertisements digital and TV uses.}

Note that we cannot provide high-resolution or vector screen captures of Google Maps; however, you may use Google Earth Pro to save and print high-resolution JPEGs of satellite imagery. Images in Google Earth Pro can be exported up to 4,800 pixels wide. Grab a free Google Earth Pro key today.

\section{USES ON THE WEB OR IN APPLICATION}

If you'd like to use our Content in a web-based project or application, please first review the general guidelines at the top of this page, especially with regard to attribution.

\section{Embeddable maps}

We have multiple APIs available to help you build and embed custom maps, including Street View, within your website or application. When using these APIs, certain restrictions may apply. If you simply need to embed a classic Google map or Street View panorama on your website, learn how to easily do so here.

\section{Google Earth images}

We know the imagery in Google Earth, both current and historical, can provide useful visual context to news websites, blogs, and other educational sites. And often these sites want to use the imagery found in Google Earth as still images, both as-is or annotated with additional labels and features. You may use a handful of these images in a news article or on a blog, just please be sure to follow our attribution rules. Note that Google Earth Pro allows you to export high-resolution JPEGs - particularly handy for these projects.

Thanks again for using Google Maps, Google Earth and Street View! 


\section{Attribution Guidelines for Google Maps and Google Earth}

All uses of Google Maps and Google Earth Content must provide attribution to both Google and our data providers. We do not approve of any use of content without proper attribution, in any circumstance. We require attribution when the Content is shown. Requests for exceptions will not be answered or granted.

Only including "Google" or the Google logo is not proper attribution when there are third-party data providers cited with the imagery. Attribution information will appear automatically on the Content if you:

Embed an interactive map using the HTML provided on Google Maps

Use one our Geo APIs to create and embed a custom map in your website or application

Export a high-res image or .mov file from Google Earth Pro

\section{Where can I find the attribution information?}

You can find the attribution in the line(s) shown on the bottom of the Content in the products along with copyright notices, such as "Map data (2015 Google". Note that the exact text of the attribution changes based on geography and content type. The attribution text must be legible to the average viewer or reader.

In Google Maps, you'll find our data providers listed in the bottom right corner of the map. Here, Google is the data provider:

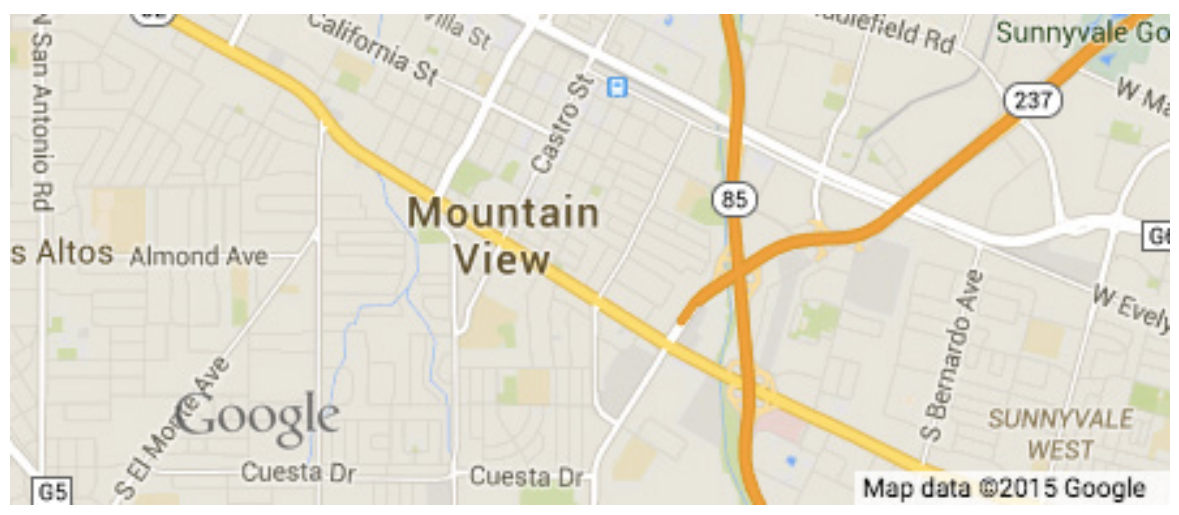

In Google Earth, you'll find our data providers listed in the bottom center of the 3D view. Here, DigitalGlobe is the data provider: 


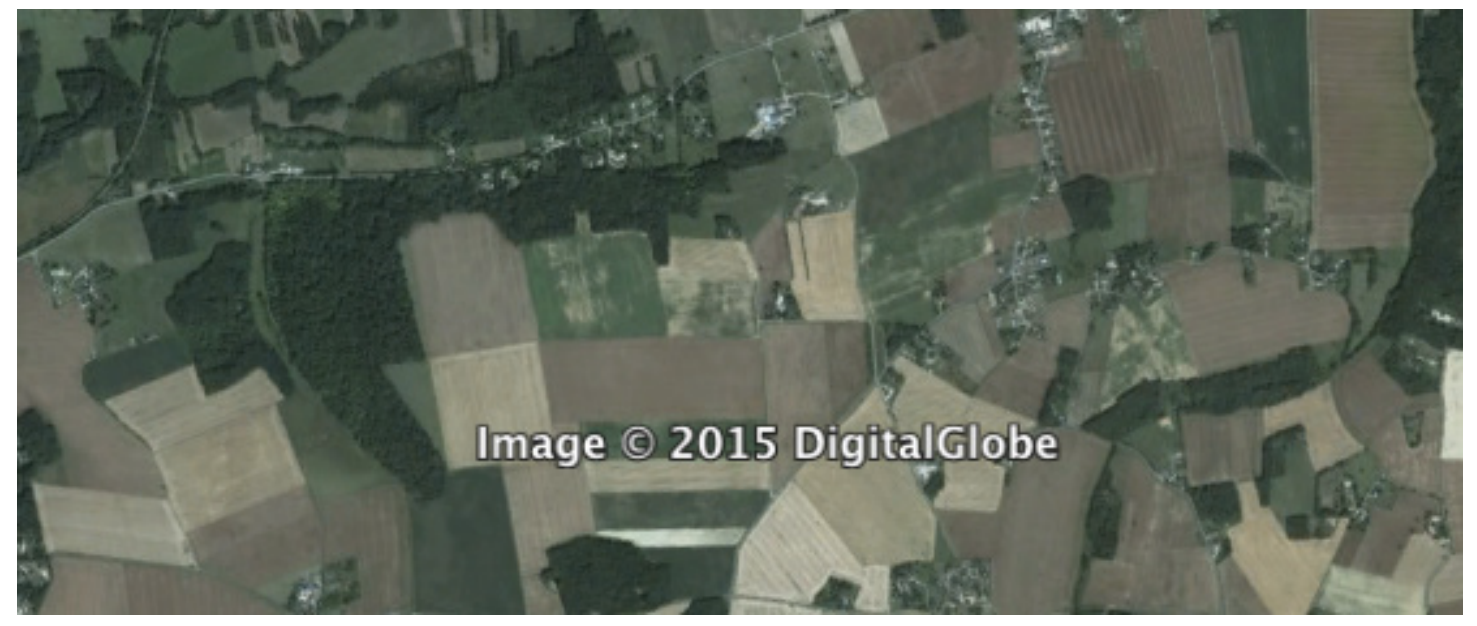

\section{Do I need to use the text provided on the imagery?}

The automatically generated Google logo and data provider attribution may only be removed or obstructed if reintroduced in a visible form elsewhere within the Content (e.g. photo caption below a Google Earth still). In other words, your text must be as visible as it would have been if you had used the default text that we provide.

\section{What does the attribution text need to say?}

If you are not using the text provided directly on Google Maps and Google Earth imagery, the text of your attribution must say the name "Google" and the relevant data provider(s), such as "Map data: Google, DigitalGlobe". You may customize the style and placement of the attribution text, just so long as the text is legible to the average viewer or reader. Note that Google logos cannot be used in-line (e.g. "These maps from [Google $\operatorname{logo} . ")$ 


\section{Google Terms of Service}

Last modified: April 14, 2014

Welcome to Google!

Thanks for using our products and services ("Services"). The Services are provided by Google Inc. ("Google”), located at 1600 Amphitheatre Parkway, Mountain View, CA 94043, United States.

By using our Services, you are agreeing to these terms. Please read them carefully.

Our Services are very diverse, so sometimes additional terms or product requirements (including age requirements) may apply. Additional terms will be available with the relevant Services, and those additional terms become part of your agreement with us if you use those Services.

\section{Using our Services}

You must follow any policies made available to you within the Services.

Don't misuse our Services. For example, don't interfere with our Services or try to access them using a method other than the interface and the instructions that we provide. You may use our Services only as permitted by law, including applicable export and re-export control laws and regulations. We may suspend or stop providing our Services to you if you do not comply with our terms or policies or if we are investigating suspected misconduct.

Using our Services does not give you ownership of any intellectual property rights in our Services or the content you access. You may not use content from our Services unless you obtain permission from its owner or are otherwise permitted by law. These terms do not grant you the right to use any branding or logos used in our Services. Don't remove, obscure, or alter any legal notices displayed in or along with our Services.

Our Services display some content that is not Google's. This content is the sole responsibility of the entity that makes it available. We may review content to determine whether it is illegal or violates our policies, and we may remove or refuse to display content that we reasonably believe violates our policies or the law. But that does not necessarily mean that we review content, so please don't assume that we do.

In connection with your use of the Services, we may send you service announcements, administrative messages, and other information. You may opt out of some of those communications.

Some of our Services are available on mobile devices. Do not use such Services in a way that distracts you and prevents you from obeying traffic or safety laws. 


\section{Your Google Account}

You may need a Google Account in order to use some of our Services. You may create your own Google Account, or your Google Account may be assigned to you by an administrator, such as your employer or educational institution. If you are using a Google Account assigned to you by an administrator, different or additional terms may apply and your administrator may be able to access or disable your account.

To protect your Google Account, keep your password confidential. You are responsible for the activity that happens on or through your Google Account. Try not to reuse your Google Account password on third-party applications. If you learn of any unauthorized use of your password or Google Account, follow these instructions.

\section{Privacy and Copyright Protection}

Google's privacy policies explain how we treat your personal data and protect your privacy when you use our Services. By using our Services, you agree that Google can use such data in accordance with our privacy policies.

We respond to notices of alleged copyright infringement and terminate accounts of repeat infringers according to the process set out in the U.S. Digital Millennium Copyright Act.

We provide information to help copyright holders manage their intellectual property online. If you think somebody is violating your copyrights and want to notify us, you can find information about submitting notices and Google's policy about responding to notices in our Help Center.

\section{Your Content in our Services}

Some of our Services allow you to upload, submit, store, send or receive content. You retain ownership of any intellectual property rights that you hold in that content. In short, what belongs to you stays yours.

When you upload, submit, store, send or receive content to or through our Services, you give Google (and those we work with) a worldwide license to use, host, store, reproduce, modify, create derivative works (such as those resulting from translations, adaptations or other changes we make so that your content works better with our Services), communicate, publish, publicly perform, publicly display and distribute such content. The rights you grant in this license are for the limited purpose of operating, promoting, and improving our Services, and to develop new ones. This license continues even if you stop using our Services (for example, for a business listing you have added to Google Maps). Some Services may offer you ways to access and remove content that has been provided to that Service. Also, in some of our Services, there are terms or settings that narrow the scope of our use of the content submitted in those Services. Make sure you have the necessary rights to grant us this license for any content that you submit to our Services. 
Our automated systems analyze your content (including emails) to provide you personally relevant product features, such as customized search results, tailored advertising, and spam and malware detection. This analysis occurs as the content is sent, received, and when it is stored.

If you have a Google Account, we may display your Profile name, Profile photo, and actions you take on Google or on third-party applications connected to your Google Account (such as +1 's, reviews you write and comments you post) in our Services, including displaying in ads and other commercial contexts. We will respect the choices you make to limit sharing or visibility settings in your Google Account. For example, you can choose your settings so your name and photo do not appear in an ad.

You can find more information about how Google uses and stores content in the privacy policy or additional terms for particular Services. If you submit feedback or suggestions about our Services, we may use your feedback or suggestions without obligation to you.

\section{About Software in our Services}

When a Service requires or includes downloadable software, this software may update automatically on your device once a new version or feature is available. Some Services may let you adjust your automatic update settings.

Google gives you a personal, worldwide, royalty-free, non-assignable and non-exclusive license to use the software provided to you by Google as part of the Services. This license is for the sole purpose of enabling you to use and enjoy the benefit of the Services as provided by Google, in the manner permitted by these terms. You may not copy, modify, distribute, sell, or lease any part of our Services or included software, nor may you reverse engineer or attempt to extract the source code of that software, unless laws prohibit those restrictions or you have our written permission.

Open source software is important to us. Some software used in our Services may be offered under an open source license that we will make available to you. There may be provisions in the open source license that expressly override some of these terms.

\section{Modifying and Terminating our Services}

We are constantly changing and improving our Services. We may add or remove functionalities or features, and we may suspend or stop a Service altogether.

You can stop using our Services at any time, although we'll be sorry to see you go. Google may also stop providing Services to you, or add or create new limits to our Services at any time. 
We believe that you own your data and preserving your access to such data is important. If we discontinue a Service, where reasonably possible, we will give you reasonable advance notice and a chance to get information out of that Service.

\section{Our Warranties and Disclaimers}

We provide our Services using a commercially reasonable level of skill and care and we hope that you will enjoy using them. But there are certain things that we don't promise about our Services.

OTHER THAN AS EXPRESSLY SET OUT IN THESE TERMS OR ADDITIONAL TERMS, NEITHER GOOGLE NOR ITS SUPPLIERS OR DISTRIBUTORS MAKE ANY SPECIFIC PROMISES ABOUT THE SERVICES. FOR EXAMPLE, WE DON'T MAKE ANY COMMITMENTS ABOUT THE CONTENT WITHIN THE SERVICES, THE SPECIFIC FUNCTIONS OF THE SERVICES, OR THEIR RELIABILITY, AVAILABILITY, OR ABILITY TO MEET YOUR NEEDS. WE PROVIDE THE SERVICES “AS IS”.

SOME JURISDICTIONS PROVIDE FOR CERTAIN WARRANTIES, LIKE THE IMPLIED WARRANTY OF MERCHANTABILITY, FITNESS FOR A PARTICULAR PURPOSE AND NON-INFRINGEMENT. TO THE EXTENT PERMITTED BY LAW, WE EXCLUDE ALL WARRANTIES.

\section{Liability for our Services}

WHEN PERMITTED BY LAW, GOOGLE, AND GOOGLE'S SUPPLIERS AND DISTRIBUTORS, WILL NOT BE RESPONSIBLE FOR LOST PROFITS, REVENUES, OR DATA, FINANCIAL LOSSES OR INDIRECT, SPECIAL, CONSEQUENTIAL, EXEMPLARY, OR PUNITIVE DAMAGES.

TO THE EXTENT PERMITTED BY LAW, THE TOTAL LIABILITY OF GOOGLE, AND ITS SUPPLIERS AND DISTRIBUTORS, FOR ANY CLAIMS UNDER THESE TERMS, INCLUDING FOR ANY IMPLIED WARRANTIES, IS LIMITED TO THE AMOUNT YOU PAID US TO USE THE SERVICES (OR, IF WE CHOOSE, TO SUPPLYING YOU THE SERVICES AGAIN).

IN ALL CASES, GOOGLE, AND ITS SUPPLIERS AND DISTRIBUTORS, WILL NOT BE LIABLE FOR ANY LOSS OR DAMAGE THAT IS NOT REASONABLY FORESEEABLE.

\section{Business uses of our Services}

If you are using our Services on behalf of a business, that business accepts these terms. It will hold harmless and indemnify Google and its affiliates, officers, agents, and employees from any claim, suit or action arising from or related to the use of the Services or violation of these terms, including any liability or expense arising from claims, losses, damages, suits, judgments, litigation costs and attorneys' fees. 


\begin{abstract}
About these Terms
We may modify these terms or any additional terms that apply to a Service to, for example, reflect changes to the law or changes to our Services. You should look at the terms regularly. We'll post notice of modifications to these terms on this page. We'll post notice of modified additional terms in the applicable Service. Changes will not apply retroactively and will become effective no sooner than fourteen days after they are posted. However, changes addressing new functions for a Service or changes made for legal reasons will be effective immediately. If you do not agree to the modified terms for a Service, you should discontinue your use of that Service.
\end{abstract}

If there is a conflict between these terms and the additional terms, the additional terms will control for that conflict.

These terms control the relationship between Google and you. They do not create any third party beneficiary rights.

If you do not comply with these terms, and we don't take action right away, this doesn't mean that we are giving up any rights that we may have (such as taking action in the future).

If it turns out that a particular term is not enforceable, this will not affect any other terms.

The laws of California, U.S.A., excluding California's conflict of laws rules, will apply to any disputes arising out of or relating to these terms or the Services. All claims arising out of or relating to these terms or the Services will be litigated exclusively in the federal or state courts of Santa Clara County, California, USA, and you and Google consent to personal jurisdiction in those courts.

For information about how to contact Google, please visit our contact page. 